SAND98-0598 • UC-700

Unlimited Release

Printed May 1998

COCEVED

MAY 27998

OSTI

\title{
Dynamics of Window Glass Fracture in Explosions
}

Edwin K. Beauchamp and Rudolph V. Matalucci

Prepared by

Sandia National Laboratories $*$ :

Albuquerque, New Mexico 87185 and Livermore, California 94550

for the United States Department of Energy

under Contract DE-AC04-94AL85000
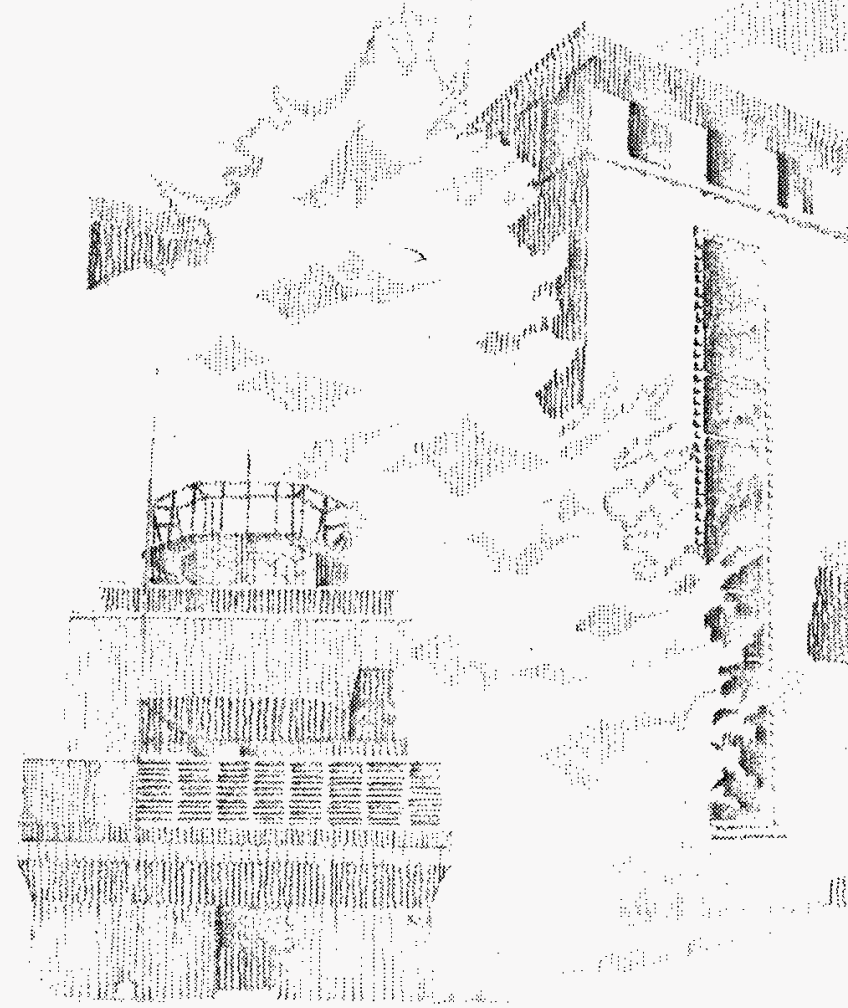
Issued by Sandia National Laboratories, operated for the United States Department of Energy by Sandia Corporation.

NOTICE: This report was prepared as an account of work sponsored by an agency of the United States Government. Neither the United States Government nor any agency thereof, nor any of their employees, nor any of their contractors, subcontractors, or their employees, makes any warranty, express or implied, or assumes any legal liability or responsibility for the accuracy, completeness, or usefulness of any information, apparatus, product, or process disclosed, or represents that its use would not infringe privately owned rights. Reference herein to any specific commercial product, process, or service by trade name, trademark, manufacturer, or otherwise, does not necessarily constitute or imply its endorsement, recommendation, or favoring by the United States Government, any agency thereof or any of their contractors or subcontractors. The views and opinions expressed herein do not necessarily state or reflect those of the United States government, any agency thereof or any of their contractors. 


\title{
Dynamics of Window Glass Fracture in Explosions
}

\author{
Edwin K. Beauchamp \\ Materials Joining Department \\ Rudolph V. Matalucci \\ Security Systems and Survivability Department \\ Sandia National Laboratories \\ P.O. Box 5800 \\ Albuquerque, NM 87185-0761
}

\begin{abstract}
An exploratory study was conducted under the Architectural Surety $\{\mathrm{sm}\}$ Program to examine the possibility of modifying fracture of glass in the shock-wave environment associated with terrorist bombings. The intent was to explore strategies to reduce the number and severity of injuries resulting from those attacks. The study consisted of a series of three experiments at the Energetic Materials Research and Testing Center (EMRTC) of the New Mexico Institute of Mining and Technology at Socorro, NM, in which annealed and tempered glass sheets were exposed to blast waves at several different levels of overpressure and specific impulse. A preliminary assessment of the response of tempered glass to the blast environment suggested that inducing early failure would result in lowering fragment velocity as well as reducing the loading from the window to the structure. To test that possibility, two different and novel procedures (indentation flaws and spot annealing) were used to reduce the failure strength of the tempered glass while maintaining its ability to fracture into small cube-shaped fragments. Each experiment involved a comparison of the performance of four sheets of glass with different treatments. In the test, incident blast pressures were measured adjacent to the front surface of the window. The fragments were captured in a backstop consisting of layers of rigid polyurethane foam. A grid with one-foot spacing on the backstop provided an approximate measure of lateral translation of fragments during flight. Penetration depth provided an approximate measure of kinetic energy of the fragments. Fractographic techniques were used in posttest analyses to obtain details of the fracture process in the different glasses.
\end{abstract}


One of the unexpected results is that the depth of penetration of tempered glass fragments into the foam was essentially the same as that of the annealed glass. Tempered glass had been regarded as intrinsically less likely to cause injuries than annealed glass because of its small fragment size and blunt shape. The apparent reason for the penetration in these tests is that the tempered glass failed to completely disintegrate into small fragments. The glass fractured into small fragments as expected, but those fragments remained coupled into assemblages with lengths of two or more inches and sufficient strength to survive the blast loading and impact on the foam backstop. Penetration occurred when those assemblages contacted the foam surface edge on.

Another unexpected result is that while the pretest introduction of indentation cracks as flaws to lower strength in the tempered glass did decrease the failure stress as expected, the decrease depended on the rate of increase of the pressure pulse as well as on the magnitude. This dependence suggests that the indentation flaws may have been modified during the four-day delay between their introduction and the test. The modification, which effectively decreased the flaw severity, probably resulted from blunting at the flaw tip as a result of chemical corrosion by water vapor. The consequence of the blunting is that flaws might not propagate under very dynamic loading at stress levels that would cause failure in quasistatic testing where the crack has time to resharpen. Thus it may not be appropriate to use strength data obtained by quasistatic testing to predict failure in blast loading. 


\section{Acknowledgments}

The authors would like to recognize the significant contributions to this report made by Director Van Romero and the staff, including Mike Stanley, of the Energetic Materials Research and Testing Center (EMRTC) of the New Mexico Institute of Mining and Technology. EMRTC provided the explosive environment testing facility, including the firing system, the explosive material, test control, high-speed photography capabilities, and the styrofoam backstop employed to capture the glass fragments. The authors appreciate the support of the EMRTC staff in performing these experiments.

The authors also wish to thank Sharon O'Connor of Tech Reps, Inc., for editorial support and John Hurtado, then with the Experimental Structural Dynamics Department at Sandia National Laboratories, for supplying a data acquisition system (DAS) for use in these experiments. The glasstesting data acquired by this DAS served as a confirmation of the test environment.

U.S. Department of Energy funding for this work was provided through the Sandia National Laboratories Strategic Surety Program managed by Laura Gilliom. 
Intentionally Left Blank 


\section{Contents}

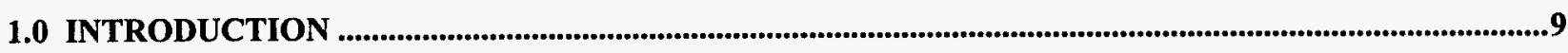

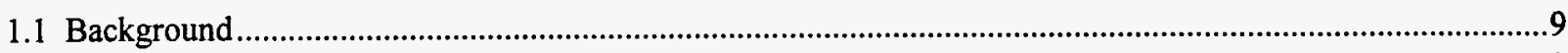

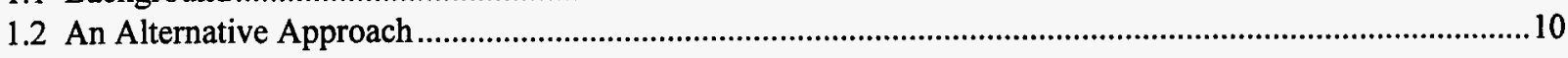

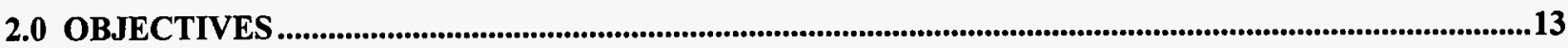

2.1 Dynamics of Glass Fracture in Explosive Shock Loading ...........................................................................13

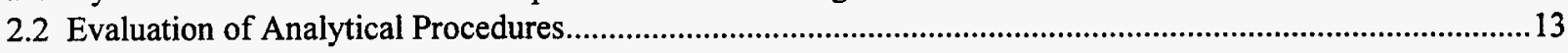

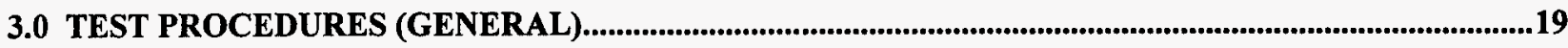

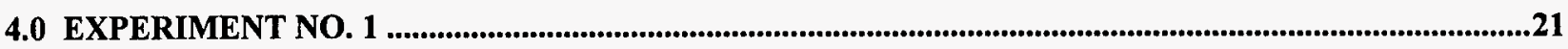

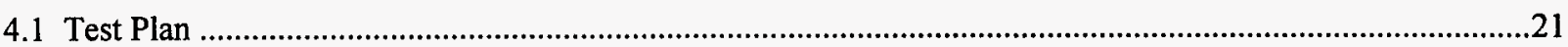

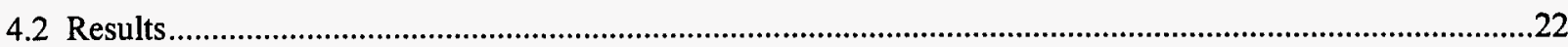

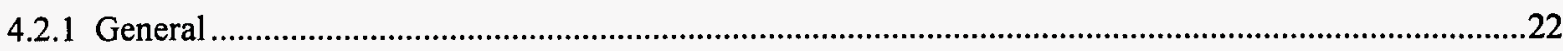

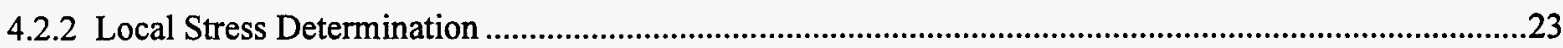

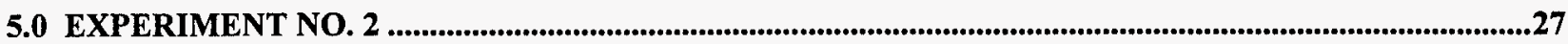

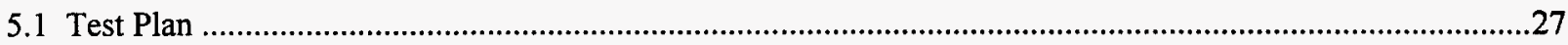

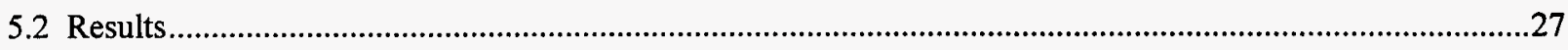

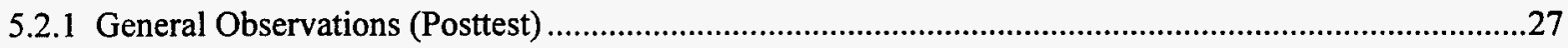

5.2.2 Phenomenology of Fracture Initiation................................................................................................27

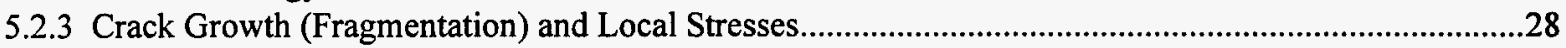

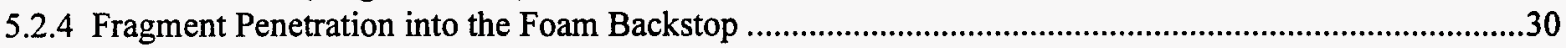

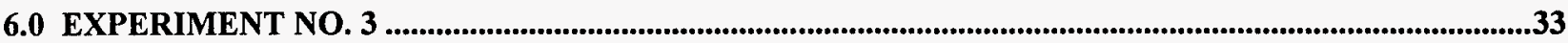

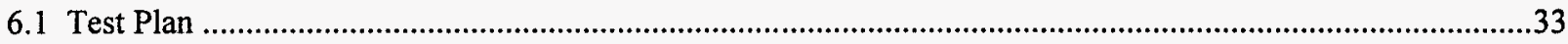

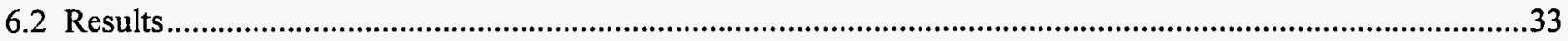

6.2.1 Sources for Fracture Initiation at Low Blast Pressure ...........................................................................33

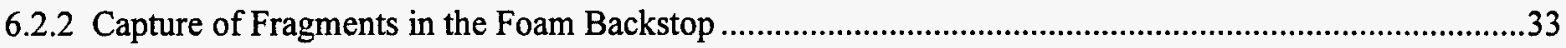

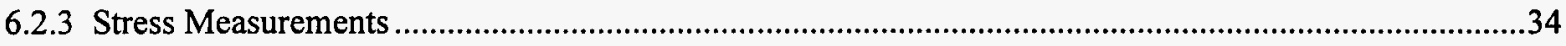

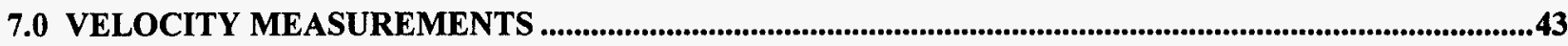

8.0 DISCUSSION

8.1 Penetration of Foam Boards by Tempered Glass................................................................................................47

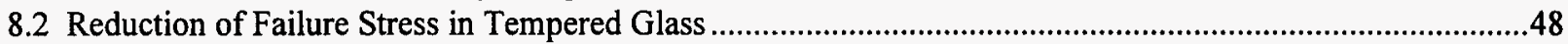

8.3 Location of Fracture Origins in Shock-Loaded Windows ….........................................................................

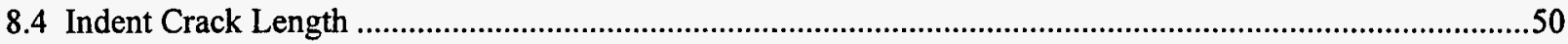

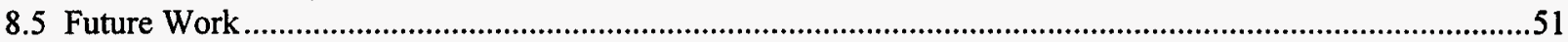

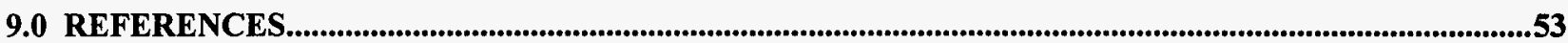

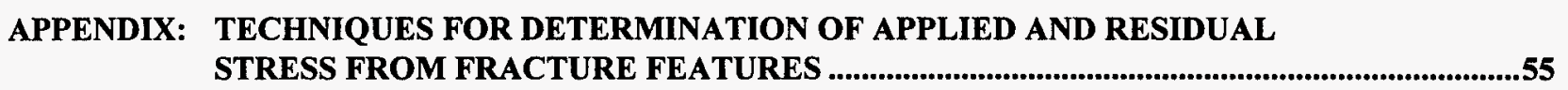

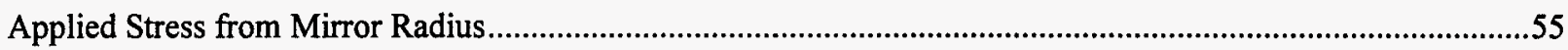

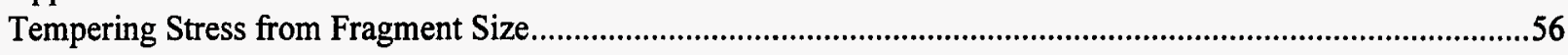

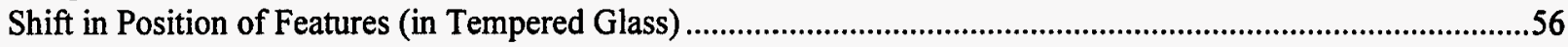

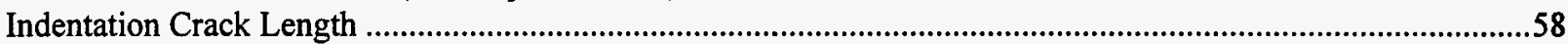

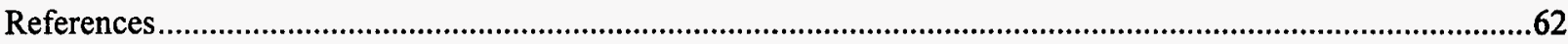




\section{Figures}

Figure 1. Reduction of Strength of Tempered and Annealed Glass by Introduction of Indentation Flaws ${ }^{8}$

Figure 2. Dependence of Particle Count (size) on Central Tension in Thermally

Stressed Glass ${ }^{10}$

Figure 3. Explosive Test Facility at Energetic Materials Research and Testing Center, Socorro, NM.

Figure 4. Schematic of Window Test .20

Figure 5. Fracture Origin (indentation flaw) in Annealed Glass, Experiment No. 1 .........................................24

Figure 6. Fracture Origin (indentation flaw) in Tempered Glass, Experiment No. 1 ........................................24

Figure 7. Fragment from Annealed Glass Showing Cracks That Had Penetrated Partway

Through Thickness, Experiment No. 2

Figure 8. Penetration of Glass Fragments into Right Side of Backstop, Experiment No. 2 …..........................31

Figure 9. Areal Distribution of Fragments Captured in Backstop from the Center Section of the Annealed Sheet, First Foam Layer

Figure 10. Areal Distribution of Fragments Captured in Backstop from the Four-Inch-Wide

Edge of the Annealed Sheet, First Foam Layer.

Figure 11. Areal Distribution of Fragments Captured in Backstop from the Four-Inch-Wide

Edge of the Annealed Sheet, Second Foam Layer

Figure 12. Areal Distribution of Fragments Captured in Backstop from the Center Section of the Tempered and Indented Sheet, First Foam Layer

Figure 13. Areal Distribution of Fragments Captured in Backstop from the Four-Inch-Wide Edge of the Tempered and Indented Sheet, First Foam Layer.

Figure 14. Areal Distribution of Fragments Captured in Backstop from the Center Section of the Tempered and Indented Sheet, Second Foam Layer.

Figure 15. Areal Distribution of Fragments Captured in Backstop from the Four-Inch-Wide

Edge of the Tempered and Indented Sheet, Second Foam Layer

Figure 16. Areal Distribution of Fragments Captured in Backstop from the Tempered and Spot-Annealed Sheet, First Foam Layer

Figure 17. Areal Distribution of Fragments Captured in Backstop from the Tempered and Spot-Annealed Sheet, Second Foam Layer

Figure 18. Areal Distribution of Fragments Captured in Backstop from the Tempered, As-Received Sheet, First Foam Layer

Figure 19. Areal Distribution of Fragments Captured in Backstop from the Tempered,

As-Received Sheet, Second Foam Layer . .42

Figure 20. Horizontal Position vs. Time for Glass Fragment Clusters .........................................................44

Figure 21. Wide-angle Photograph of Glass Fragments Moving from Window at Right ...................................44

Figure A.1 Stress Profiles in Thermally Tempered Glass Sheet with Applied Bending Stress.............................59

Figure A.2 Fracture Surface in Thermally Tempered Sheet with No Applied Stress............................................60

Figure A.3 Fracture Surface in Thermally Tempered Sheet with Applied Bending Load ....................................60

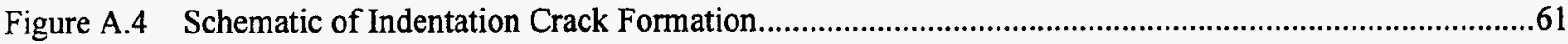

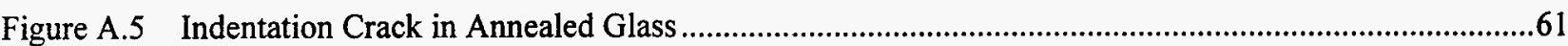




\section{Tables}

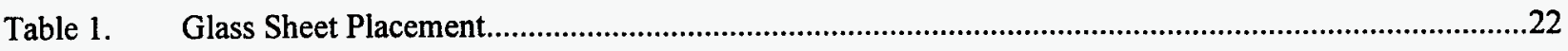

Table 2. Sandia Glass Experiments: Shock Conditions.....................................................................................23

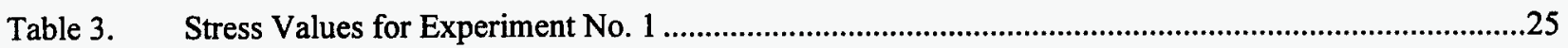

Table 4. Experiment No. 3: Stresses Calculated from Fracture Features ......................................................36 
Intentionally Left Blank 


\subsection{Introduction}

\subsection{Background}

One of the concerns raised by terrorist bombings is the large number of casualties caused by flying glass. In the Oklahoma City Federal Building bombing, many injuries were caused far from the site of the explosion by shards of glass projected at high velocity by the blast wave. ${ }^{1}$ A major issue in current Architectural Surety $\{\mathrm{sm}\}$ Program* efforts to mitigate the effects of terrorist activities and natural disasters is how to reduce injuries from flying glass.

One proposed approach is to use thermally tempered or otherwise prestressed glass in windows. The presumed advantage of highly prestressed (fully tempered) glass over annealed glass in typical glazing applications is that, in fracturing, the prestressed glass is very rapidly converted into a weakly coupled assembly of small fragments. The planar orientation of the residual stresses in the tempered glass results in fragments that have a roughly cubic shape with right-angle corners on the fragment edges. This cubic shape has led to the use of the term "dicing" to describe the fracture process for prestressed glass.

\footnotetext{
*For further information, see R. V. Matalucci and D. S. Miyoshi, An Introduction to the Architectural Surety \{sm \} Program, in the proceedings of Assuring the Performance of Buildings and Infrastructures: A Conference on Architectural Surety, held in Albuquerque, NM, May 14-15, 1997, Sandia National Laboratories Security Systems and Technology Center, Albuquerque, New Mexico.
}

In contrast, the fracture of annealed (stress-free) glass commonly produces substantially larger shards with lance shapes. When annealed glass fails under a bending load such as that produced by an impact or a pressure wave, the resulting shards often have very sharp cutting edges that can produce severe wounds even at low velocity. In conventional glazing applications such as patio doors, fatalities have occurred as a result of injuries caused by those shards. The much smaller size of the fragments from tempered glass plus the lesser damage from contact with the 90-degree edges has led the construction industry to recommend the use of tempered glass (or laminated glass) in commercial buildings and homes. In recommending the use of tempered glass for structures vulnerable to bombing, there is a tacit assumption that the blast environment will also yield the very small fragment size produced in the more usual failures.

However, the advantages of tempered glass in the more benign structural applications do not necessarily make it the preferred choice for reducing the injury potential in the event of a nearby explosion. A possible disadvantage is that the residual stress system that produces dicing fragmentation could also provide high strength to the glass sheet. High strength assures that the window will sustain much higher blastpressure loading before it fails, creating potential problems. In one scenario, the resistance to failure of the glass could drive the sheet out of the frame as a single unit. This large projectile could cause much more damage than if the glass had fragmented. Several studies have shown that at a given velocity, the severity of injuries increases rapidly as the mass of the projectile increases. ${ }^{2,3,4,5}$ In another scenario, the blast wave would bow the glass inward until it 
fails, then drive it forward with much higher velocity than if it had failed at a lower loading. Furthermore, in either of these scenarios, retention of the glass sheet in the frame until a high blast pressure is reached can put high loading into the glass frame assembly and the surrounding structure. That higher loading increases the possibility of collapse of the building structure.

Another proposed approach to reducing casualties from flying glass is to contain the glass by laminating it to an elastomer layer, for example, or by applying a protective film to the surfaces of a single sheet. Either of these containment methods might be used with a system that would anchor the glass sheet by mechanically constraining it within the frame. Particularly with a system that anchors the sheet to the structure, increased structural loading would be anticipated from blast overpressure. Without anchoring, the blast wave might separate the glass sheet from the structure and carry it forward as a large projectile. In one set of tests, sheets of $1 / 2$-inch-thick glass, 75.5 by 49 inches (150 pounds of glass) coated with a 0.007 -inch-thick film were propelled as far as 16 to 20 feet after ejection from their frames. ${ }^{6}$

\subsection{An Alternative Approach}

A better blast response for both the structure and its occupants might result from taking advantage of the small fragment size of fractured tempered glass while promoting its fracture at low applied stress. Thus the tempered plate would fail during the early stages of loading by the blast wave. A crack velocity of 5000 feet per second during fragmentation of the tempered sheet means that the sheet would lose its strength in less than one millisecond, and thus the blast-wave loading on the sheet would no longer be transferred to the structure.
If the glass plate fails before a substantial bowing of the plate occurs, the blast wave should initially move the fragmented sheet forward as a planar assembly. The velocity vector imparted by the residual compressive stress in the sheet would be transverse to the forward motion of the blast-wave direction. That velocity vector should separate the dicing fragments in the plane of the plate, reducing the areal density of the fragments as they move forward. Presumably, the lower density of the fragments impinging on a body would mean less damage to the body.

A computer modeling program generated by ACTA, Inc. indicates that it may also be possible that early separation into dicing fragments results in substantially lower energy transferred to the particles by the blast wave so that their forward velocity is reduced. ${ }^{7}$ Thus it may not be necessary to provide a shield to stop the fragments; at the least, it may be much easier to reduce the velocity of fragments produced by early failures.

Providing a means for the early onset of dicing during blast loading should be relatively easy. One approach would be to sensitize a spot on the sheet so that a very low applied load would result in fracture. This could be accomplished by:

- shielding the spot from quenching during the tempering process, so that the magnitude of the surface compressive stress is reduced;

- annealing the spot after tempering; or

- introducing a flaw into the surface of the sheet after tempering.

One problem with these approaches is that the sheet would be somewhat more vulnerable to accidental breakage during handling before and during its insertion into the structure. However, for ordinary glazing procedures, it should be acceptable to adjust the strength reduction so that the sheet retains the strength of untempered 
(annealed) glass during installation and use. That strength should also be sufficient for the sheet to survive ordinary wind loads.

An alternative to a sustained loss of strength of the window might be to introduce a critical flaw into the sheet at the moment of arrival of the blast wave. This could be accomplished by installing an indenter in the window frame, so that the blast wave drives the tempered glass plate against it, creating a flaw that leads to rapid fracture. A more reliable procedure would be to provide a spring-loaded device activated by motion of the window or in some other way by the blast wave that would drive a sharp projectile into the glass.
To evaluate these concepts for reducing the injury potential by promoting early fracture in tempered glass, Sandia National Laboratories arranged a series of tests to be conducted in conjunction with ongoing explosive tests at the New Mexico Institute of Mining and Technology, Socorro, NM. The series of preliminary experiments described in this report were intended as an introductory exploration of those concepts. The experiments also provided the opportunity to examine the dynamics of glass fracture during explosive loading and to evaluate techniques of fractographic analysis in posttest examination of windows exposed to explosive shock waves. These experiments were conducted at the Energetic Materials Research and Testing Center (EMRTC). 
Intentionally Left Blank 


\subsection{Objectives}

\subsection{Dynamics of Glass Fracture in Explosive Shock Loading}

The experiments at EMRTC were intended primarily as an exploratory attempt to describe the interaction between a blast wave and glass windows in a frame. An assessment of the factors that govern the potential for injury from fragments of broken glass was of particular interest. The size and shape of fragments as well as their velocity are important parameters for defining the injury potential. ${ }^{3,4,5,6}$ Consequently, there is great interest in the pattern of fracture in annealed glass as compared with that in tempered glass and also in the dynamics of interaction of the blast wave with fragments that determine the kinetic energy of the fragments. The primary subject of the experiments is a comparison of the fragmentation of tempered glass and annealed glass and the subsequent interaction of the fragments with the blast wave.

Two different approaches were used to promote early fracture in the glass. The first was the introduction of strength-reducing defects by indenting the glass at high applied indentation loads. Each of the three tests included samples that had been indented prior to testing. The reduction of strength with indent flaws was previously studied and reported in Reference 8. Figure 1 is a plot of the data showing the effect of flaws introduced with a Vickers indenter (at various indenter loads) on the strength of sodalime glass with two different levels of tempering. The figure also includes a plot of failure stress vs. indentation load for annealed glass.

The second approach for reducing the effective failure strength of tempered glass while retaining its ability to disintegrate into fine fragments was to reduce the tempering stress in selected areas. This was done by heating a spot until part of the compressive surface stress was reduced.

Among the issues to be addressed in the experiments was the question of whether fragments from the test windows could be captured in a way that would provide information on the potential for producing injury to building occupants. The fragments were captured in a backstop consisting of two outer layers of 1-inch-thick polyurethane foam backed with three layers of 2-inch foam. Depth of penetration through these layers was determined by velocity and mass of fragments as well as their orientation when they contacted the backstop. By placing a grid on the backstop, the position of the captured fragments could be obtained and used to provide a rough indication of the trajectories of those fragments. After calibration, in future work in which penetration of fragments with known velocity will be measured, velocity data obtained from the penetration will be compared with that gained from high-speed photography. Predictions from computer modeling also will be compared to the penetration-derived velocity data.

\subsection{Evaluation of Analytical Procedures}

The Sandia National Laboratories experiments at EMRTC also provided an opportunity to evaluate fractographic techniques for characterizing the response of glass to shock loading. Reference 9 provides an excellent introduction to the use of fractography in analyzing fracture. 


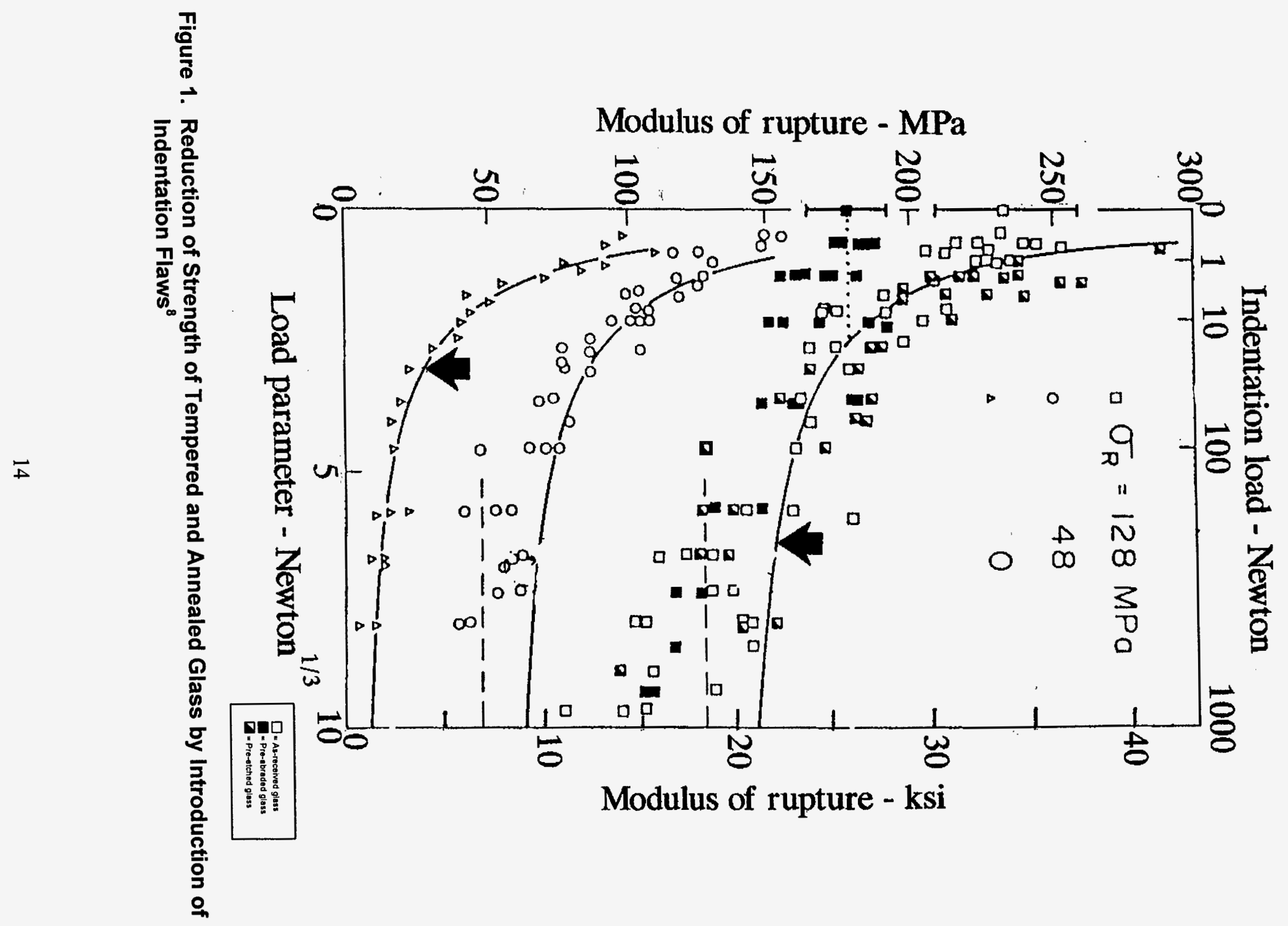


The techniques involve examination of the fracture patterns and features on fracture surfaces after the event to determine the level of stress present at a selected point on a glass sheet at the moment of failure. ${ }^{9}$ By observing the growth of indentation flaws, it might also be possible to determine maximum tensile stress at a specified point even when failure did not occur. The techniques for these stress determinations are outlined below and presented in more detail in Appendix A.

One technique for estimating the tensile stress at failure involves measuring the branching distance, i.e., the distance between points where the crack branches into multiple paths. ${ }^{9}$ This distance decreases as the maximum tensile stress present in the glass at failure increases. This technique is exemplified for tempered glass in Figure $2 .{ }^{10}$ That figure shows the dependence of the number of fragments per unit area produced in the fracture of tempered glass on the magnitude of the central tension, i.e., the maximum tensile stress produced by the tempering process. These data can be used to determine the maximum tensile stress from fragment size (and plate thickness). Fragment size (or particle size) is equivalent to branching distance.

The plots in Figure 2 assume no applied stress at fracture. However, additional applied stress, which increases or decreases the maximum tensile stress, will affect the branching distance and hence the size of fragments. For example, if simple bending is applied to a tempered sheet during failure, the particle shape will change from essentially bilaterally symmetrical (equiaxed) to shortened parallel to the applied stress. It should be possible to estimate the magnitude of the applied stress from the dimensional changes. The results of the branching process can also be used for analysis of fracture in annealed glass. The distance between branches provides a measure of the magnitude of the stress, while the branching angle provides information on the type of loading. 
Central tension, $\mathrm{ksi}$

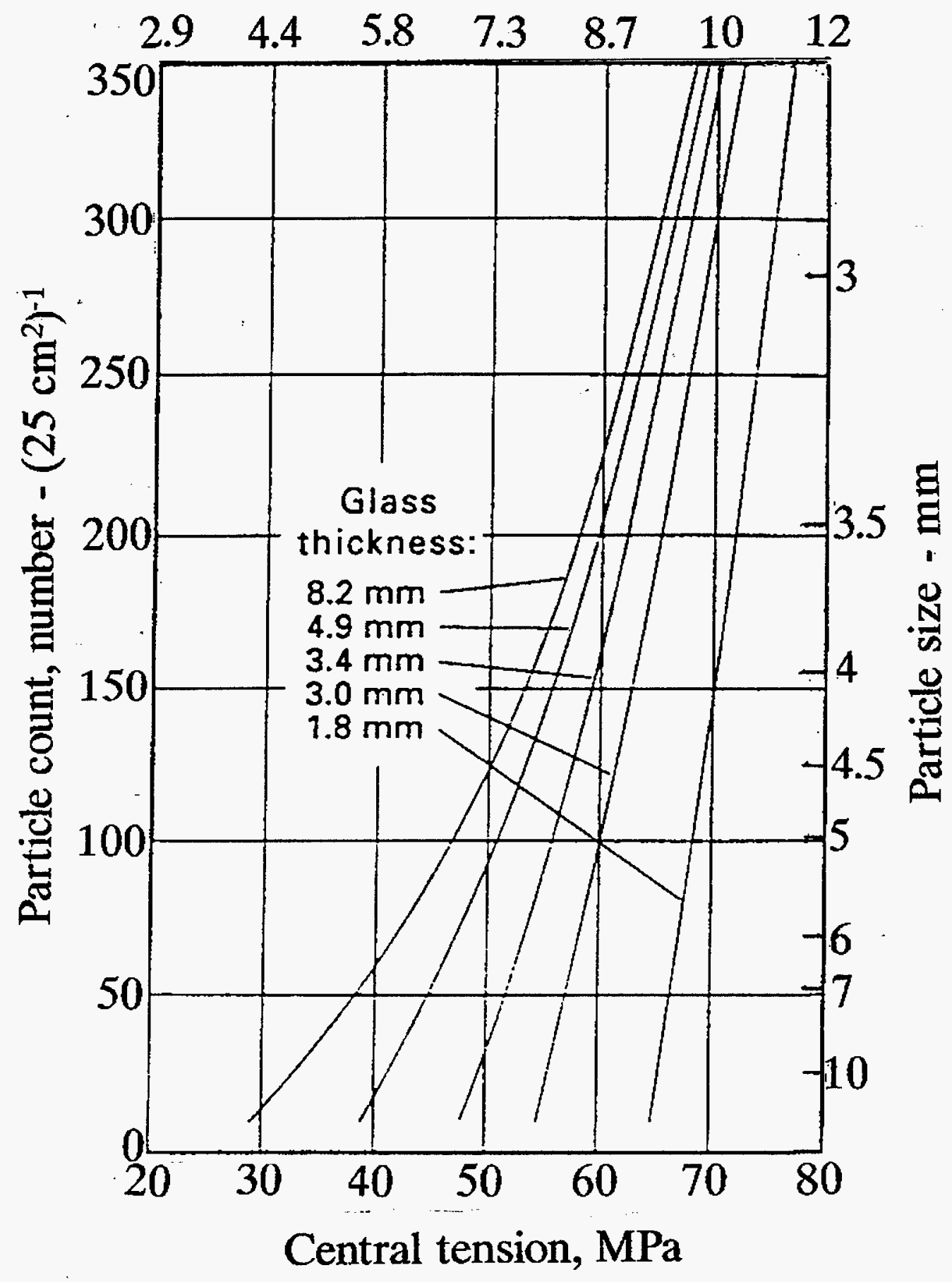

Figure 2. Dependence of Particle Count (size) on Central Tension in Thermally Stressed Glass ${ }^{10}$ 
When the origin of failure can be located, the fracture surface near that location will usually show a "mirror" region where the fracture surface is very smooth and, adjacent to that, a "mist" region where the fracture surface gives a diffuse reflection. The distance from the center of the originating flaw to the boundary between the mirror and mist regions, the mirror radius, can provide an estimate of the stress at failure.

Another technique for analysis of stresses, applicable only to tempered glass, evaluates the change in the stress distribution produced by the blast loading. The evaluation is possible because crack growth in tempered glass produces unusual features on the fracture surfaces. High compressive stress on the surface of a tempered sheet results in a tensile stress in the interior layer. In tempered glass with no applied stress, the first stage of crack growth involves very rapid propagation through that tensile layer. Subsequently, the crack extends toward the outer surfaces of the sheet, propagating perpendicularly to its original direction. The result is a clear line of demarcation on the fracture surface where no stress was present before fracture. When a flexural stress is applied to the sheet during fracture, the lines of demarcation shift. That shift can be used to infer the magnitude of the applied stress.

Another procedure that provides a measure of the maximum local stress during shock loading uses cracks produced by an indenter. In sodalime silicate glasses like those used in typical glazing, these cracks are obtained at loads of about 100 grams or greater using a Vickers indenter; the cracks extend from the diagonals of the indent. When moderate tensile stresses are subsequently applied to the glass, these cracks will grow in a stable manner; i.e., they will grow until the intensity of the local stress field at the crack tip, $\mathrm{K}_{\mathrm{I}}$, drops below the critical value, $\mathrm{K}_{\mathrm{Ic}}$. If subcritical crack growth is possible, growth continues until $K_{1}$ decreases to the threshold value for that process. The increase in length of the cracks provides a useful measure of the magnitude of the stress even if the cracks do not reach the critical size necessary to propagate through the glass plate.

In principle, one of the possible applications of the procedure in which the growth of indentation cracks is used to determine applied stress would be to obtain a map of maximum tensile stresses produced on the surface of a glass sheet during shock loading. That map would be obtained by introducing indents at various spots on the sheet and shock loading it at a pressure that was slightly too low to cause failure. Because the Vickers indenter produces a pair of orthogonal cracks, values for the orthogonal planar stresses could be obtained.

In the event that an indent crack was the origin of failure, the data in Figure 1 could be used to obtain a value for the local stress at that point. The dimensions of the fracture mirror could also be used to obtain a value for the failure stress. Moreover, as will be seen in the results of the current experiments, even when one of the indent flaws causes failure, the extension of others present on the sheet can be used to measure the stress at the locations of those flaws at the moment of failure.

The Sandia National Laboratories experiments at EMRTC were also intended to demonstrate the utility of these techniques and advocate their use in other experimental studies of this type. One use for these procedures would be to obtain detailed maps of stress distributions in glass sheets at the moment of failure to validate computer stress analyses. Currently, the laboratories engaged in the study of glass fracture by explosive shock do not appear to be taking advantage of the insight and knowledge that could be provided by these procedures. 
Intentionally Left Blank 


\subsection{Test Procedures (General)}

The three tests were conducted at EMRTC using the structure shown in Figure 3. The walls of this building are 12-inch-thick reinforced concrete backed with steel plate. The window opening at the center of the wall is 36 inches wide by 48 inches high. A window frame constructed of angle iron, 1 inch wide by $1 / 4$ inch thick, accommodated four panes of glass, 17.5 inches wide and 23.5 inches in width. The open area for each pane of glass was 16 inches by 22 inches. Glass sheets were held in the frame with soft putty. A 1-inch-wide, 1/8-inch- thick layer of foam separated the glass surface from the angle iron. As shown schematically in Figure 4, explosive charges were placed on a line normal to the plane of the window and passing through the center of the window.

Within the building, a backstop, intended to capture glass fragments, was placed parallel to and behind the window. In Experiment Nos. 1 and 2, the backstop was 4 feet to the rear of the window. In Experiment No. 3, it was 6 feet to the rear. The backstop consisted of two sections, each made from 4-foot by 8 -foot polyurethane foam panels backed by a $3 / 4$-inch-thick plywood sheet. Those two sections will be referred to as the right and left sections as viewed from the front.

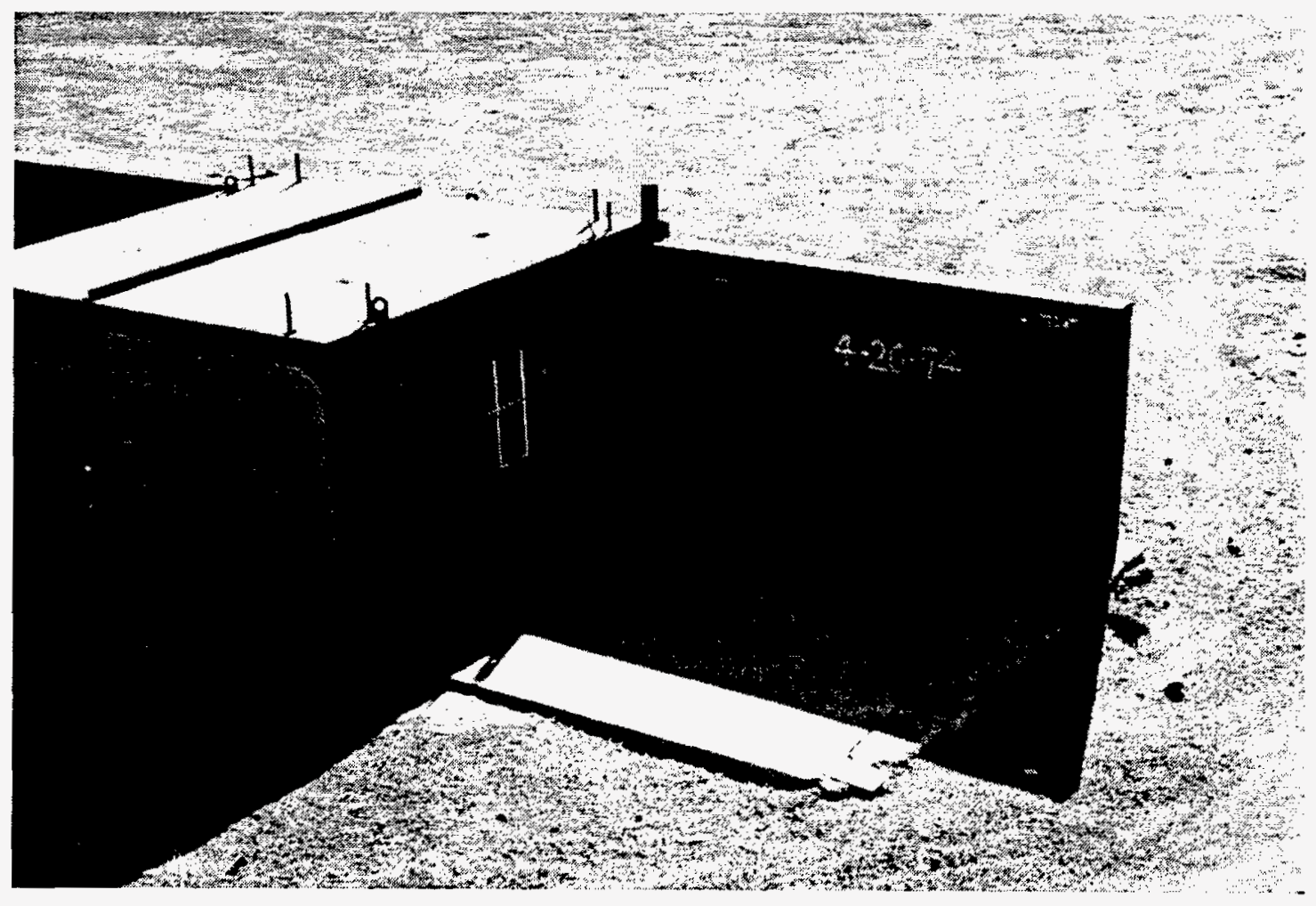

Figure 3. Explosive Test Facility at Energetic Materials Research and Testing Center, Socorro, NM 

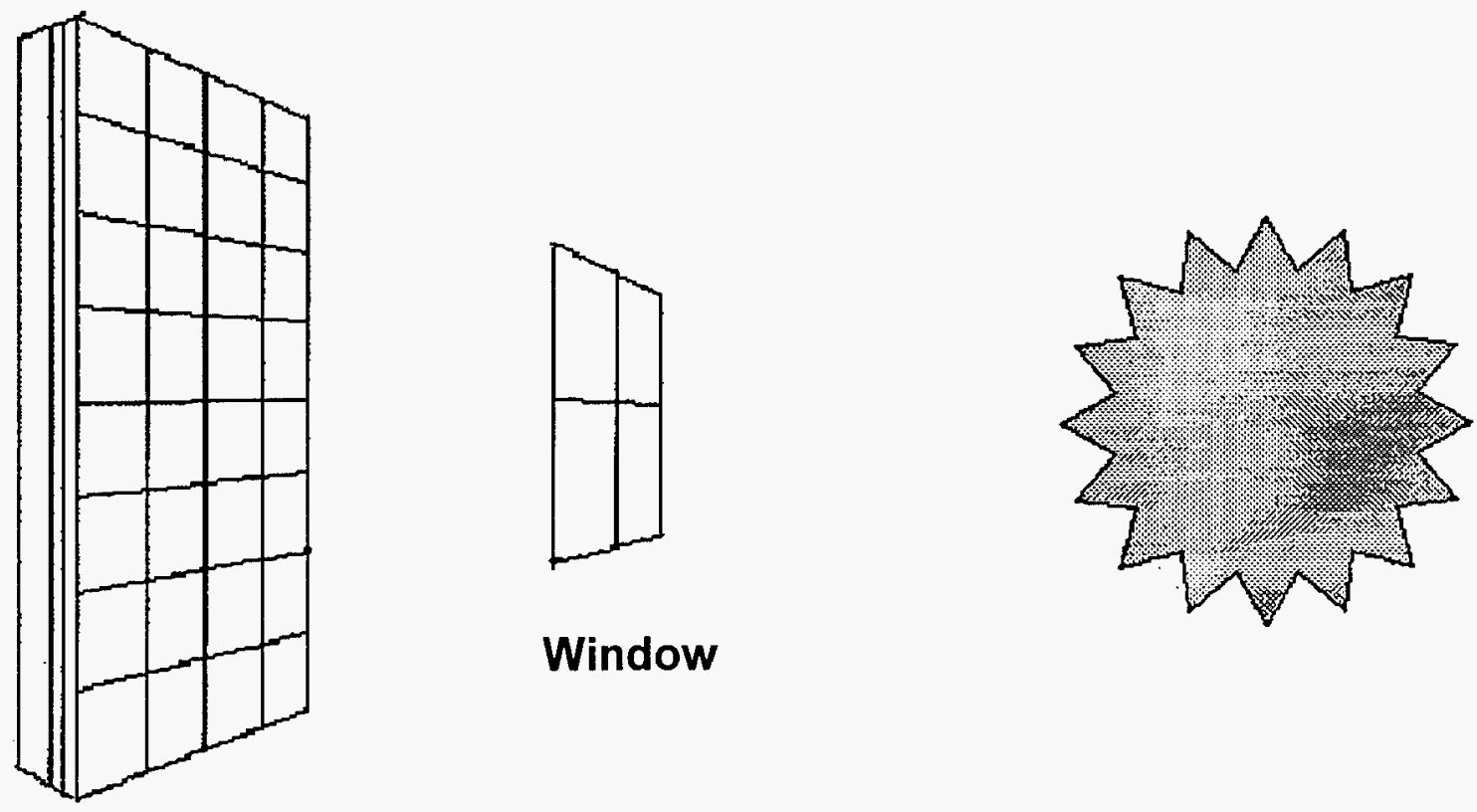

Window

\section{Backstop}

Figure 4. Schematic of Window Test (Explosive is placed on line normal to backstop surface and passing through window center.)

The two sections of the backstop were placed side by side with their common edge parallel to the vertical center line of the window and on the line from the explosive charge through the center of the window. A grid with 1 foot spacing between elements was drawn on the front foam panels. The grid was intended to permit a rough measure of the dispersion of fragments as they left the window and were captured in the backstop. The center of the grid was on the line passing through the window center and the explosive charge.

For the first two experiments, shock conditions were measured with pressure monitors outside the building (near the vertical edges of the window) and with strain gages mounted on the interior surface of the wall facing the explosive. In all three experiments, high-speed cameras were positioned to record the motion of the glass fragments toward the backstop and provide a measure of fragment velocity. However, in the first two experiments, the cameras failed to function and in the third experiment, the light level was too low to obtain useful pictures. Subsequent to the three Sandia experiments, an additional test of annealed glass of several different thicknesses was conducted using the same blast conditions as those in Experiment No. 3. Additional lighting in that test resulted in high-speed photographs that were used for estimating fragment velocity. 


\subsection{Experiment No. 1}

\subsection{Test Plan}

Because the researchers had minimal experience in conducting this type of test, the selected approach was very conservative. Earlier experiments by others suggested that at about 2 psi overpressure, windows would break and some kinetic energy would be imparted to the glass fragments. For a preliminary experiment with the primary interest in the fracture process in annealed and tempered glass sheets and how that might be affected by the presence of indentation flaws in the glass, shock conditions were selected that would provide overpressure only slightly in excess of 2 psi.

For small deformations of a plate (deflection at the plate center less than 1.5 times the thickness), the maximum tensile stress on a plate simply supported and loaded with uniform pressure, $\mathbf{w}$, is given by the linear equation (from Reference 11, p. 225):

$$
\sigma=\beta w b^{2} / t^{2}
$$

where $\mathbf{b}$ is the plate width, $\mathbf{t}$ is the thickness, and $\beta$ is a correction factor that depends on the ratio of the width to length of the plate. For the windows in these tests, it has a value of 0.425 . This equation indicates that, to obtain a maximum tensile stress of at least $8,000 \mathrm{psi}$ in a window with an opening of 16 inches by 22 inches at 2 psi pressure, the thickness must be less than 0.165 inch. The thinnest glass sheet available with full tempering was $4 \mathrm{~mm}(0.157$ inch) thick. All experiments were conducted with tempered glass of that thickness and, except for the first experiment, the annealed sheets used in the experiments were $4 \mathrm{~mm}$ thick.

To try to obtain fracture of the 4-mm-thick tempered glass at 2 psi pressure, five indentation flaws were introduced, $1 \mathrm{inch}$ apart on the plate vertical center line, using a 30-kilogram load on the Vickers indenter. Even with this high load, the data in Figure 1 indicated that it would be questionable whether fracture could be produced. For the 4-mm annealed glass, a 3kilogram load was used on the indenter to produce a line of five flaws. The data in Figure 1 indicate a nominal failure stress of about $4 \mathrm{ksi}$ with that load. To enhance recovery of fragments in the indented zone after the experiment, a 2-inch by 2 -inch piece of duct tape was applied to those areas after the indents were introduced.

To discriminate between fragments from the tempered sheet and the annealed sheet during recovery, the sheets were coated with Magic Markers $^{\mathrm{TM}}$ of different colors. On the expectation that the trajectories of fragments from the edges of the sheets would be significantly different from those from the center, a four-inch-wide band at the sheet edge was colored differently than the center section.

To evaluate the procedure for using the extension of indent cracks to measure local stress during the shock, indents of various sizes were introduced in 1/4-inch- and 1/2- inch-thick sheets. Except for the 10-kilogram load on the $1 / 4$-inch sheet, none of the loads on the indenter $(1,3$, and 10 kilogram on the $1 / 4$-inch sheet and 3,10 , and 30 kilogram on the $1 / 2$ - inch sheet) should have caused catastrophic failure at $2 \mathrm{psi}$ pressure. To keep these two sheets together in the event the glass fractured, plastic adhesive tape was applied to the entire sheet surface (on the indented side) after the sheets were indented. The thin, low-modulus tape would have only a very minor effect on the stresses generated in the glass. Locations of the four sheets of glass 
within the frame for each of the experiments are shown in Table 1.

Table 2 shows the explosives used in each of the three experiments and the nominal shock conditions anticipated at the window. These nominal conditions were obtained from handbook data for the explosives used in the experiments. As shown, in the first experiment, 0.22 pound of $\mathrm{C} 4$ explosive was used to obtain a shock with nominal peak overpressure of 2.52 psi and specific impulse of $2.09 \mathrm{psi}-\mathrm{msec}$ at the front surface of the window. The peak overpressure measured by two gages at the front of the window was $4 \mathrm{psi}^{12}$

\subsection{Results}

\subsubsection{General}

The 4-mm annealed and tempered sheets fractured and, except for a few fragments held in the frame by the putty, all glass from these sheets was ejected from the window. However, no fragments penetrated the foam in the backstop. Judging from the position of the fragments between the window and the backstop after the test, it is doubtful that any fragments reached the backstop. In fact, most fragments from both sheets were found in front of the test building, i.e., between the window and the explosive. The implication is that the sheets fractured under the initial positive overpressure, when tensile stress was generated at the surface containing the indentation flaws, but were not separated from the frame until loaded by the release wave, i.e., a negative differential pressure at the end of the shock wave. Although the $1 / 4$-inch annealed glass sheet also fractured, it and the unfractured $1 / 2$-inch sheet remained in the frame.

Table 1. Glass Sheet Placement

\begin{tabular}{|c|c|c|c|c|}
\hline & Upper Left & Lower Left & Upper Right & Lower Right \\
\hline $\begin{array}{c}\text { Experiment } \\
\text { No. 1 }\end{array}$ & $\begin{array}{c}\text { Annealed } 4 \mathrm{~mm}, \\
\text { indented at center }\end{array}$ & $\begin{array}{c}\text { Annealed } 1 / 4 \text { inch, } \\
\text { indented at center }\end{array}$ & $\begin{array}{c}\text { Annealed } 1 / 2 \text { inch, } \\
\text { indented at center }\end{array}$ & $\begin{array}{c}\text { Tempered } 4 \mathrm{~mm}, \\
\text { indented at center }\end{array}$ \\
\hline $\begin{array}{c}\text { Experiment } \\
\text { No. 2 }\end{array}$ & $\begin{array}{c}\text { Tempered } 4 \mathrm{~mm}, \\
\text { flame annealed } \\
\text { spot at center }\end{array}$ & $\begin{array}{c}\text { Tempered } 4 \mathrm{~mm}, \\
\text { indented at center }\end{array}$ & $\begin{array}{c}\text { Annealed } 4 \mathrm{~mm}, \\
\text { indented at center }\end{array}$ & $\begin{array}{c}\text { Tempered } 4 \mathrm{~mm}, \\
\text { as received }\end{array}$ \\
\hline $\begin{array}{c}\text { Experiment } \\
\text { No.3 }\end{array}$ & $\begin{array}{c}\text { Tempered } 4 \mathrm{~mm}, \\
\text { indented at } \\
\text { corners and center }\end{array}$ & $\begin{array}{c}\text { Tempered } 4 \mathrm{~mm}, \\
\text { laser-annealed } \\
\text { spots at corners } \\
\text { and center }\end{array}$ & $\begin{array}{c}\text { Tempered 4 } \mathrm{mm}, \\
\text { as received }\end{array}$ & $\begin{array}{c}\text { Annealed } 4 \mathrm{~mm}, \\
\text { indented at } \\
\text { conners and center }\end{array}$ \\
\hline
\end{tabular}


Table 2. Sandia Glass Experiments: Shock Conditions

\begin{tabular}{|c|c|c|c|}
\hline & Explosive & $\begin{array}{c}\text { Peak Overpressure } \\
\text { (psi) }\end{array}$ & $\begin{array}{c}\text { Specific Impulse } \\
\text { (psi-msec) }\end{array}$ \\
\hline $\begin{array}{c}\text { Experiment } \\
\text { No. 1 }\end{array}$ & $\begin{array}{c}\mathrm{C} 4,{ }^{\mathrm{a}} 0.22 \mathrm{lb} \\
\text { (a) } 12.0 \mathrm{ft}\end{array}$ & 2.52 & 2.09 \\
\hline $\begin{array}{c}\text { Experiment } \\
\text { No. 2 }\end{array}$ & $\begin{array}{c}\text { ANFO, }{ }^{\mathrm{b}} 25 \mathrm{lb} \\
\text { @ } 20 \mathrm{ft}\end{array}$ & 12.7 & 20.22 \\
\hline $\begin{array}{c}\text { Experiment } \\
\text { No. 3 }\end{array}$ & $\begin{array}{c}\text { ANFO, } 13 \mathrm{lb} \\
\text { @ } 20 \mathrm{ft}\end{array}$ & 8.22 & 13.41 \\
\hline $\begin{array}{l}{ }^{\mathrm{a}} \text { Composition 4 } \\
{ }^{\mathrm{b}} \text { Ammonium nitrate and fuel oil }\end{array}$ & & \\
\hline
\end{tabular}

\subsubsection{Local Stress Determination}

Both the annealed 4-mm sheet and the tempered 4-mm sheet failed from indentation flaws at the sheet center. Figure 5 shows the fracture surface at the failure origin in the 4-mm-thick annealed sheet. The arrows indicate the limits of the mirror region at the tensile surface. The indent flaw is midway between those arrows. The failure stress was calculated using half the distance between those points as the mirror radius (approximately $2.2 \mathrm{~mm}$ ). Procedures for determining the local stress from the dimensions of the mirror are described in Appendix A. Table 3 shows the results of the analyses. As shown in that table, a value of $5.9 \mathrm{ksi}$ was obtained for the failure stress using the mirror radius equation and a value of $5.6 \mathrm{ksi}$ was obtained for the local stress at failure using a data plot from Reference 13. Assuming that the plate deformed linearly to failure so that Equation 1 represents the relationship between maximum tensilestress and pressure, the pressure at which it failed was about $1.3 \mathrm{psi}$.
Figure 6 shows the fracture surface near the failure origin of the indented tempered glass sheet. The central tension was determined to be $8.3 \mathrm{ksi}$ from the mirror dimensions, specifically from half the distance between the points marked with the arrows in the micrograph. Assuming that the tempering stress distribution was parabolic, the surface compression was 16.6 ksi. The failure stress was determined to be 7.8 ksi from the shift in the position of the tensile stress maximum in an adjacent part of the fracture surface as described in Appendix A. Figure 1 includes a plot of failure stress as a function of indentation load for fully tempered glass (surface compressive stress of $128 \mathrm{MPa}$ $\{18.3 \mathrm{ksi}\})$. There is considerable scatter in the failure stress data for indentation loads in the range of the 30 kilogram but no value less than $100 \mathrm{MPa}(14.3 \mathrm{ksi})$. The value of $7.8 \mathrm{ksi}$ obtained in Experiment No. 1 for glass with nearly the same compressive surface stress is substantially lower. 


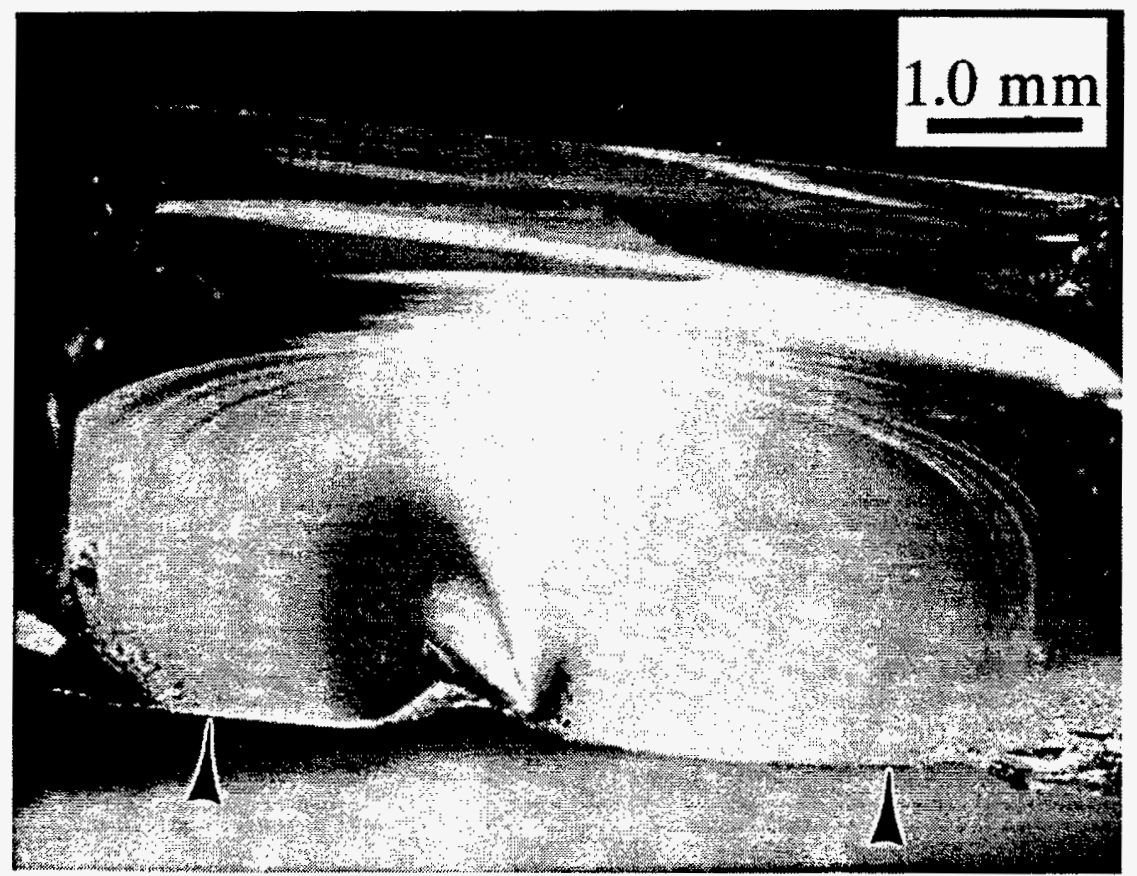

Figure 5. Fracture Origin (indentation flaw) in Annealed Glass, Experiment No. 1 (Arrows indicate limits of mirror region at tensile surface.)

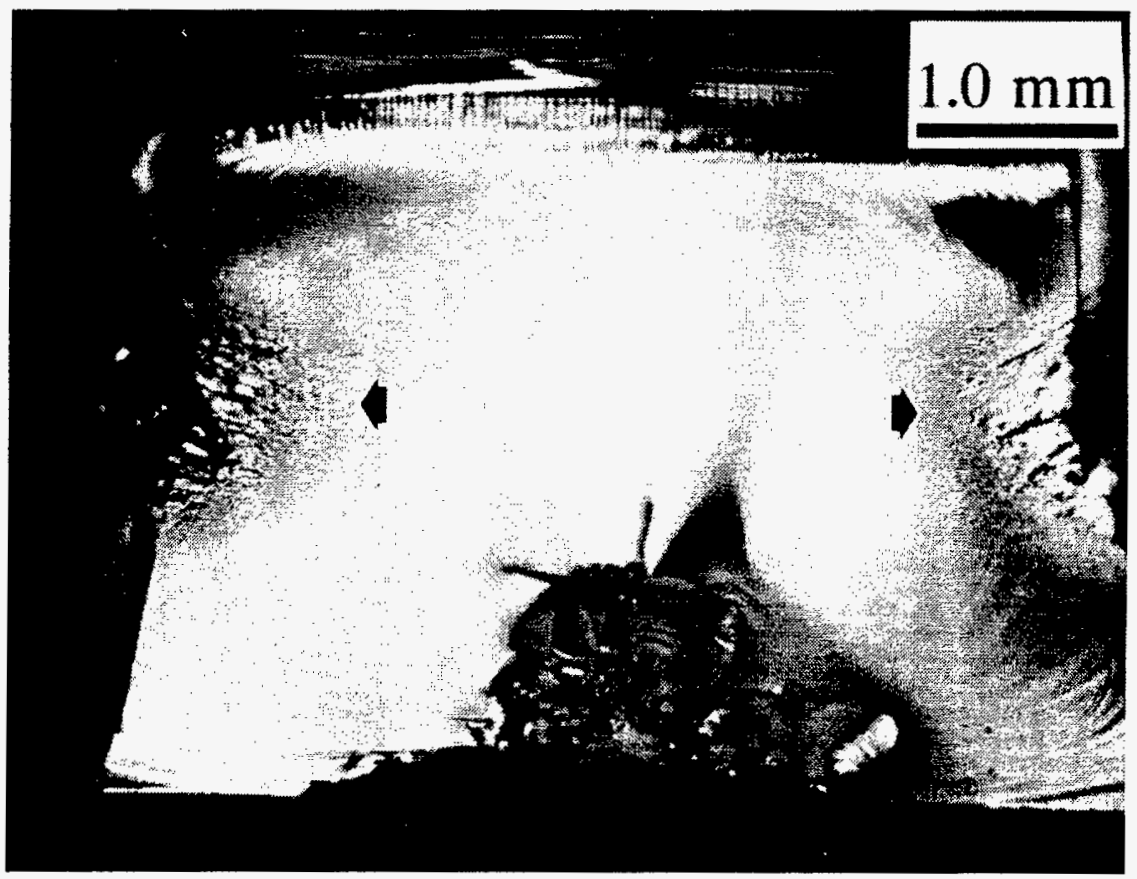

Figure 6. Fracture Origin (indentation flaw) in Tempered Glass, Experiment No. 1 (Arrows indicate mirror/mist boundary.) 
Table 3. Stress Values for Experiment No. 1

\begin{tabular}{|c|c|c|c|c|c|}
\hline & $\begin{array}{l}\text { Crack } \\
\text { Length } \\
\text { Change } \\
\text { (Indent) }\end{array}$ & $\begin{array}{c}\text { Mirror } \\
\text { Radius } \\
\text { Equation }\end{array}$ & $\begin{array}{l}\text { Mecholsky } \\
\text { Plot }\end{array}$ & $\begin{array}{l}\text { Shift in } \\
\text { Feature } \\
\text { Position }\end{array}$ & Prediction $^{d}$ \\
\hline $\begin{array}{l}\text { Tempered }^{\mathbf{a}} \\
\text { Central Tension } \\
\text { Failure Stress } \\
\text { Pressure }\end{array}$ & & $8.3 \mathrm{ksi}$ & & $\begin{array}{l}7.8 \mathrm{ksi} \\
1.74 \mathrm{psi}\end{array}$ & $\begin{array}{l}22.5 \mathrm{ksi}(30 \mathrm{~kg}) \\
5.1 \mathrm{psi}\end{array}$ \\
\hline $\begin{array}{l}\text { Annealed }(4 \mathrm{~mm})^{\mathrm{b}} \\
\text { Failure Stress } \\
\text { Pressure }\end{array}$ & & $\begin{array}{l}5.87 \mathrm{ksi} \\
1.31 \mathrm{psi}\end{array}$ & $\begin{array}{l}5.6 \mathrm{ksi} \\
1.25 \mathrm{psi}\end{array}$ & & $\begin{array}{l}3.8 \mathrm{ksi}(10 \mathrm{~kg}) \\
0.85 \mathrm{psi}\end{array}$ \\
\hline $\begin{array}{l}\text { Annealed }(1 / 4 \text { in })^{c} \\
\text { Failure Stress } \\
\text { Maximum Stress } \\
\text { Pressure }\end{array}$ & $\begin{array}{l}2.44 \pm 0.1 \mathrm{ksi} \\
1.08 \mathrm{psi}\end{array}$ & & $\begin{array}{l}4.7 \mathrm{ksi} \\
2.07 \mathrm{psi}\end{array}$ & & $\begin{array}{l}2.99 \mathrm{ksi}(10 \mathrm{~kg}) \\
1.28 \mathrm{psi}\end{array}$ \\
\hline $\begin{array}{l}{ }^{2} 3.95 \mathrm{~mm} \text { thick. Vic } \\
\text { b3.95 mm thick. Vi } \\
{ }^{\mathrm{c}} 0.219 \text { inch thick. V } \\
{ }^{\mathrm{d}} \text { Based on data in Fi }\end{array}$ & $\begin{array}{l}\text { ers indent with } \\
\text { kers indent wit } \\
\text { ckers indent wi } \\
\text { ure } 1 .\end{array}$ & $\begin{array}{l}\text {-kg load. } \\
\text {-kg load. } \\
\text { 10-kg load. }\end{array}$ & & & \\
\hline
\end{tabular}

For the 1/4-inch annealed sheet, one of the 10kilogram-load indent flaws propagated and caused extensive fracture. The tape kept the fragments together and the sheet remained in the frame. The failure stress for that flaw was determined (from the mirror radius equation) to be $4.7 \mathrm{ksi}$, indicating a pressure of $2.1 \mathrm{psi}$ at failure. Three of the other indent cracks produced with the 10-kilogram load also showed some growth during the test. Stresses calculated from the crack length changes are shown in Table 3. None of the 3-kilogram-load or 1-kilogram-load indent cracks in the 1/4-inchthick sheet showed any growth. As noted in Appendix A, the lack of growth during the blast loading is attributed to the fact that the indentation cracks had the opportunity to grow subcritically prior to that loading. If that subcritical growth exceeded the crack length that could have been produced in the blast loading, no additional growth would have occurred. To determine whether crack growth would occur from the applied stress (of the blast loading), that stress value is inserted into Equation A-8 (Appendix A). If the $\mathrm{K}_{1}$ value exceeds the critical stress intensity, $\mathrm{K}_{\mathrm{Ic}}$, crack growth can occur.

In the $1 / 2$-inch-thick sheet, which did not fracture, only the 30-kilogram-load indent cracks showed any growth during the test. To determine whether crack growth should have occurred for these indents, the pressure determined from the 10-kilogram-load indents in the $1 / 4$-inch-thick sheet was used to calculate the tensile stress generated in the $1 / 4$-inch and $1 / 2$ inch sheets during the shock loading. The stress was then inserted into Equation A-8 (Appendix A) and the $K$ value was calculated. For the 1kilogram-load indentation flaw in the $1 / 4$-inch sheet and for the 3-kilogram-load and 10- 
kilogram-load flaws in the $1 / 2$-inch-thick sheet, the $\mathrm{K}$ values were less than $\mathrm{K}_{\mathrm{Ic}}\left(0.7 \mathrm{MPam}^{1 / 2}\right)$; thus no additional crack growth would have been possible during the shock loading. For the 3-kilogram-load indent in the 1/4-inch sheet, the $\mathrm{K}$ value was 0.7 ; thus a small increase in crack length should have been possible. 


\subsection{Experiment No. 2}

\subsection{Test Plan}

The second experiment did not include the $1 / 4-$ and $1 / 2$-inch-thick plates of annealed glass that were used in the first experiment. Instead, the experiment was designed to compare the fracture and subsequent transport, by the blast wave, of an as-received tempered plate with two other tempered plates that were weakened to initiate failure early in the blast loading. The behaviors of those sheets would be compared with that of an annealed sheet. All plates were 4 $\mathrm{mm}$ thick. As noted above, two different procedures were used to reduce the failure strength. In one of the plates, the strength was diminished by reducing the compressive stress in a small area in the center of the plate. The low- strength area was produced by annealing with a propane torch. In the other plate, the strength was reduced by indenting with a Vickers indenter at a load of 30 kilogram. In the annealed sheet, indentation flaws were introduced at the sheet center using a load of 3 kilogram. Positioning of the sheets in the window is noted in Table 1.

The amount of explosive used in this test was substantially greater than that in the first test. Moreover, to provide a higher impulse from the shock wave, the explosive type was changed from C-4 to ANFO (ammonium nitrate/fuel oil). With 25 pounds of ANFO at 20 feet from the window, the peak incident overpressure was predicted to be $12.7 \mathrm{psi}$, while the impulse was predicted to be 20.22 psi-msec.

\subsection{Results}

\subsubsection{General Observations (Posttest)}

The 25 pounds of ANFO proved to be excessive for the experimental setup. The right section of the backstop was found lying on its front face. Apparently the lower support failed, the blast rotated that section around the upper support, and the section then dropped to the floor. The left section of the backstop rotated about a vertical axis so that it was oriented about 90 degrees from its original location but remained standing. The displacements of the backstop sections occurred after the glass fragments were captured in the backstop.

The two front foam panels ( 1 inch thick) on the left side of the backstop were so severely fragmented that an area approximately 18 inches wide and $3 \frac{1}{2}$ feet high was torn from both of those panels. As a consequence, all glass fragments that had impacted that area were lost (for the purposes of determining penetration depth and trajectory). The right section of the backstop was not quite as severely damaged; thus it was possible to obtain some data on penetration.

\subsubsection{Phenomenology of Fracture Initiation}

A comparison of the first two experiments yielded a very surprising result. Although fracture initiated at indents in the center of both the annealed and tempered glass sheets in the first experiment, that was not the case in the second. Instead, in every glass sheet, fracture initiated at one of the corners, presumably from flaws on the edge of the sheet. These flaws would likely have been produced in cutting the glass or subsequent handling. In typical window 
applications, these types of flaws are responsible for failure.

The difference in location of the fracture origination between Experiment No. 1 and Experiment No. 2 is apparently a result of the higher pressure and the rapid rise in pressure in Experiment No. 2. At low applied pressure with deflection less than the plate thickness, stresses in the sheet are described as bending stresses. In that event, the resultant tensile stress is a maximum at the center of the sheet. However, if the deflection at the center of the plate exceeds the thickness of the sheet, the plate is treated as a membrane in stress analysis. The nonlinear stress analysis that is then applicable shows that the maximum tensile stress is at the corners of the plate and results from local bending. ${ }^{1}$ The tensile stress near the center of the sheet is lower than at the corners and nearly uniform through the thickness. Therefore, particularly because the worst defects in a sheet are ordinarily at the sheet edges, failure would typically start at a corner. The surprise in considering the results of Experiment Nos. 1 and 2 comes from the fact that indent flaws at the sheet centers had resulted in crack origination at the sheet center for the 4-psi overpressure experiment, but those same indent flaws were ineffective in the 12.7psi overpressure experiment. Possible explanations for this phenomenon will be presented below.

\subsubsection{Crack Growth (Fragmentation) and Local Stresses}

The membrane deformation behavior of the glass sheets in Experiment No. 2 was also evident in the fragmentation of the sheets and in the local stresses in the sheets. For the annealed glass sheet, a different color had been used on a 4-inch band at the edge of the sheet than had been used in the center, permitting a comparison of the crack propagation details in the different parts of the sheet. Fragments from the peripheral area ranged from more than 2 inches to less than 0.2 inch in length and from about 0.8 inch to less than 0.1 inch in width. This small fragment size indicates a high tensile stress at fracture. Most of the larger fragments from the periphery had additional cracks extending approximately halfway through the thickness. These cracks were present as a roughly parallel array running on the long dimension of the fragment as shown in the example in Figure 7. Separation of these partial cracks was in the range of 0.1 inch.

Fracture in the central area of the annealed sheet had a very different character. The area surrounding the indent flaws at the sheet center had been taped prior to the shot so that an area of more than 6 square inches was recovered. Most of the fragments in this area were much larger than those from the edge of the plate Moreover, most of the fracture that produced this fragmentation was produced by a bending stress with opposite sign from that at the periphery; i.e., the surface of the sheet facing the explosive was in tension, not compression. Apparently, this area did not fragment when the periphery did. Instead, it remained essentially crack-free as it separated from the periphery. The fragmentation probably occurred when that large piece struck the backstop or some other object, creating a bending load leading to the unusual stress condition.

As noted above, fracture of the annealed sheet did not initiate at any of the indents at the center of the plate. Nevertheless, some crack growth occurred at three of the five indents; thus a measure of the maximum tensile stress at those flaws during the blast loading could be made. The values for the applied tensile stress calculated from the crack extensions at those flaws were $3.5,3.2$, and $3.3 \mathrm{ksi}$. 


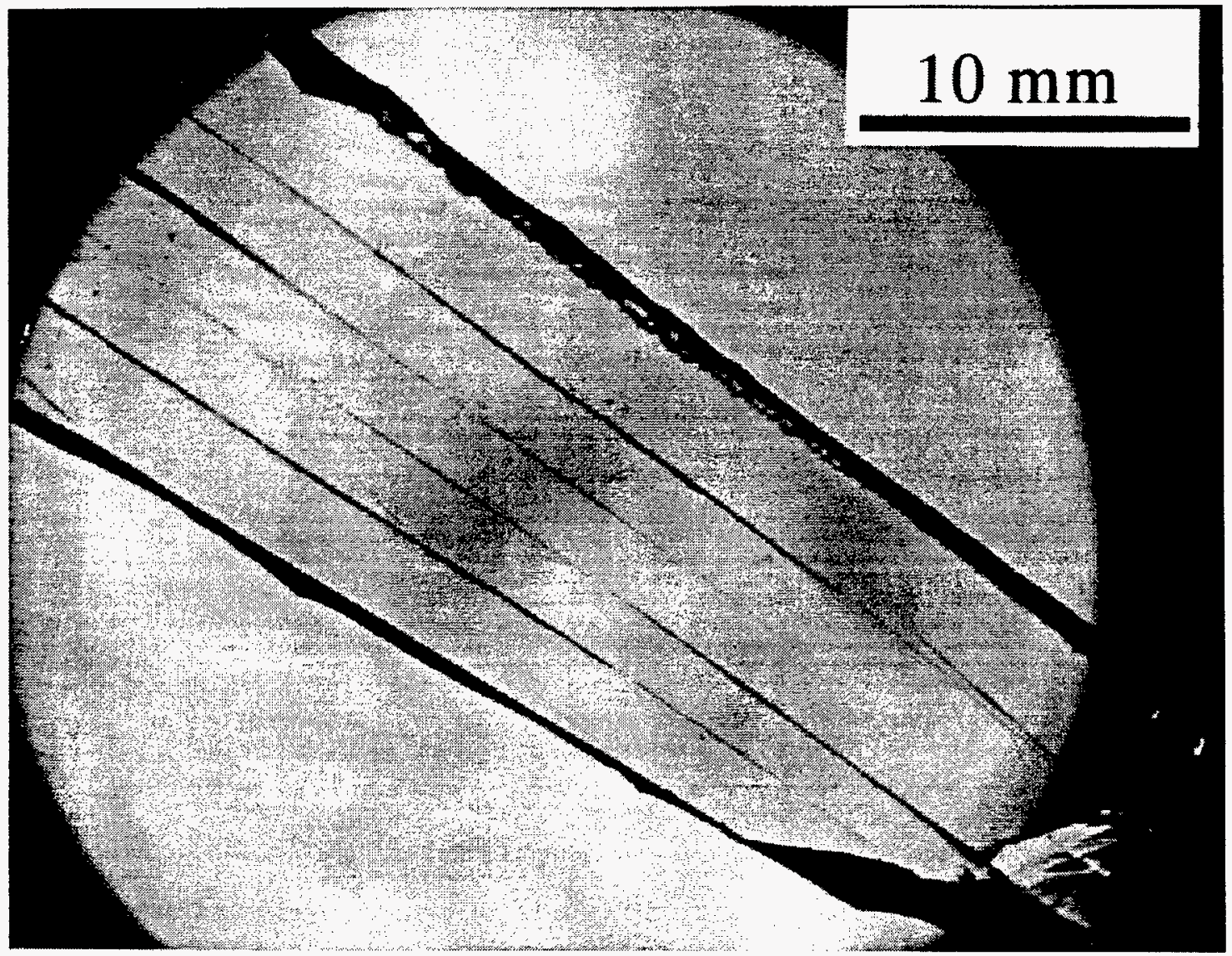

\section{Figure 7. Fragment from Annealed Glass Showing Cracks That Had Penetrated Partway Through Thickness, Experiment No. 2}

This pattern of fracture of the annealed sheet is consistent with a fracture mode in blast loading referred to as circumferential in Reference 14. That mode results from membrane deformation of the sheet with very large strains at the periphery and small strains at the center. In the high-strain regions, where the maximum tensile stress is high, the sheet disintegrates into small fragments; in the low-strain region, little or no fragmentation occurs.

For the as-received (no deliberate reduction in strength) tempered sheet, tape had been applied at the corners as well as at the center prior to the test in an effort to capture the material in the vicinity of the origin for subsequent examination. Although unsuccessful in capturing the origin in any of the recovered areas, preserving those areas did provide the opportunity to compare the fracture behavior of the center with that of the corners. As with the annealed sheet, it was clear that the stress from the blast wave was much lower at the center than at the corners. At the center, the shift of the demarcation lines indicated an applied tensile 
stress of $42 \mathrm{MPa}(6.1 \mathrm{ksi})$ in one fragment, 58 $\mathrm{MPa}(8.5 \mathrm{ksi})$ in another fragment, and effectively zero in a third fragment from the taped area. In contrast, a sample in the lower left corner showed a shift corresponding to $198 \mathrm{MPa}$ (28.7 ksi) applied stress, while the applied stress in the upper left corner was measured at 221 $\mathrm{MPa}$ (32 ksi).

\subsubsection{Fragment Penetration into the Foam Backstop}

The damage to the backstop during this test forced a change in the strategy for analyzing the penetration. Only the right side of the backstop survived the explosion. Rather than attempting to map the areal distribution of fragments from the four glass sheets captured in that side, a plot was made of the total mass of glass from each sheet that penetrated through different layers of the foam. In that plot, shown in Figure 8, the sheet identities are Annealed, Temper.nopo (no treatment after tempering; i.e., as received), Temper.inde (indented), and Temper.anne (annealed center spot). On the Position axis, Sheet $\# 1$ refers to fragments captured in the first 1 -inch sheet of foam, Interface $1 / 2$ refers to fragments that penetrated the first foam sheet (Sheet \#1) but were not trapped in the second (Sheet \#2), and so forth.

The most obvious feature of these data is that most of the captured fragments came from the Annealed and Temper.nopo sheets. This happened simply because those two glass sheets were mounted in the right side of the window. The very small quantity of the glass from the other two glass sheets indicates very little lateral dispersion as the glass moved from the window to the backstop.

The other unexpected observation is that the penetration of the tempered glass fragments is essentially the same as that of the annealed glass. The apparent reason for that penetration is that, like the annealed glass fragments, the tempered glass fragments were large pieces with dimensions up to two inches. These large pieces showed the extensive fracturing expected from the dicing process in tempered glass, but no separation at the fracture surfaces. The pieces were actually assemblages of dice fragments. These smaller fragments were coupled strongly enough that they survived the transit by the blast wave and the impact on the backstop.

Note that the total mass of the annealed and asreceived tempered glass sheets that was captured was only a small fraction (about $5 \%$ of the total) of the mass of the original sheets. Those glass sheets weighed about 2.34 kilogram, and only 129 grams of the annealed glass and 100 grams of the as-received tempered glass were captured in the backstop. Some additional material would have been captured in the left side of the backstop, but most of the rest of the fragments presumably reached the backstop and bounced off without penetrating. Most of that material was found on the floor in front of the backstop and most of the tempered sheet material on the floor was in the form of small fragments, i.e., single dice fragments or small clusters. 


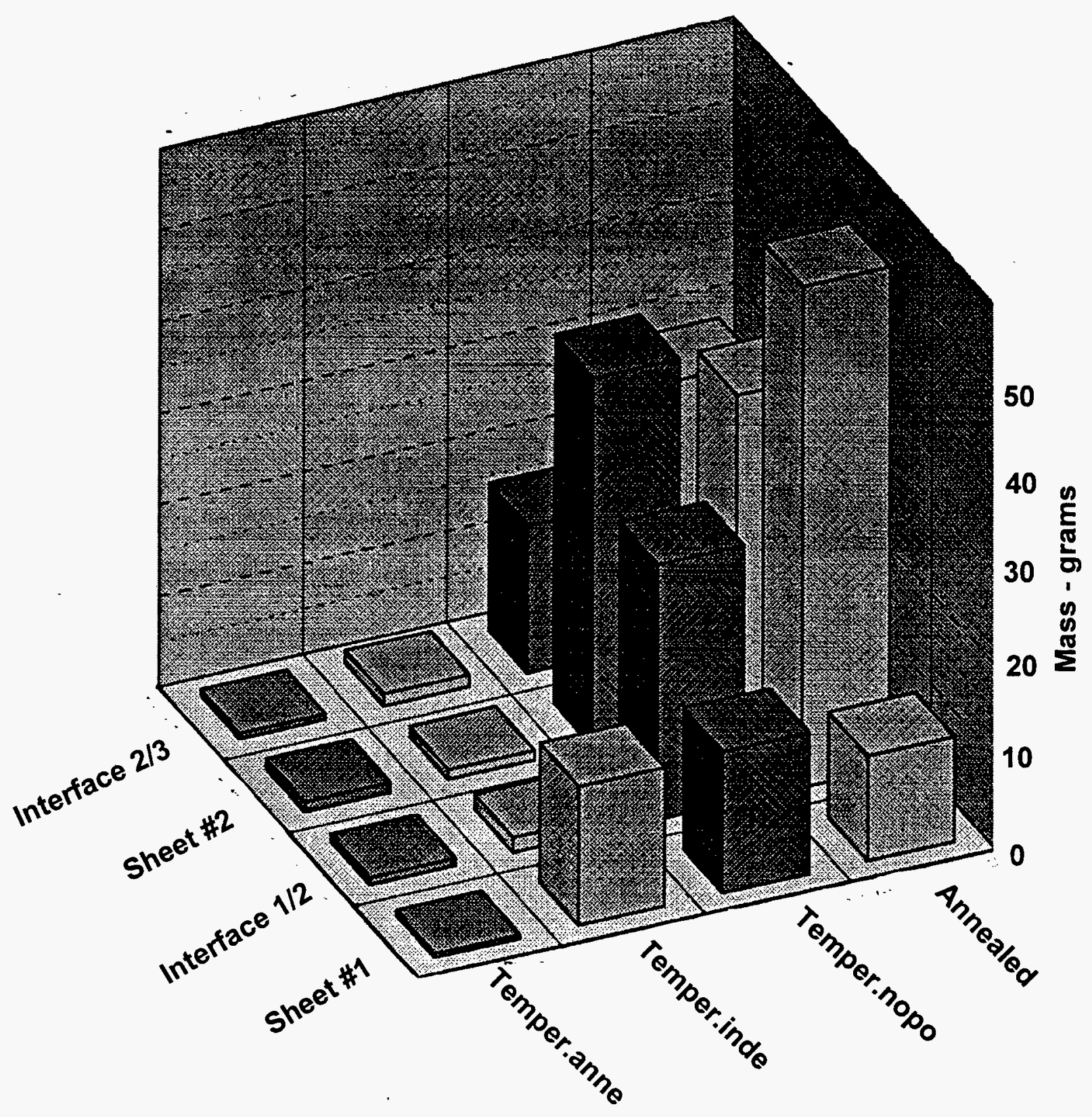

Figure 8. Penetration of Glass Fragments into Right Side of Backstop, Experiment No. 2 (As-received tempered and annealed sheets were also on right side of window. Temper.nopo $=$ tempered, as received; Temper.inde $=$ tempered, indented; Temper.anne $=$ tempered with annealed spots.) 
Intentionally Left Blank 


\subsection{Experiment No. 3}

\subsection{Test Plan}

For Experiment No. 3, the amount of explosive was reduced to 13 pounds of ANFO. As noted in Table 1, at a distance of 20 feet from the window, that quantity of explosive was expected to produce a peak overpressure at the window of $8.22 \mathrm{psi}$ and a specific impulse of 13.41 psimsec. Pressure was not monitored in this experiment. As in Experiment No. 2, the four sheets of glass included one sheet of annealed glass of $4 \mathrm{~mm}$ thickness. The other three were fully tempered glass sheets, also $4 \mathrm{~mm}$ thick, two of which were treated before the test (indented or spot-annealed) to reduce the pressure required to initiate failure. In Experiment No. 2, in which the backstop was 4 feet behind the window, the captured fragments were concentrated near the center of the backstop. To obtain a somewhat broader dispersion in Experiment No. 3, the backstop was located 6 feet from the window. To ensure that the backstop would fall face up after capturing fragments, the bottom rear of the backstop was heavily braced while the top was held in place with strips of duct tape.

\subsection{Results}

\subsubsection{Sources for Fracture Initiation at Low Blast Pressure}

In Experiment No. 2, the fractures initiated at the corners of each of the plates. That happened despite the introduction in three of the plates of features to reduce the local failure stress in the center of the plate. Fractures were expected to initiate at those weak spots; because of the nature of the plate deformation, fractures did not originate at the expected locations (the weakened spots in the centers of the plates). In
Experiment No. 3, weak spots were placed at the four corners as well as the center of the plates to try to ensure that failure would initiate at deliberately introduced weak spots. For the tempered sheet with indentation flaws, three indents (using a 30-kilogram load) were placed near each corner on a vertical line at 2 inches from the vertical edge of the plate and at the vertical center line of the plate. Similarly for the annealed plate, three indentation flaws (using a 3-kilogram load) were placed at each of the four corners and at the center.

For the fourth plate, the failure stress was reduced by annealing a small circular spot at the center of the plate and near the corners of the plate (approximately 2 inches from the plate edges). A polariscope ascertained that the treatment produced stress changes; however, no attempt was made to measure those stresses. Although no obvious change was observable on the plate surface immediately after the heat treatment, some very shallow cracking was observed several hours later. This cracking indicates that the heat treatment did more than reduce the local compressive tempering stress; it probably developed tensile stress in a shallow layer at the surface of the sheet.

To permit recovery of the glass in the vicinity of the flaws after the explosion, 2-inch-wide and about 3-inch-long strips of duct tape were placed over the areas where the flaws had been introduced. Strips of tape were also placed in the same areas on the as-received tempered glass.

\subsubsection{Capture of Fragments in the Foam Backstop}

As intended, the backstop tipped over during the test so that both sections were found face up on the floor. The front surfaces of both sections 
showed fragments captured in the top layer of foam and holes indicating deeper penetration of other fragments. As in Experiment No. 2, these features were concentrated near the center of the backstop.

As noted earlier, the glass sheets were coated with different Magic Marker ${ }^{\mathrm{TM}}$ colors so that it would be possible to identify fragments from a given sheet after fragmentation. For the annealed sheet and the tempered sheet with indentation flaws, a 4-inch-wide band at the edge of the plate was coated with a different color than the center of the sheet. The lateral spread of glass fragments from each of the plates during the flight to the backstop was monitored by removing the fragments from each of the rectangular sectors in the backstop and weighing the total mass of particles from a given glass sheet that were found in each sector.

Plots of the distributions of the mass captured in each of the grid sectors are shown in Figures 9 to 19. For the annealed sheet and the tempered sheet with indentation flaws, separate plots are included for fragments from the edge and from the center. The plots are oriented so that the grid coordinates (horizontal A to $\mathrm{H}$, vertical 1 to 7) correspond with those of the grid on the backstop. To provide a reference for the relative position of the corresponding plate in the window, the projection of that plate on the backstop is indicated by filling that area with a darker tone. The total mass of fragments from a given glass sheet captured in a given foam layer is indicated next to the plot. Separate plots show penetration into the second foam layer. No fragments penetrated into the third layer. Note that the scale for the mass data in Figure 9 is slightly different from the scale in the other plots.

As in the results from Experiment No. 2, the penetration of fragments from the tempered sheets is not much different from that of fragments from the annealed sheet. In fact, the mass captured from the tempered glass with indentation flaws was slightly greater than that of the annealed sheet. As in the prior experiment, the deeply penetrating segments of tempered glass were assemblages of smaller fragments. In all tempered sheets, these fragments contained arrays of cracks consistent with that expected from the central tension in the tempering stress profile.

Comparing the plots for the center of the sheet with those for the edge of the sheet for the annealed sheet (Figures 9 through 11) and the tempered sheet with the indent flaws (Figures 12 though 15), fragments from the edge of a sheet spread more than those from the center. The inference is that the fragments from the edge have a larger lateral velocity component than those from the center. That larger component is probably associated with the membrane deformation mode for these sheets. In that mode, the edge of the sheet bows out while the center section is relatively flat and parallel to the plane of the window. The bowing at the edge leads to a load component parallel to the plane of the window, hence an acceleration in that plane. For the tempered sheet with indent flaws, fragments from both the center and the edge show a broader dispersion than for the annealed sheet. That greater dispersion is consistent with separation of the fragments in the plane of the tempered sheet as a result of the compressive tempering stresses. Note also, in comparing the total mass of edge fragments and center fragments captured in the foam, that the 4-inchwide region of the sheet had a mass of about $1600 \mathrm{gm}$ compared with about $1000 \mathrm{gm}$ for the center portion.

\subsubsection{Stress Measurements}

Table 4 shows the values of local stress at failure calculated for the various glass sheets in Experiment No. 3. Note that local stress at failure is calculated from the shift in the position of the center line of the fracture surface features. 
That calculation assumes that the applied stress is a bending stress and thus the stress profile through the thickness is linear. That is not necessarily the case everywhere in a sheet in these experiments. If the deflection of the sheet center is large enough that the deformation must be described in terms of membrane deformation behavior, the local stress will vary in profile as well as in magnitude. At the center of the sheet, for example, the stress will be nearly uniform tension through the thickness, while at the edge, stresses will be primarily flexural. Table 4 also shows values of the central tension, i.e., the maximum tensile stress, as determined from fragment size or from the mirror radius. In these cases, the mirror radius was taken as half the distance between the mirror/mist boundaries as marked by the arrows in Figure 6 . 
Table 4. Experiment No. 3: Stresses Calculated from Fracture Features

\begin{tabular}{|c|c|c|c|c|c|c|}
\hline & $\begin{array}{c}\text { Central } \\
\text { Tension (ksi) }\end{array}$ & $\begin{array}{l}\text { Center } \\
\text { (ctr) } \\
\text { (ksi) }\end{array}$ & $\begin{array}{l}\text { Upper Left } \\
\text { (ul) } \\
\text { (ksi) }\end{array}$ & $\begin{array}{c}\text { Upper } \\
\text { Right } \\
\text { (ur) } \\
\text { (ksi) }\end{array}$ & $\begin{array}{c}\text { Lower Left } \\
\text { (li) } \\
\text { (ksi) }\end{array}$ & $\begin{array}{c}\text { Lower } \\
\text { Right } \\
\text { (lr) } \\
\text { (ksi) }\end{array}$ \\
\hline $\begin{array}{l}\text { Tempered, } \\
\text { as received }\end{array}$ & 8.7 (FS) & 10.3 (CLS) & 16.9 (CLS) & 23.4 (CLS) & & 23.1 (CLS) \\
\hline $\begin{array}{l}\text { Tempered, } \\
\text { indented }\end{array}$ & $\begin{array}{l}9.6 \text { (FS)(ctr) } \\
10.0,9.6,11.0 \\
\text { (MR)(ctr) }\end{array}$ & $\begin{array}{l}19.6 \text { (CLS) } \\
15.7 \text { (CLS) }\end{array}$ & 25.57 (CLS) & 13.4 (CLS) & 17.7 (CLS) & $\begin{array}{l}35.1,31.3 \\
\text { (CLS) }\end{array}$ \\
\hline $\begin{array}{l}\text { Tempered, } \\
\text { annealed } \\
\text { spot }\end{array}$ & $\begin{array}{l}5.0 \text { (MR)(ur) } \\
7.0 \text { (FS) } \\
4.5 \text { (MR)(ll) } \\
6.4(\mathrm{MR})(\mathrm{ul})\end{array}$ & 5.1 (CLS) & 1.64 (CLS) & 3.8 (CLS) & 3.35 (CLS) & 2.89 (CLS) \\
\hline Annealed & N/A & $<2(\mathrm{FS})$ & $\begin{array}{l}3.9,4.5 \\
(\mathrm{FS})^{*}\end{array}$ & $6.3(\mathrm{MR})$ & & \\
\hline $\begin{array}{r}\text { Methods for } \\
\begin{array}{r}1 . \mathrm{F} \\
2 . \mathrm{C} \\
\text { 3. M }\end{array} \\
\text { * At corner }\end{array}$ & $\begin{array}{l}\text { stress determinat } \\
\mathbf{S}=\text { Fragment siz } \\
\mathbf{L S}=\text { Center line } \\
\mathbf{R}=\text { Mirror radil } \\
\text { f center section }\end{array}$ & $\begin{array}{l}\text { on } \\
\text { shift (Appliec } \\
\text { s (at origin) } \\
4 \text { inches from }\end{array}$ & $\begin{array}{l}\text { tensile stress } \\
\text { edge of sheet) }\end{array}$ & surface duri & g failure) & \\
\hline
\end{tabular}




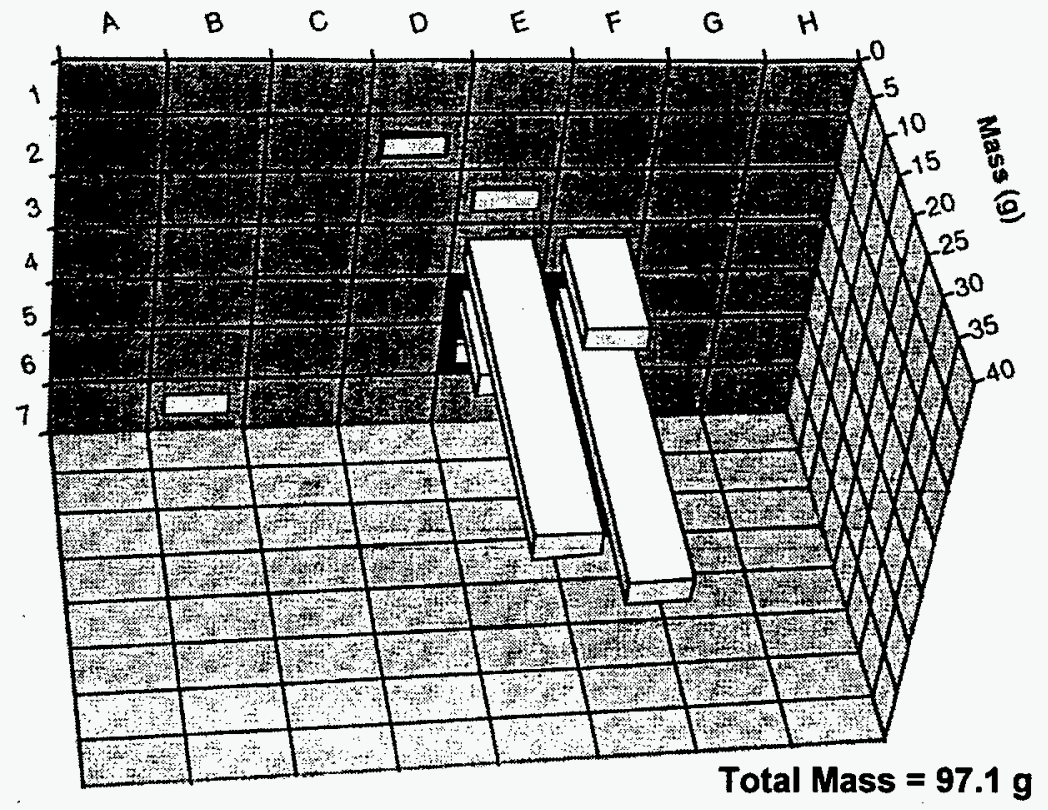

Figure 9. Areal Distribution of Fragments Captured in Backstop from the Center Section of the Annealed Sheet, First Foam Layer

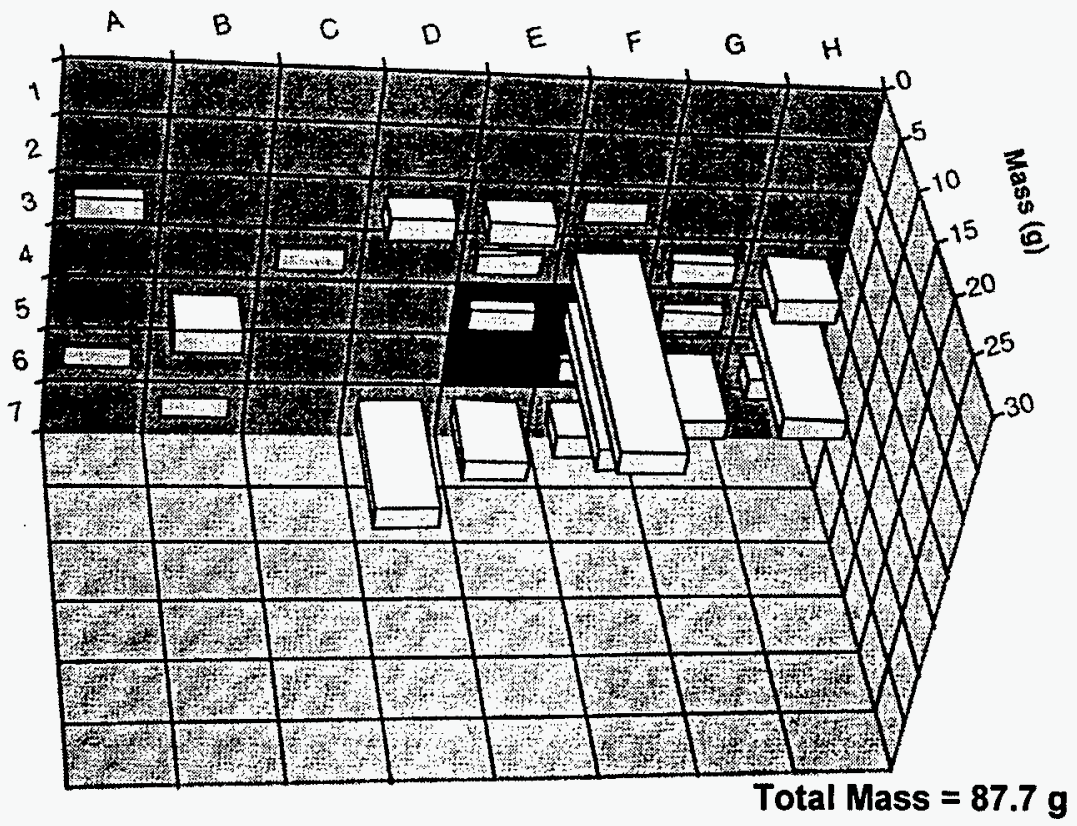

Figure 10. Areal Distribution of Fragments Captured in Backstop from the Four-InchWide Edge of the Annealed Sheet, First Foam Layer (Darker zone on backstop is the projection of the annealed window opening on the backstop.) 


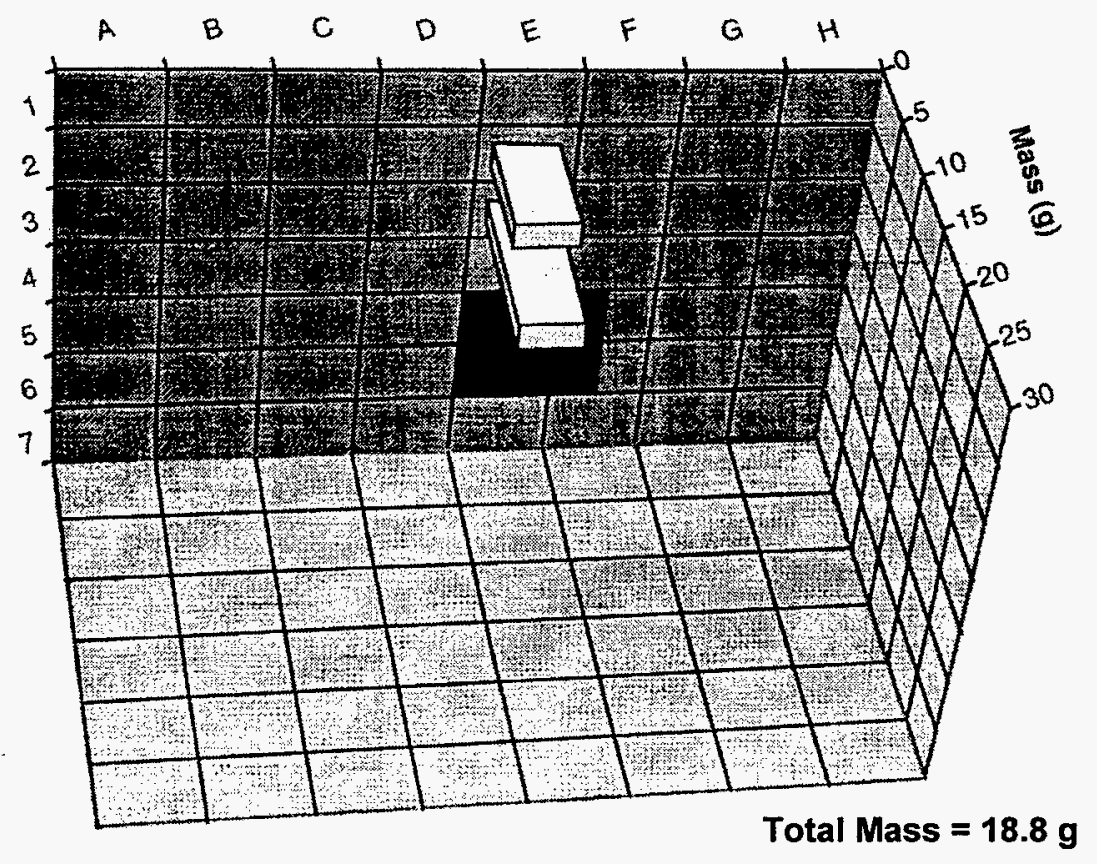

Figure 11. Areal Distribution of Fragments Captured in Backstop from the Four-InchWide Edge of the Annealed Sheet, Second Foam Layer 


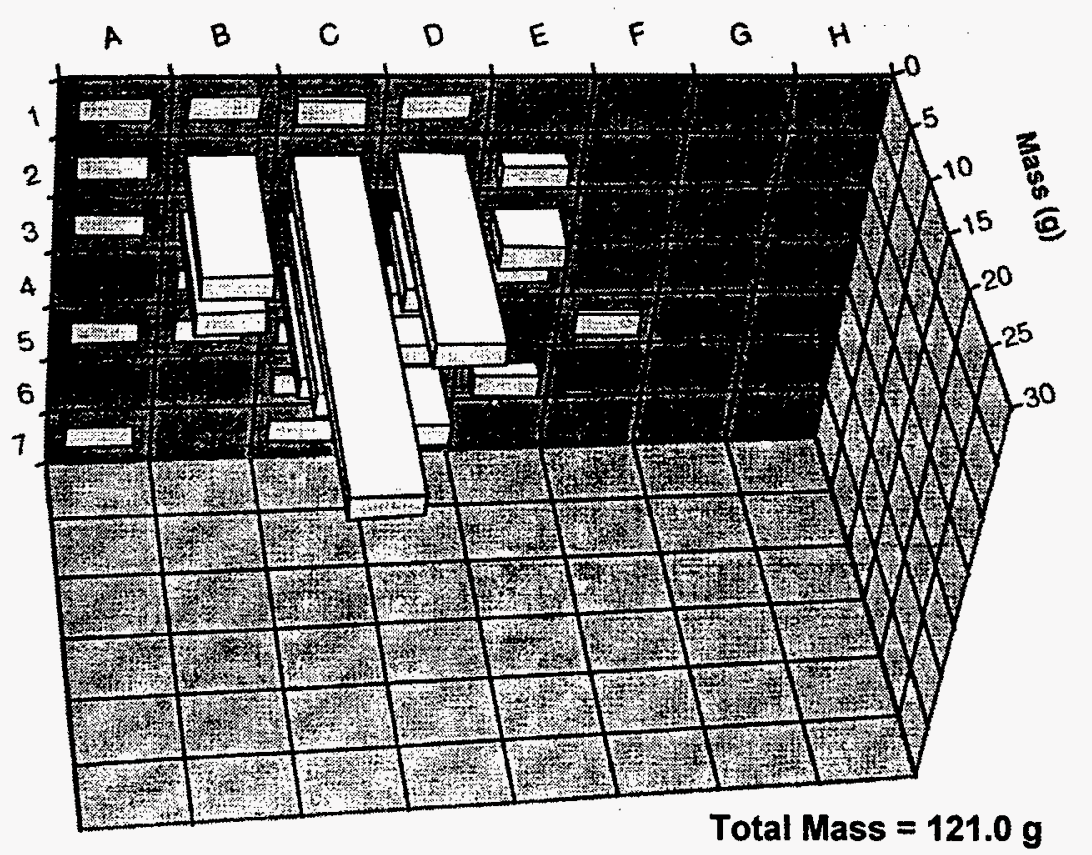

Figure 12. Areal Distribution of Fragments Captured in Backstop from the Center Section of the Tempered and Indented Sheet, First Foam Layer

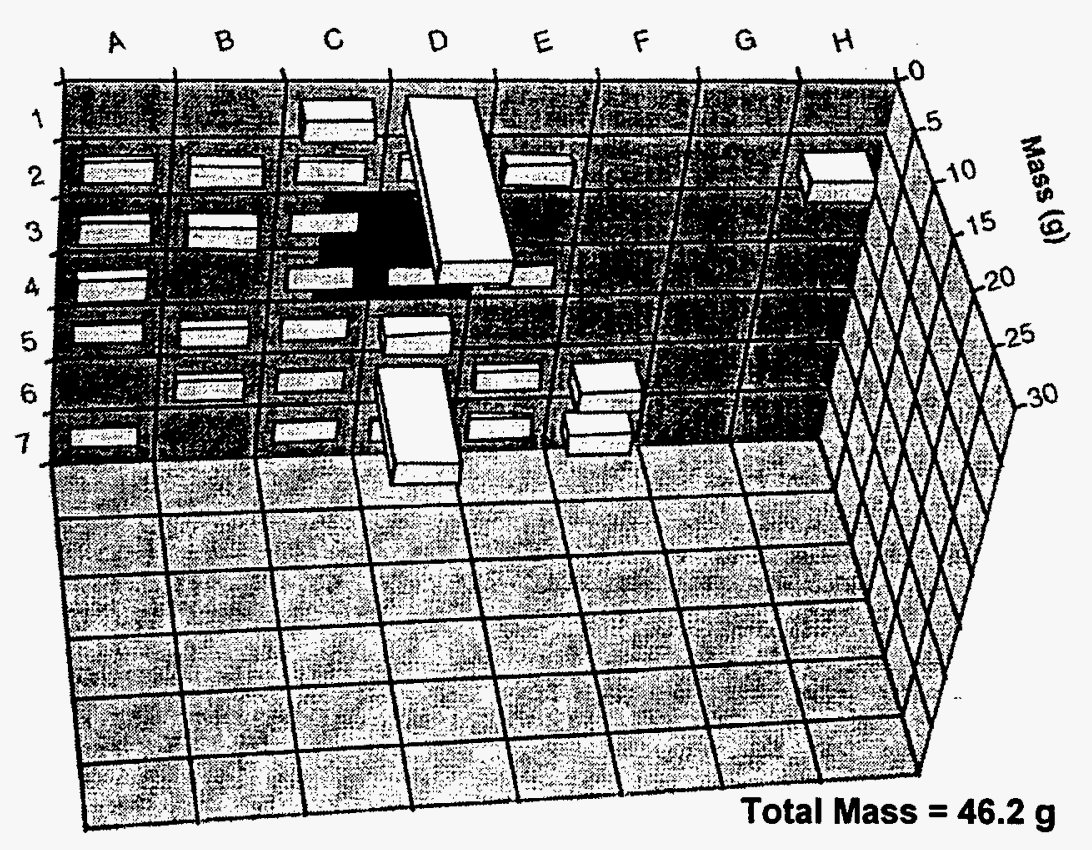

Figure 13. Areal Distribution of Fragments Captured in Backstop from the Four-InchWide Edge of the Tempered and Indented Sheet, First Foam Layer 


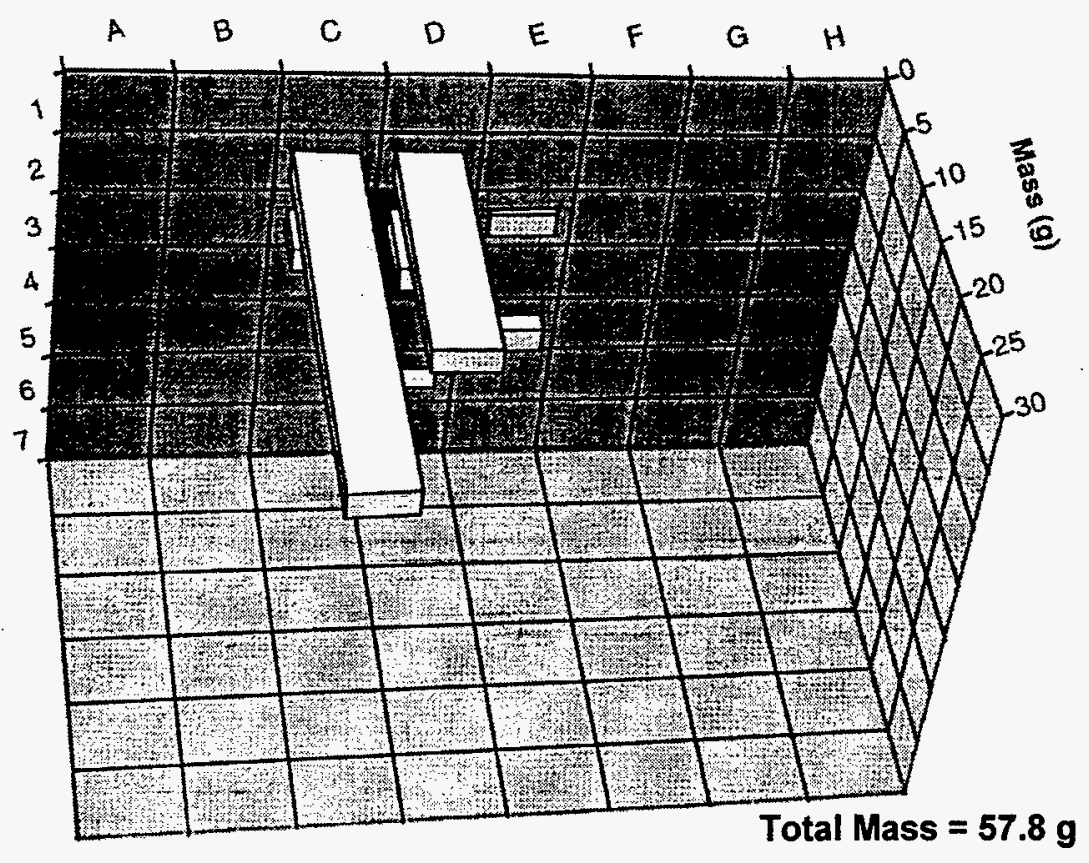

Figure 14. Areal Distribution of Fragments Captured in Backstop from the Center Section of the Tempered and Indented Sheet, Second Foam Layer

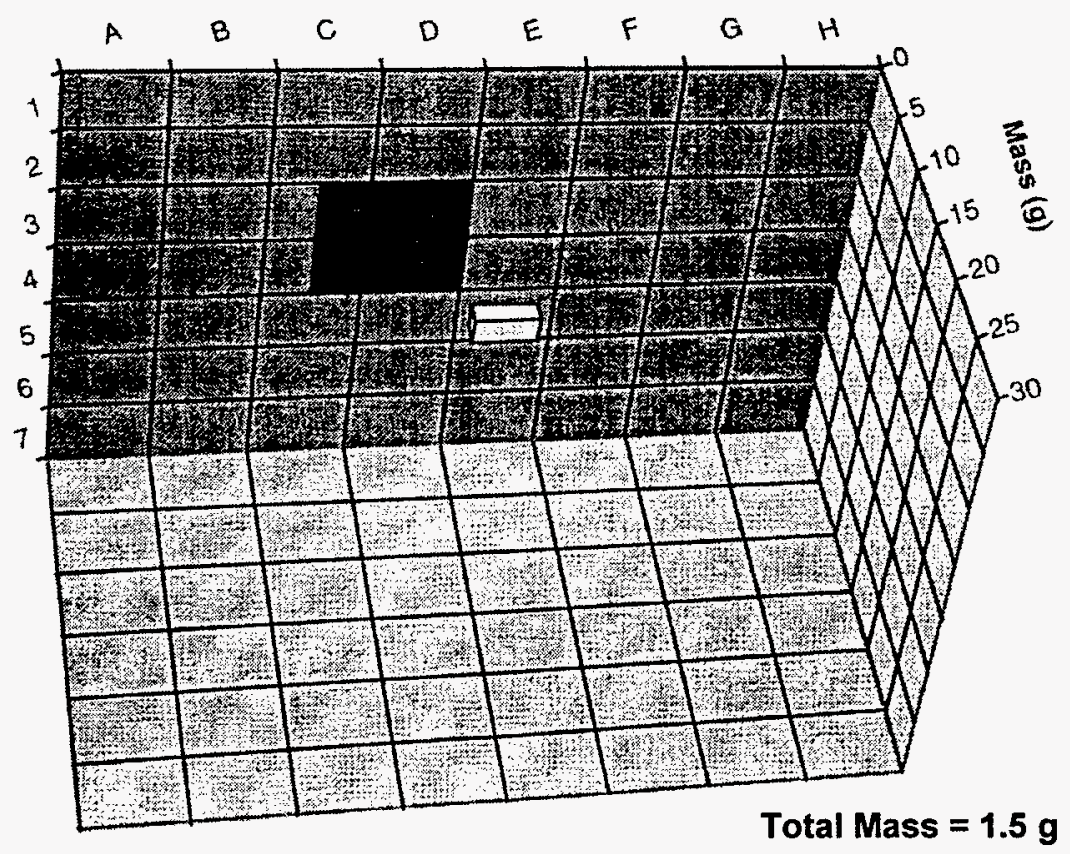

Figure 15. Areal Distribution of Fragments Captured in Backstop from the Four-InchWide Edge of the Tempered and Indented Sheet, Second Foam Layer 


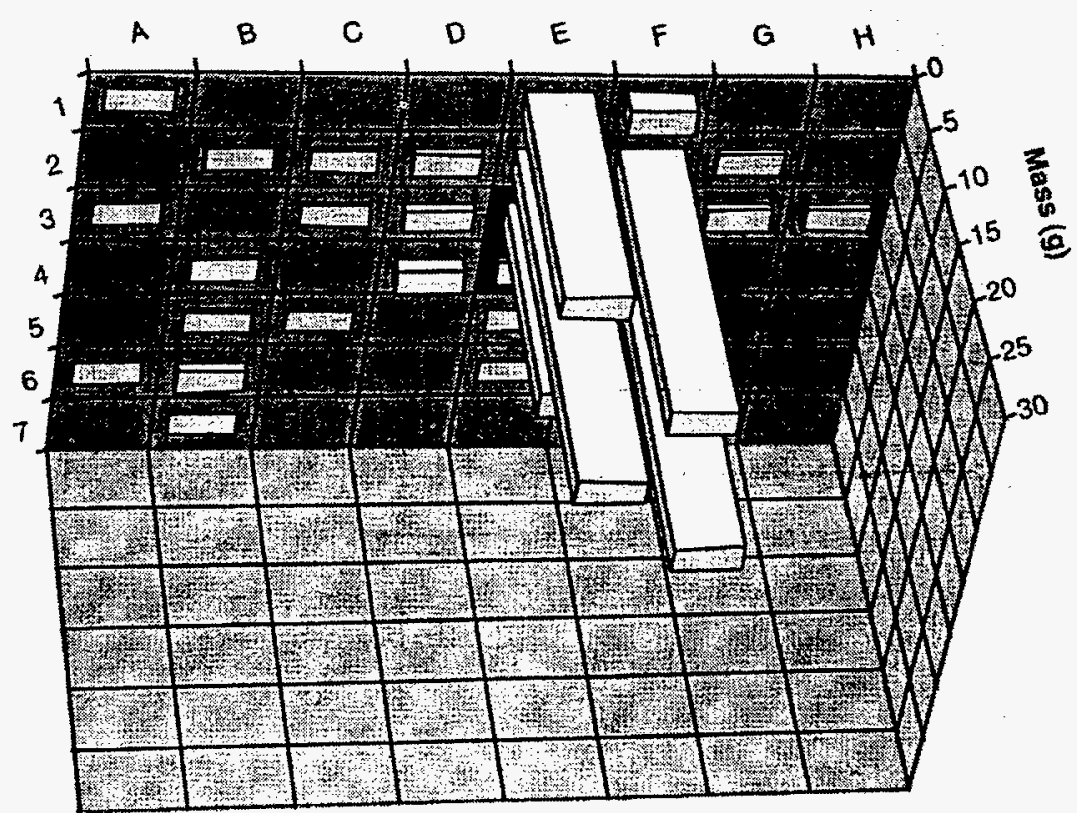

Total Mass $=121.8 \mathrm{~g}$

Figure 16. Areal Distribution of Fragments Captured in Backstop from the Tempered and Spot-Annealed Sheet, First Foam Layer

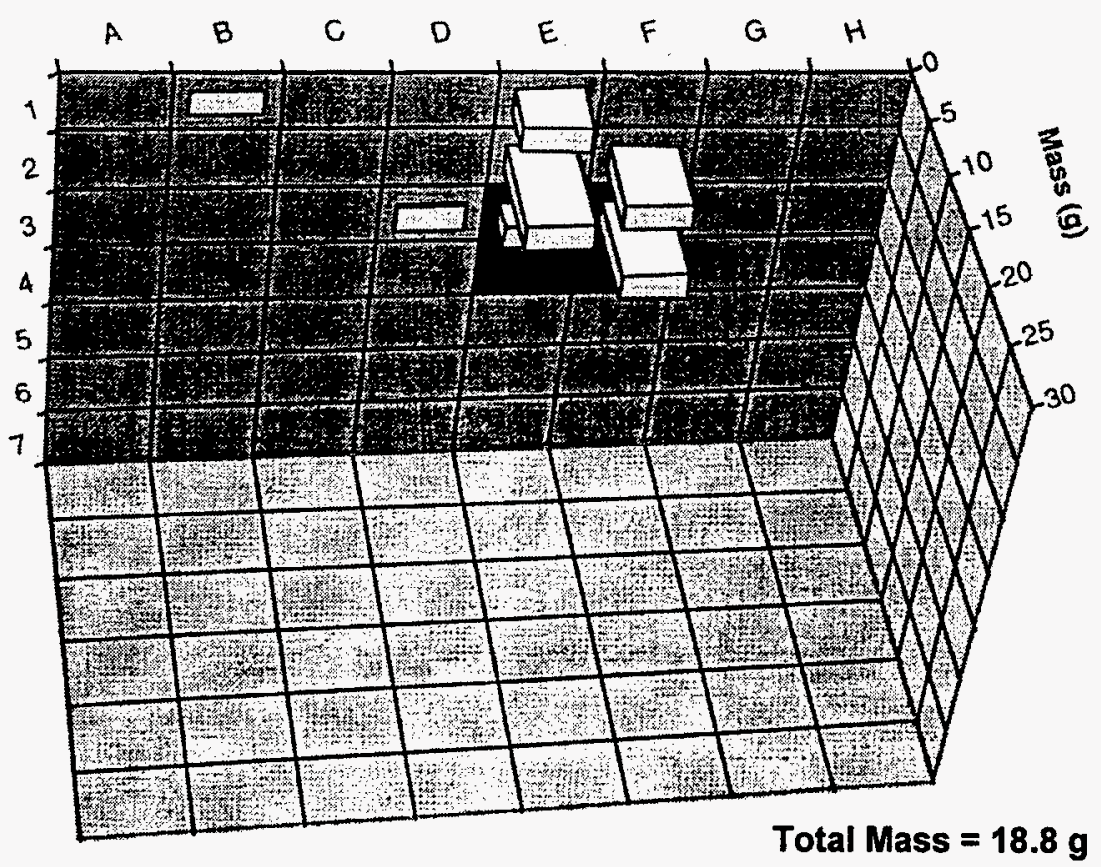

Figure 17. Areal Distribution of Fragments Captured in Backstop from the Tempered and Spot-Annealed Sheet, Second Foam Layer 


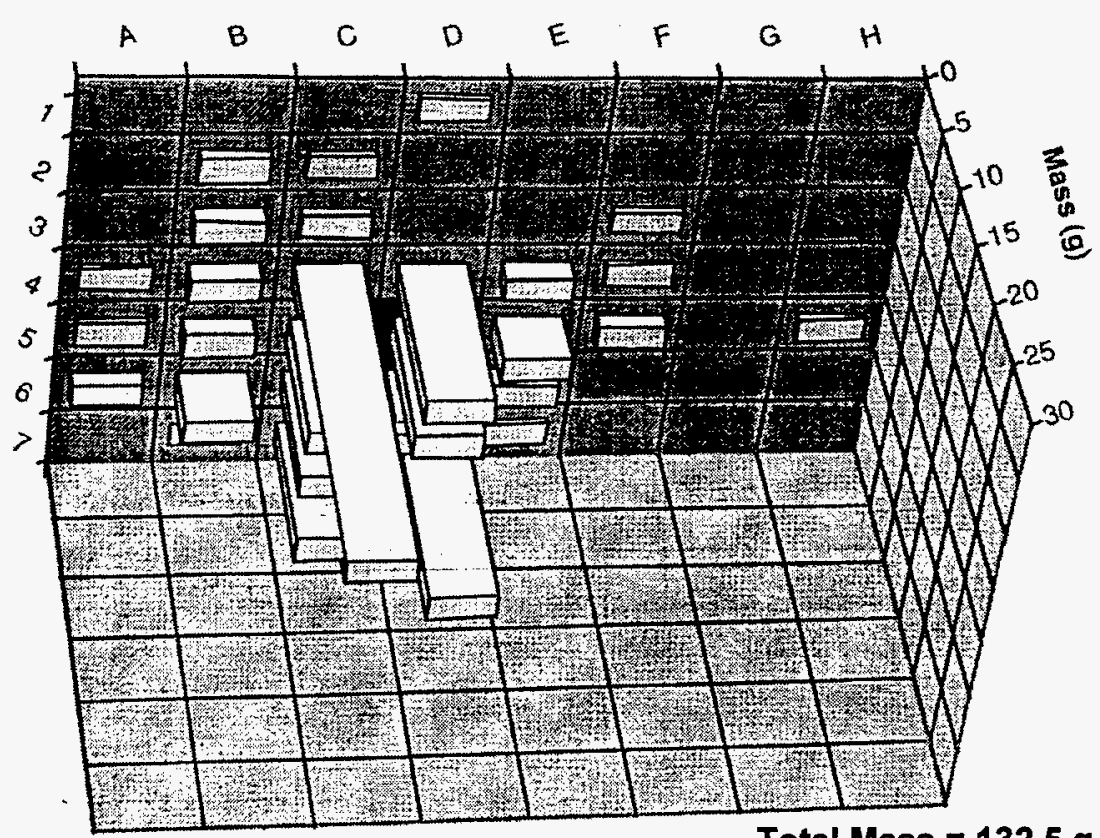

Total Mass $=132.5 \mathrm{~g}$

Figure 18. Areal Distribution of Fragments Captured in Backstop from the Tempered, As-Received Sheet, First Foam Layer

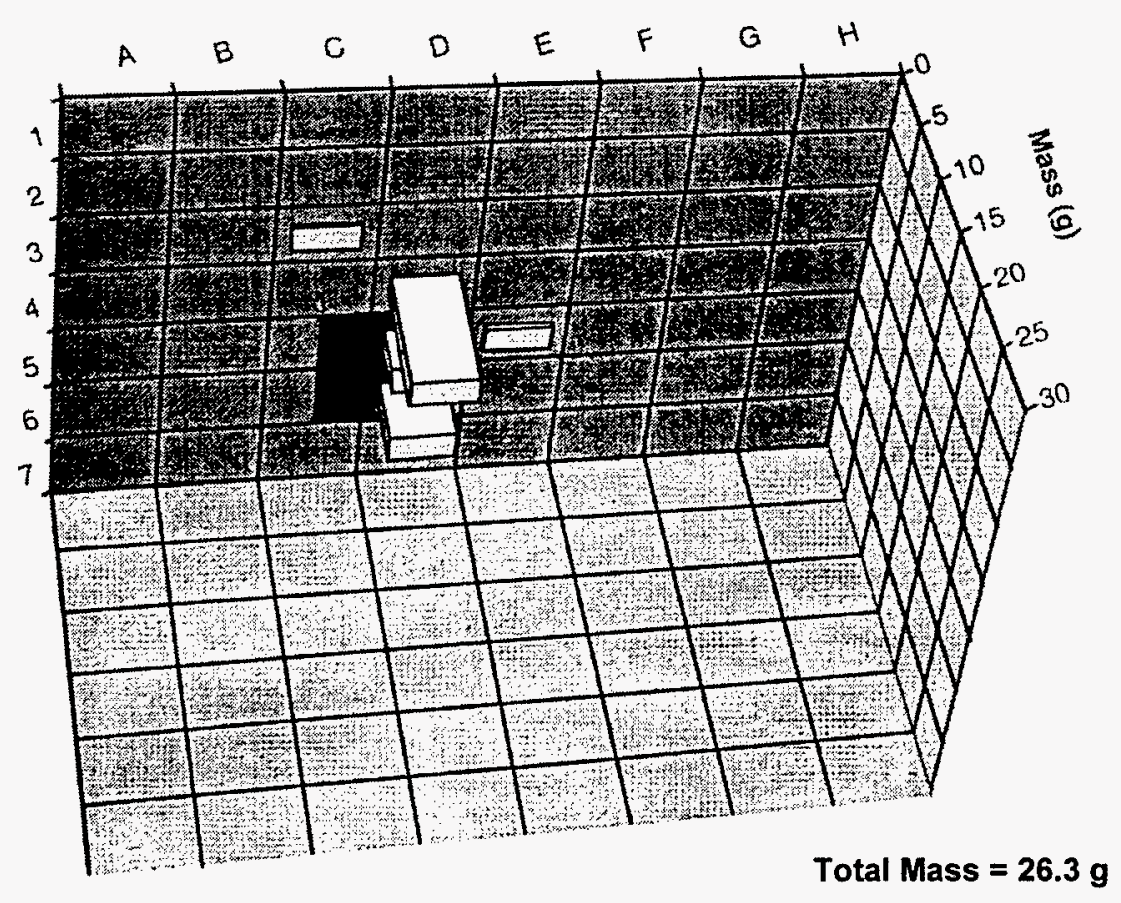

Figure 19. Areal Distribution of Fragments Captured in Backstop from the Tempered, As-Received Sheet, Second Foam Layer 


\subsection{Velocity Measurements}

Although the efforts to obtain high-speed photographic records of the glass fragment transport during the three Sandia National Laboratories experiments were unsuccessful, a subsequent non-Sandia test with improved lighting was successfully photographed. In that experiment, which used the same explosive materials and blast conditions as those in Experiment No. 3, only annealed glass was used in the window. Two sheets each of $1 / 8$-inchthick and $1 / 4$-inch-thick glass were placed so that sheets of the same thickness were located diagonally in the window.

The horizontal translation of the fragments from the four sheets was determined from their position relative to a grid. Those data are plotted as a function of time in Figure 20. In this plot, zero time corresponds to the instant when the explosive detonated. That instant was recorded as a bright flash in one frame of the film. The window was 20 feet from the explosive. The fact that no motion of the glass occurred until 0.015 second later indicates that the blast-wave velocity was at least 1300 feet per second.

In Figure 20, the higher velocities were attained by the $1 / 8$-inch-thick glass, as expected. The highest of the velocities was attained by the $1 / 8$ inch-sheet lower in the window. Note that there is essentially no change in velocity with distance. The terminal velocity was reached very early, perhaps by the time that fragmentation of the sheets had been completed.

The high-speed images also provided some useful information on the trajectories of the fragments. Figure 21 is a frame from the film taken with a second camera, placed about halfway between the window and the backstop, that viewed a larger area than the one used for the velocity measurements. In this view, the glass fragments are moving from the window at the right toward the backstop at the left. The dark vertical streak at the lower center of the picture is a cluster of fragments from the lower 1/8-inch-thick sheet. At about 2 feet from the window, the fragments were still oriented approximately as they were when the sheet fractured. The frames used for the velocity measurements showed that by the time the fragments had moved 5 feet from the window, most had rotated out of their original plane. However, few of these fragments had rotated so that their long axes are oriented normal to the backstop; i.e., they did not have an orientation that would be expected to produce maximum penetration of the foam in the backstop.

Although the fragments in this cluster slowly rotated, there was very little separation in the plane of the cluster. At 5 feet from the window, the vertical dimensions of the cluster were nearly the same as at 2 feet from the window.

A careful examination of frames early in the flight of the glass fragments showed that the cluster in Figure 21 was from the center of the sheet. The motion of that cluster contrasted sharply with that of fragments from the periphery (an estimated 2-inch-wide strip) of the sheet. Fragments from that strip separated rapidly from the central cluster, indicating large velocity components in the original plane of the sheet. These fragments also had lower horizontal velocity, so that they quickly lagged behind the central cluster and they rotated much more rapidly. Some of those fragments can be seen below and behind the cluster in Figure 21. 


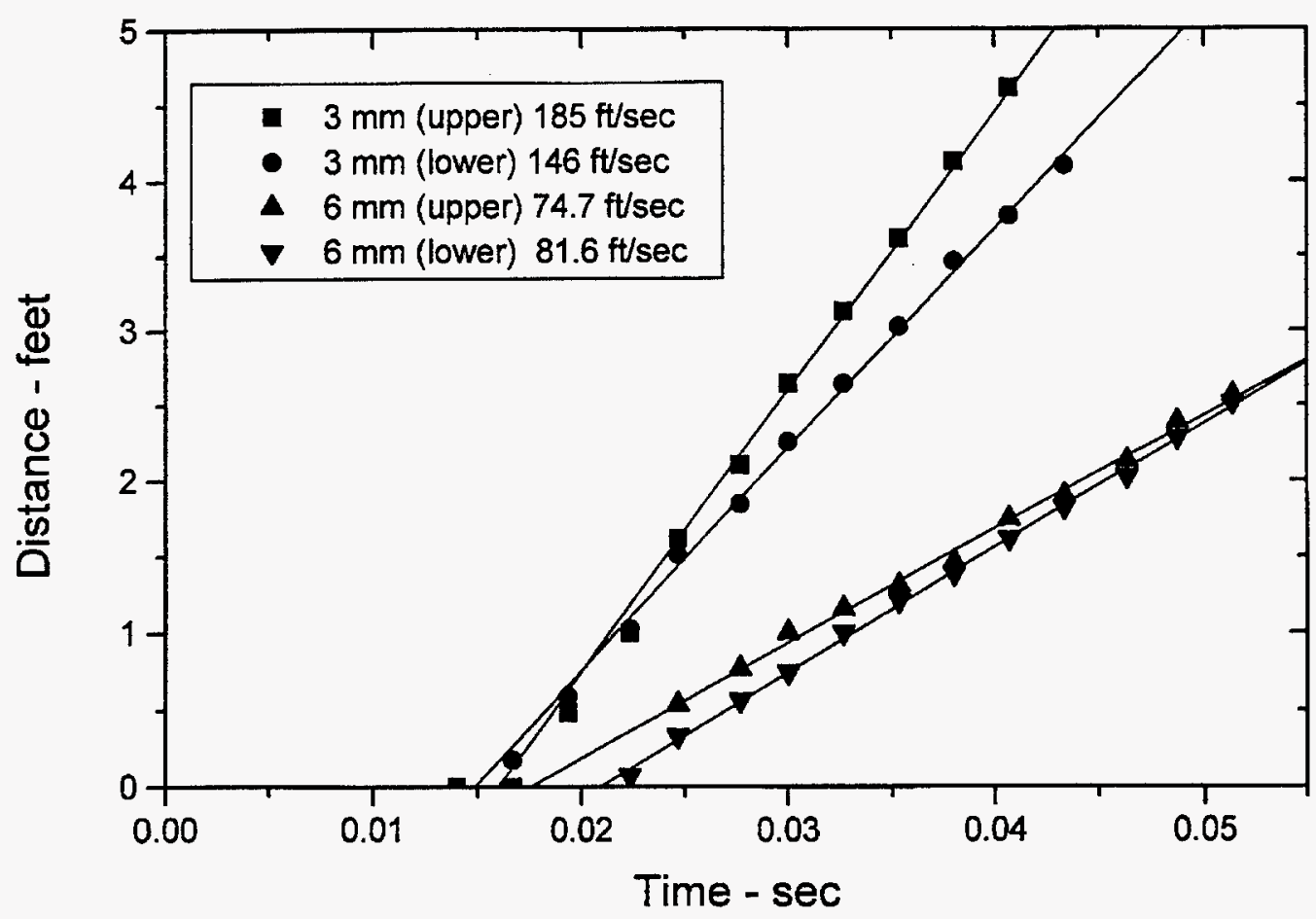

Figure 20. Horizontal Position vs. Time for Glass Fragment Clusters (From highspeed photography frames obtained in a test subsequent to Experiment No. 3.)

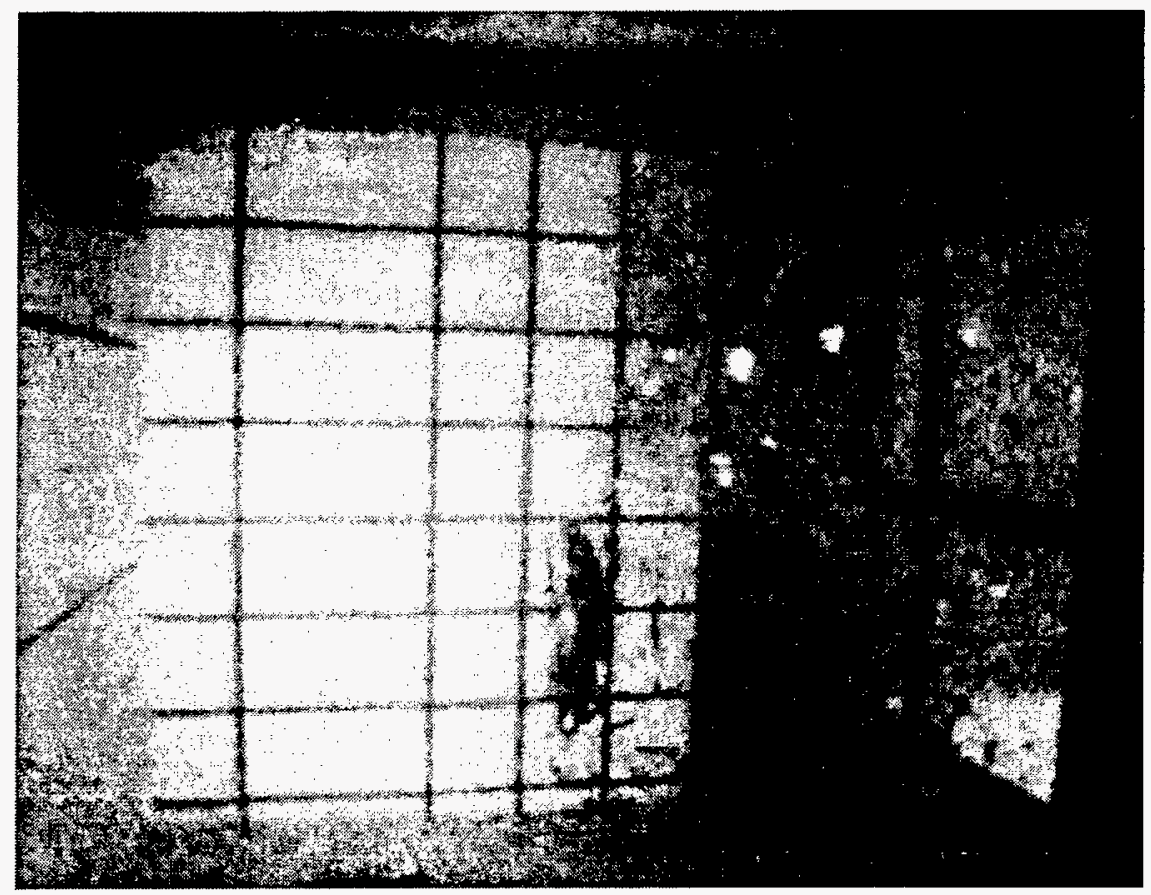

Figure 21. Wide-angle Photograph of Glass Fragments Moving from Window at Right Toward Backstop at Left (Grid spacing is 1 foot.) 
This general behavior was also seen in the motion of the other three sheets; however, the upper sheets showed somewhat more separation of fragments from the center of the sheet than the lower sheets showed. The fragments from the upper sheets are difficult to see in Figure 21 because they are a lighter color than the two lower sheets. (The lower 1/4-inch-thick sheet is in the dark zone nearer the window and is difficult to see in this picture.)

The motion of the glass sheet fragments in this test is consistent with membrane deformation of the sheets prior to fracture. As noted above, in that type of deformation the center of the sheet is nearly planar, while the edge curves, producing a shape similar to a shallow rectangular, flat-bottomed tub. At the moment of fracture, the velocity vectors produced by the pressure loading are essentially normal to the surface at that point. As a consequence, the fragments at the center of the plate will move horizontally with no strong tendency to separate. On the other hand, fragments from the periphery will have velocity components in the plane of the sheet. Moreover, those velocity components will vary with position away from the frame; thus fragments from the periphery will have a strong tendency to rotate.

The observation that the center of the sheets in this test remained in a cluster of fragments with little rotation may explain the fact that only a small fraction of the mass of any of the sheets in the earlier experiments was captured in the backstop. Apparently, most of the fragments struck the backstop flat (i.e., with an orientation that precluded penetration) and they bounced off. 
Intentionally Left Blank 


\subsection{Discussion}

\subsection{Penetration of Foam Boards by Tempered Glass}

One of the unexpected results from these experiments was the deep penetration into the foam boards by the tempered glass fragments. In Figure 8, which shows the results from Experiment No. 2, there are some differences in detail, but the overall conclusion is that the tempered glass and the annealed glass showed nearly the same degree of penetration. In Experiment No. 3, the total mass of fragments from the tempered, indented sheet that penetrated the foam was slightly greater than the mass from the annealed sheet. The masses from the as-received tempered sheet and from the tempered sheet with the annealed spots were slightly less. On the basis of earlier work that showed rapid fragment separation during fracture of prestressed sheets, ${ }^{2-5}$ a much smaller amount of penetration from fragments of the tempered sheets had been expected. That expectation was based on the assumption that the small fragments produced by dicing of the tempered glass would separate from one another and impact the foam as individual fragments. Instead, large areas (dimensions of 2 to 3 inches or more) of the tempered glass impacted the foam and penetrated it. These areas showed the closely spaced branching fractures expected for dicing, but separation did not occur at those fractures.

Although these assemblages of smaller fragments survived the stresses associated with moving out of the window and impacting the foam, they were not exceptionally strong. In many instances, they disintegrated as they were being removed from the foam. Their survival during impact with the foam may be attributed to the nature of the loading during that impact.
All large segments that penetrated the backstop had impacted the foam surface essentially edgeon; thus the loading in the plane of the segment was compressive. In contrast, an impact at a small angle between the plane of the glass fragment and the backstop could produce some tensile stress. Pieces with that impact mode would be expected to fragment either during the collision or after rebounding and hitting the floor.

The failure of the tempered glass to separate consistently into smaller fragments during the fracture process was unexpected. The stress profile usually assumed to exist in a tempered glass sheet includes a compressive stress layer in which the magnitude of the stress increases monotonically toward the sheet surfaces. The continuous redistribution of stresses as the crack grows through the compressive region should cause the crack to penetrate almost to the sheet surface. The strain energy in a tempered sheet is calculated by integrating $\sigma^{2} / \mathrm{E}$ through the sheet thickness, assuming a parabolic profile for the stress distribution. In that equation, $\sigma$ is the local stress and $E$ is Young's modulus. That calculation showed that the strain energy in the compressive stress region of a tempered sheet is $60 \%$ greater than that in the tensile stress region. However, the fracture surface produced by that energy is only $2 / 3$ that produced in the tensile stress region. The implication is that substantially more energy is available in the compressive region than necessary to generate the fracture surfaces during dicing. Much of that extra strain energy was expected to be converted into kinetic energy of the individual fragments in a manner that would separate them with some velocity.

The conversion of strain energy from the compressive stress region into kinetic energy of 
dicing fragments has been observed in chemically strengthened glasses and glassceramics. ${ }^{15}$ For the more energetic materials tested (higher residual compressive stresses), particle velocities of greater than $40 \mathrm{feet} / \mathrm{second}$ were measured. Finite element calculations showed that greater than $60 \%$ of the original strain energy was released in the dicing process and about half of that was converted to kinetic energy of the fragments.

In the tempered glass used in this study, the tempering process apparently did not produce a stress profile that was conducive to rapid and complete separation of the dicing fragments. One possible explanation for the failure to separate may be that the stress profile was not monotonically increasing to the surface, but rather had a maximum within the sheet. The two-stage cooling process used in tempering windows for general use may cause such a turnover in the stress profile. ${ }^{16}$ However, the sheets used in these experiments were tempered at a local custom-glass supplier. The variation between sheets in dicing size and central tension indicates that the processing of these sheets was not precisely controlled. It is possible that the performance of these sheets is not typical of standard tempered glass manufactured on a production line. It is also possible that standard tempered glass does not result in complete separation of dicing fragments. Further testing is indicated to resolve this question.

It is possible that the presence of the flexural stresses from the blast loading could affect the propagation of the fracture to the sheet surfaces as well as the energy imparted to the fragments. However, during tests to determine a suitable heat treatment for spot-annealing the tempered glass, a companion sheet to those used in these experiments was fractured. With no applied stress except that at the annealed spot, the same pattern of fracture was observed: many pieces with dimensions of 2 to 3 inches that contained fracture patterns with separations of 0.2 to 0.4 inch. Blast loading was expected to enhance the separation rather than limit it. At the surface where the bending load produces the tension, it would be much easier to propagate the crack to the surface, even if the tempering stress did not monotonically increase to the surface. At the surface where the bending load produces compressive stress, fracture should also be enhanced, once the fracture at the tensile side is completed. The extra compressive stress from the bending load should also result in more energy for separating the particles.

Note that penetration into a foam board may not provide an accurate measure of the potential for producing injury to the human body. If the performance of the tempered glass in these experiments is representative of thermally tempered glass, the assumption that tempered glass would produce fewer injuries than annealed glass in a blast environment requires further study. If the current procedures for tempering glass typically result in fragment clusters, modification may be required so that separation into small fragments can be assured in a blast environment.

\subsection{Reduction of Failure Stress in Tempered Glass}

Both techniques intended to reduce the failure stress for tempered glass proved successful. Indentation flaws were more effective than predicted by the data ${ }^{8}$ shown in Figure 1. In Experiment No. 1, the tempered sheet had a central tension of $8.3 \mathrm{ksi}$ and a compressive stress at the sheet surface of $16.6 \mathrm{ksi}(115 \mathrm{MPa})$. (If it had not been indented, the failure stress would have been substantially greater than 16.6 ksi.) In the experiment, failure originated with an applied tensile stress of $7.8 \mathrm{ksi}(54 \mathrm{MPa})$ at an indentation flaw produced with a 30kilogram load at the center of the sheet. In Figure 1, the large arrow on the line drawn through the data for the fully tempered glass 
(128 $\mathrm{MPa}$ compressive stress on the surface) indicates a failure stress of slightly over 150 $\mathrm{MPa}(21.8 \mathrm{ksi})$ with an indentation flow introduced with a 30-kilogram $(294 \mathrm{~N})$ load. The lowest data point in Figure 1 for that load is about $110 \mathrm{MPa}(16 \mathrm{ksi})$, twice the stress at which the sheet in Experiment No. 1 failed. In contrast, the 3- kilogram-load indentation flaw in the annealed glass in Experiment No. 1 reduced the failure stress to about $5.6 \mathrm{ksi}(39$ $\mathrm{MPa}$ ), only slightly greater than the value marked by the arrow on the annealed glass plot in Figure 1.

The data in Table 4 contradict the results in Experiment No. 1. In Table 4, most stress values for the as-received sheet are actually lower than those for the indented sheet. The only explanation for the contradiction is that the asreceived sheet had an unusually severe processing flaw that lowered its strength. The most likely place for such a flaw would be the sheet edge. The membrane deformation would enhance the likelihood of activating such a flaw. Unfortunately, the fracture origin was not present in any of the taped areas that were recovered so that possibility could not be substantiated.

In Experiment No. 3, three of the corner areas of the tempered sheet with annealed spots were recovered for subsequent examination. In all three of those areas, fracture had propagated from the annealed spots. As a result, fragmentation of the sheet occurred by essentially simultaneous development of crack networks from at least those three sites. As shown in Table 2, shifts in the center line of the fracture surface features indicated local tensile stresses (i.e., the effective failure stresses) from the blast loading ranging from $3.8 \mathrm{ksi}$ down to $1.64 \mathrm{ksi}$ in the vicinity of those flaws. Central tension from tempering, determined from fragment size, was between 4.5 and $7.0 \mathrm{ksi}$; thus the surface compressive stress (except at the spots that had been annealed) was at least 9.0 ksi $(63 \mathrm{MPa})$. The failure stress without the induced flaws would have been substantially greater than $9.0 \mathrm{ksi}$. This very substantial reduction of failure stress suggests that the annealing treatment may have gone beyond reducing the magnitude of the compressive tempering stress at those spots. It may have produced some tensile stress. The presence of shallow cracks at these annealed spots after the treatment but before the test supports that possibility.

Reduction of the failure stress in the tempered sheet with annealed spots was accompanied by a significantly lower penetration of fragments from that sheet (Figures 16 and 17) compared to all other sheets. The total mass of fragments from this glass sheet captured in the foam was 140 grams compared with 225 grams for the tempered sheet with no posttreatment. This reduced penetration mass may be a consequence of the substantial reduction in the failure stress for this sheet that resulted in a reduction of the velocity of the fragments.

\subsection{Location of Fracture Origins in Shock-Loaded Windows}

The observation in Experiment No. 2 that failure initiated at the corners of all four glass sheets, despite three of the sheets having severe flaws in the center, has important implications for window failure in a blast environment. It is unlikely that the shock pressure could increase to the 12.7 psi maximum value without first creating a condition in the glass sheet with stress in the center of the sheet at least as high as in Experiment No. 1. Why then didn't the indent flaw propagate and cause failure? The answer may be in the behavior of a crack held at low stress intensity $(\mathrm{K})$ values in conditions where very slow subcritical crack growth could occur (at what is referred to as the stress corrosion limit). Reference 17 showed that under such aging conditions water vapor acting on the crack 
tip can effectively blunt it, so that the stress necessary to restart the crack growth increases substantially with aging time. Moreover, the onset of crack growth would be delayed until the crack tip was resharpened. That delay time decreases as the applied $\mathrm{K}$ value increases (beyond the $\mathrm{K}$ value at which the aging took place). All data reported in Reference 17 were obtained during testing under quasistatic conditions and do not provide a basis for estimating the response of a blunted crack to very rapid loading.

The implication of the Reference 17 results for the tests described here is that during the 3 to 5 days between indenting the sheets and running the tests, the cracks probably grew until the $\mathrm{K}$ value dropped to the stress corrosion limit and then the crack tips blunted. During Test No. 2, the stress acting on the indent flaws increased rapidly, then dropped off as the deformation of the sheet changed from linear to membrane deformation mode. The prior blunting of the flaws prevented them from propagating under the short-term, high tensile stress present during the linear mode loading. After the transition to membrane deformation, the higher stress at the corners resulted in a shorter delay time to propagation than at the center. As a consequence, the failure started there, even though the fabrication flaws at the corners might have been less severe than the indent flaws at the center.

Blunting at the crack tip and the consequent failure to respond to applied stress may also explain why some of the indent cracks failed to grow in the test. In the $1 / 4$-inch sheet, for example, four of the five 10-kilogram-load indent cracks grew, but one did not. For stresses only slightly greater than that necessary to propagate an indent crack with a sharp crack tip, there is simply not enough time for the resharpening of the crack that must precede its growth.
The importance of these observations in understanding the response of windows to shock loading is that data obtained in quasistatic testing of windows may have little relevance to the behavior of identical windows in the shock environment. In quasistatic testing, strain rates are much lower; thus the delay of a blunted crack in responding to the applied stress would probably not even be apparent. The flaws that limit glass strength during quasistatic testing may be from an entirely different population than those that initiate failure in blast loading. Using procedures that try to account for subcritical crack growth would be inappropriate for projecting failure probabilities under blast loading. Because of crack tip blunting, the effective strength of blast-loaded windows may be much greater than any projection based on subcritical crack growth. The response of glass under dynamic loading requires more study before its behavior can be predicted.

This result (failure initiating in sheet corners) also suggests a strategy for the proposed use of indentation or annealing flaws to lower strength of tempered glass in the blast environment. The flaw should be placed in the corner where it can respond to the stresses generated during membrane deformation by the high differential pressures produced near explosions. On the other hand, corner flaws are not likely to be activated by stresses generated in natural events such as tornadoes.

\subsection{Indent Crack Length}

The growth of indent cracks in Experiment No. 1 showed promise as a method for determining the maximum local applied tensile stress produced during the shock loading of the glass sheets. The values from this approach agree reasonably well with those derived using other techniques. Better agreement may be possible by obtaining more accurate values of the parameters in the equations used for the 
calculations. Values acquired in other studies for the residual stress parameter, $\chi$, the critical stress intensity factor, $\mathrm{K}_{\mathrm{Ic}}$, and the $\mathrm{K}_{\mathrm{I}}$ value after subcritical crack growth were used in the calculations for Tables 3 and 4.

In Experiment No 1, the indents introduced with lower loads in both the 1/4-inch and 1/2- inch annealed glass sheets did not show any growth. The reason these sheets showed no growth during shock loading is that the cracks were allowed to grow subcritically during the 3 to 5 days between their introduction into the glass and the shock loading. For the smaller indent loads, that growth was greater than that possible during shock loading. In shock loading, the crack would have stopped growing when $\mathrm{K}$ dropped below $\mathrm{K}_{\mathrm{Ic}}$. It would be highly desirable to prevent subcritical crack growth between introduction of indent cracks and application of the load. Smaller indent loads could then be used to obtain useful data and, for larger loads, the larger length changes during shock loading would provide greater precision in the determination of local stresses.

Preventing subcritical crack growth in glass for long periods of time is very difficult. The most common agent that makes subcritical crack growth possible is water, usually in vapor form. Even at dew points below $-90^{\circ} \mathrm{C}$, significant growth rates can be obtained from the water vapor in air. For short-term experiments, like those described in Reference 8, materials such as paraffin oil have been applied to the surface prior to indenting and left until the experiment is conducted. 'This approach is reasonably effective, but even paraffin oil has some permeability to water. To measure accurately stress from crack growth during blast loading, an impermeable coating must be developed to prevent subcritical crack growth. This coating could be applied to the flaw zone, but it would not interfere with the crack length measurement.

\subsection{Future Work}

Although inferences have been drawn from the observations made in this series of experiments, it is important to recognize that the processes for fracture and for the subsequent flight of fragments in the blast wave are stochastic. The details of differences in the dispersion and the penetration of fragments from annealed and tempered glass may be a result of the randomness of the process rather than of the nature of the stresses and flaws present in the sheets prior to the experiments. Thus the possibility that the potential for injury by glass fragments from tempered glass may be the same as that from annealed glass requires further investigation. Whether the results in the experiments described here were a consequence of a particular tempering stress profile that prevented the crack from propagating to the surface of the sheets or had some other basis should be investigated. It would be useful to determine if a stress profile with compressive stress peaking away from the sheet surface is responsible for the failure of the tempered fragments to dice and, if so, whether the tempering process can be modified to produce a profile that assures separation and subsequent lateral motion of the fragments.

The current experiments showed clearly that the failure stress of tempered glass sheets can be substantially reduced by either of the procedures tested. The loading of the support structure by the pressure on the windows can be reduced. In Experiment No. 3, the fragments from the tempered sheet with the annealed spots showed significantly reduced penetration of the foam boards compared with fragments from the asreceived tempered sheet. That difference suggests that lowering the failure stress of the tempered glass (1.64 ksi with annealed spots compared with at least $16.9 \mathrm{ksi}$ in the asreceived sheet) can be effective in reducing the kinetic energy of fragments. However, failure of tempered sheets to separate into individual 
fragments prevented any real test of the thesis tempered glass can reduce the potential for that deliberately induced early fracture of injury from fragments. 


\subsection{References}

1. S. Mallonee, S. Shariat, G. Stennies, R. Waxweiler, D. Hogart, and F. Jordan, "Physical Injuries and Fatalities Resulting From the Oklahoma City Bombing," JAMA, Vol. 276, p. 382, August 7, 1996.

2. D. N. Neades and R. R. Rudolph, "An Examination of Injury Criteria for Potential Application to Explosive Safety Studies," in Minutes of the Explosives Safety Seminar $\left(21^{\text {st }}\right)$ held at Houston, TX, pp. 1343-1354, August 28-30, 1984.

3. I. G. Bowen, D. R. Richmond, M. B. Wetherbe, and C. S. White, "Biological Effects of Blast from Bombs: Glass Fragments as Penetrating Missiles and Some of the Biological Implications of Glass Fragmented by Atomic Explosions," AECU3350 , Lovelace Foundation for the AEC, June 1956.

4. R. E. Fletcher, D. R. Richmond, and J. T. Yelverton, "Glass Fragment Hazard from Windows Broken by Airblast," Report No. DNA-IACRO-76-634 (DNA Report No. 55931), Lovelace Biomedical and Environmental Research Institute, Albuquerque, NM, May 30, 1980.

5. S. Glasstone and P. J. Dolan, "The Effects of Nuclear Weapons," $3^{\text {rd }}$ Ed., United States Department of Defense and Department of Energy, Washington, DC, 1977.

6. N. J. Glover, "Report on GSA Protective Glazing Tests No. $4 \& 5,7 \& 9$, August 1996, Range 19, Fort Polk, LA," August 15, 1996.
7. A. I. Bodner, J. D. Chrostowski, M. R. Legg, K. B. Overbeck, and J. R. Westlake, "Program Description Document for the BLASTC Computer Model," Tech. Rpt. No. 93-282/31-04.2, ACTA Inc., 1993.

8. D. B. Marshall and B. R. Lawn, "Strength Determination of Thermally Tempered Glass Plates," J. Am Ceram. Soc. 61 [1-2], pp. 21-27, 1978.

9. V. D. Frechette, Failure Analysis of Brittle Materials, Adv. In Ceramics, Vol. 28, Amercian Ceramic Soc., 1991.

10. K. Akeyoshi et al., Rept. Res. Lab., Asahi Glass Company, Ltd., Vol. 17 (No. 1), pp. 23-36, 1967.

11. R. J. Roark, Formulas for Stress and Strain, $4^{\text {th }}$ Ed., McGraw-Hill, Inc., 1965.

12. J. E. Hurtado, "Sensor Readings from Glass Fracture Dynamics Experiments at Socorro: Experiments 1 \& 2," Sandia National Laboratories internal report, April 29, 1997.

13. J. J. Mecholsky, S. W. Freiman, and S. M. Morey, "Fracture Surface Analysis of Optical Fibers," in Fiber Optics, B. Bendow and S. S. Mitra, eds., Plenum Press, NY, 1979.

14. R. J. Harris, M. R. Marshall, and D. J. Moppett, "The Response of Glass Windows to Explosion Pressures," I. Chem. E. Symp. Series No. 49, pp. 83-97, 1997.

15. E. K. Beauchamp, "Fracture and Strain Energy Release in Prestressed Glass and Glass-Ceramics," Fracture Mechanics of Ceramics, Vol. 3, R. C. Bradt, D. P. H. Hasselman, and F. F. Lange, eds., Plenum Press, NY, p. 823, 1978. 
16. Robert Gardon, personal communication to Edwin K. Beauchamp, May 19, 1997.

17. T. A. Michalske, "The Stress Corrosion Limit: Its Measurement and Implications," in Fracture Mechanics of Ceramics, Vol. 5, R. C. Bradt, D. P. H. Hasselman, and F. F. Lange, eds., Plenum Press, NY, pp. 277$289,1973$.

\section{Other Recent Sandia Publications on Glass} Fracture

S. Nicolaysen and M. J. Readey, "StrengthLimited Weaklink Feasibility Study," Sandia Internal Report, August 8, 1994.

S. D. Nicolaysen and P. J. Skogmo, "A Review of Shock Weaklink Technology for Improving Nuclear .Weapon Safety," SAND94-2109, UC-744, September 1994.

E. K. Beauchamp, "Mechanisms for Hackle Formation and Crack Branching," Ceram. Trans. 64, pp. 409-445, 1996.

E. K. Beauchamp, "Crack Front Stability and Hackle Formation in High-Velocity Glass Fracture," J. Am. Ceram. Soc. 78 [3], pp. 689-697, 1995. 


\section{Appendix: Techniques for Determination of Applied and Residual Stress From Fracture Features}

\section{Applied Stress from Mirror Radius}

During the passage of a crack front through a brittle material like glass, a variety of features are formed on the fracture surface that provide a record of the progress of the crack. From these features it is possible to determine the local stress at the moment of failure, the distribution of stresses along the crack path, the location and nature of the origin, and the velocity of propagation of the crack, as well as some of the details of environmental effects. Reference A-1 is a good introductory text describing fractographic analysis, the general methodology for examining and interpreting these features. For prestressed glass, such as the thermally tempered glass used in the current work, with a well-defined residual stress distribution present prior to fracture, some additional features are generated that can aid in understanding the failure. The interpretation of those features is described below.

One commonly used procedure in fractographic analysis is the determination of failure stress (the tensile stress present at the point of origin of the fracture) from the mirror radius. This procedure was used for analysis in this report. In fracture of homogeneous, isotropic brittle materials like glass, the fracture surface in the immediate vicinity of the origin of the crack is very smooth (hence the term mirror). If the crack accelerates as it propagates away from the origin, the surface develops visible features that are characterized as mist. The features grow in size as the crack progresses farther, resulting in a zone characterized as the hackle region. Ultimately, the crack branches. A description of the processes at the crack tip during generation of these features is given in Reference A-2.

When a crack grows in a uniform tensile stress field, so that propagation is the same in all directions from the origin, the mirror region, the mist region, and the hackle region have boundaries that are circular arcs. The distance from the origin to the mirror/mist boundary is called the mirror radius, $R_{m}$. Similarly, the distance to the mist/hackle boundary is characterized by $R_{h}$ and the distance to the branching point is $R_{b}$.

The mirror, mist, and hackle features (collectively known as velocity hackle features) are important in the analysis of fracture because there is an inverse relationship between the tensile stress at failure, $\sigma_{\mathrm{f}}$, and a given boundary radius, $\mathrm{R}_{\mathrm{j}}$ :

$$
\sigma_{\mathrm{f}}=\mathbf{A}_{\mathrm{j}} / \mathbf{R}_{\mathrm{j}}{ }^{1 / 2}
$$

where $A_{j}$ are constants for a given material. Thus with a knowledge of $A_{j}$, measurement of the mirror radius or one of the other radii can provide an estimate of the failure stress. Reference A-3 shows that this equation described data for cracks with mirror sizes ranging from $0.5 \mu \mathrm{m}$ to more than $5 \mathrm{~mm}$.

For some analyses of failure stress in this report, the plot in Figure 1 of Reference A-3 that shows failure stress as a function of mirror radius was used. Although those data were obtained on 
fused silica glass, the fracture behavior of the soda-lime silica glasses used in the current experiments is similar. No significant error results from the use of that plot.

\section{Tempering Stress from Fragment Size}

In tempered glass with a residual tensile stress present in the interior of the glass sheet, the branching distance (i.e., the size of the fragments produced in fracture of the sheet) depends on the magnitude of the residual tensile stress. In particular, it depends on the maximum tensile stress at the central plane of the sheet (the central tension). It also depends on the thickness of the sheet. That dependence is shown in Figure 2 of this report. (For the determination of central tension in this report, values for 4-mm glass were obtained by interpolating between the $3.4-\mathrm{mm}$ and $4.9-\mathrm{mm}$ curves.)

More accurately, the fragment size is determined by the maximum tensile stress in the sheet so that an applied stress can influence the size. In the event that the applied stress increases the maximum tensile stress above the value of the central tension, the branching distance will be shortened. Similarly, if the applied stress reduces the maximum tensile stress, the branching distance will be lengthened. Those length changes can be used to obtain a quantitative estimate of the magnitude of the applied stress. They also can be used to qualitatively evaluate the nature of the stress. As an example, if the branching distance is shortened in one direction but is not affected in the orthogonal direction, the applied stress can be assumed to be uniaxial tension.

\section{Shift in Position of Features (in Tempered Glass)}

Fracture of tempered glass occurs in two stages. In the first stage, fracture is limited to the central zone of the sheet where residual tension is present. Because of the high tensile stress, that fracture is very rapid. The entire fracture pattern in the tensile zone of a one-meter-square sheet is completed in less than a millisecond. In that brief interval, the stress in the tensile zone adjacent to the fracture surfaces is reduced; however, because the inertial mass of the plate severely limits the separation of the fragments, there is little change in the stresses in the compressive zone. Subsequently, in the second stage of fracture, the fragments begin to separate as the compressive stress in the outer layer pushes the fragments apart. The fracture velocity for this stage is much slower.

The transition from the fast-fracture stage to the slow-fracture stage often results in well-defined lines of demarcation on the fracture surface between the tensile stress zone and the compressive stress zones. These lines of demarcation result from the propagation differences in the two stages of fracture. In the first stage, the fracture direction is parallel to the plate surface with the highest velocity at the central plane of the plate and the lowest at the zero stress plane. In the second stage of fracture, the fracture propagates toward the surfaces of the plates, i.e., perpendicular to the direction of the first stage crack growth. A common result of this change in direction is the formation of twist hackle linear features oriented perpendicular to the plate surface.

Usually tempering stresses are symmetrical with respect to the midplane of the sheet; thus the lines of demarcation between the two stages of fracture will be equidistant from the central plane of the sheet. However, if a bending stress is applied to the sheet when the glass is fractured, the lines of demarcation will be 
shifted toward the surface of the sheet that is put into tension by the applied load. That shift is shown schematically in Figure A-1.

In the thermal tempering process, the tempering stress profile is usually nearly parabolic. In that event, the central tension is about one-half the magnitude of the compressive stress at the surface of the sheet. The stress distribution can then be described by the function:

$$
\sigma(\mathbf{x})=\mathbf{a} \mathbf{x}^{2}+\mathbf{b}
$$

where $\mathrm{x}$ is the distance from the central plane of the sheet. Because the stress at $x=0$ is the central tension, $b$ is equal to the central tension. Consequently, with the surface compression equal to -2 times the central tension, CT, Equation A-2 becomes:

$$
-2 \mathrm{CT}=\mathrm{a}(\mathrm{t} / 2)^{2}+\mathrm{CT}
$$

where $t$ is the sheet thickness, so that:

$$
a=-3 C T /(t / 2)^{2}
$$

Most failures of windows are caused by bending loads for which the applied stress can be represented by:

$$
\sigma(\text { applied })=\mathbf{m x}
$$

When that stress is added to the tempering stress, Equation A-2 becomes:

$$
\sigma(\mathbf{x})=\mathbf{a x ^ { 2 }}+\mathbf{m x}+\mathbf{b}
$$

In Figure $\mathrm{A}-1$, the application of a bending stress moves the point of maximum tensile stress toward the surface where the applied stress is tensile. The points on the resultant curve with zero stress are also moved toward that surface. Assuming that a value for the central tension of the unloaded plate has been determined (from the fragment size or some other technique), the distance from the central plane to one of these new lines of demarcation on the fracture surface can be measured. That $\mathrm{x}$ value can be inserted into Equation A-6 to obtain a value for $\mathrm{m}$, noting that at that $\mathrm{x}$ value, $\sigma(x)=0$. The magnitude of the applied stress at the sheet surface is then obtained by inserting $\mathrm{t} / 2$ into Equation A-5.

An alternative to using the shift of the lines of demarcation to determine the applied stress is to use the shift in position of the maximum tensile stress. In a symmetric stress field, even if the tempering stress is not parabolic, the minimum is at $\mathrm{x}=0$ in the unstressed sheet. An applied bending load moves the minimum toward the tensile stress side associated with the bending load. For parabolic stress, the first derivative of Equation A-5 is:

$$
\mathbf{d} \sigma / d x=2 a x+m
$$

For $d \sigma / d x=0, x=-m / 2 a$ is the distance of the new minimum from the central plane. (See Figure A-1.) Thus if the value of the central tension is known, the value of the applied stress from the shift in the position of the minimum can be calculated, the value for $\mathrm{m}$ can be obtained, and Equation A-5 can be used to calculate the value for the applied stress. For the stress determinations in this report, the position of the minimum was taken to be midway between the lines of demarcation. The central tension was determined from the fragment size using the plots in Figure 2.

Figure A-2 is an example of a fracture surface showing the lines of demarcation in a tempered sheet that fractured with no applied stress. Figure A-3 shows a similar surface in which the lines of demarcation have been shifted by an applied bending stress. The lines of demarcation are marked with the short, blunt arrows. The larger arrows show the position of the sheet surface. 
For the tempered glass used in the current tests, the lines of demarcation were not in the predicted location (i.e., where they should have been if the stress profile were truly parabolic and the first stage of fracture terminated at the point where the stress was zero). One possible explanation is that the tempering process used for these plates did not generate a parabolic distribution. In that case, Equations A-2 through A-6 above could not be used to determine the stress. The other possibility is that the stress profile was parabolic, but the crack did not stop where the stress was zero. In that event, the applied stress could not be directly determined from the shift of the lines of demarcation. However, it would still be valid to use the shift of the stress minimum to calculate the applied stress. The tables in this report are based on the second explanation. The midpoint between the positions of the lines of demarcation are considered to be the position of the stress minimum.

\section{Indentation Crack Length}

This procedure for determining the applied stress involves the growth of cracks emanating from the corners of indentations produced at the glass surface by Knoop or Vickers indenters, as shown schematically in Figure A-4. The cracks appear in glass at an indenter load in excess of about 100 grams. If no other stress field is present, the driving force for the generation of the cracks at the indent is a consequence of compaction of the material under the indenter during loading. When sufficient force is applied to the indenter, a permanent depression remains when the indenter is removed from the surface. When the indenter is unloaded, the material immediately beneath that depression is constrained from recovering its original volume by the surrounding material. As a consequence, that zone develops residual compressive stress while the surrounding material is placed in tension. Because of the geometry of the indenter, the tensile stress has its maximum value perpendicular to the planes passing through the diagonals of the indent; thus cracks generated by that stress are predominantly oriented along those diagonals. Figure A-5 shows a glass surface with an indent and cracks running from the indent diagonals.

The stress produced by the indent decreases with distance from the indent. As a consequence, a crack propagated by that stress initially grows rapidly, then slows, and finally stops growing. Growth stops when the stress intensity, $K_{l}$, drops to the critical stress intensity, $\mathrm{K}_{\mathrm{Ic}}$. In the event that subcritical crack growth is possible, the crack will continue to grow. The rate of growth (the crack velocity) decreases as the crack grows; crack growth finally stops when $K_{I}$ drops to the threshold value for subcritical crack growth.

The effect of an applied stress is to change the length of the crack emanating from the indent. If the stress is present when the surface is indented, tensile stress raises the $K_{I}$ value, increasing the crack length; conversely, a compressive stress shortens the cracks. The equation for calculating those stresses is derived from fracture mechanics and based on the assumption that the crack grows until the stress intensity at the crack tip drops to $\mathrm{K}_{\mathrm{Ic}}$. The net stress intensity, which includes contributions from the residual stress at the indent and the stresses, $\sigma_{\mathrm{a}}$, present from other sources, is expressed by:

$$
\mathbf{K}_{1}=\chi_{\mathrm{r}} \mathbf{P} / \mathbf{c}^{3 / 2}+\sigma_{\mathrm{a}} \Phi \mathbf{c}^{1 / 2}
$$

where $\chi_{r}$, the residual stress parameter, is associated with the compaction of material under the indent. $\Phi$ is a parameter that accounts for the geometry of the crack, and $c$ is the crack length measured from the center of the indent. ${ }^{A-4}$ 


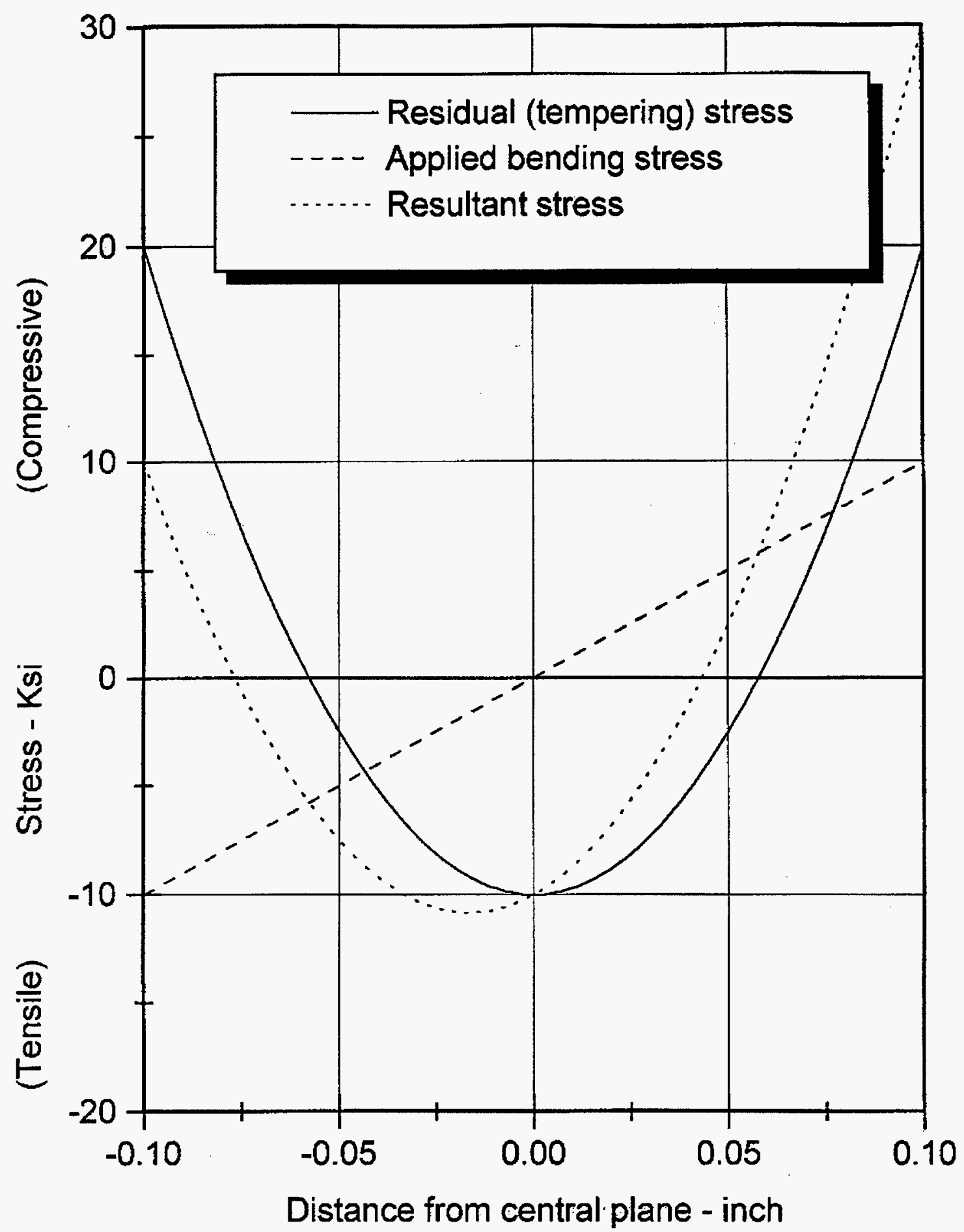

Figure A.1 Stress Profiles in Thermally Tempered Glass Sheet with Applied Bending Stress (Note the shifts of the zero stress points and the stress minimum toward the surface where bending stress is tensile.) 


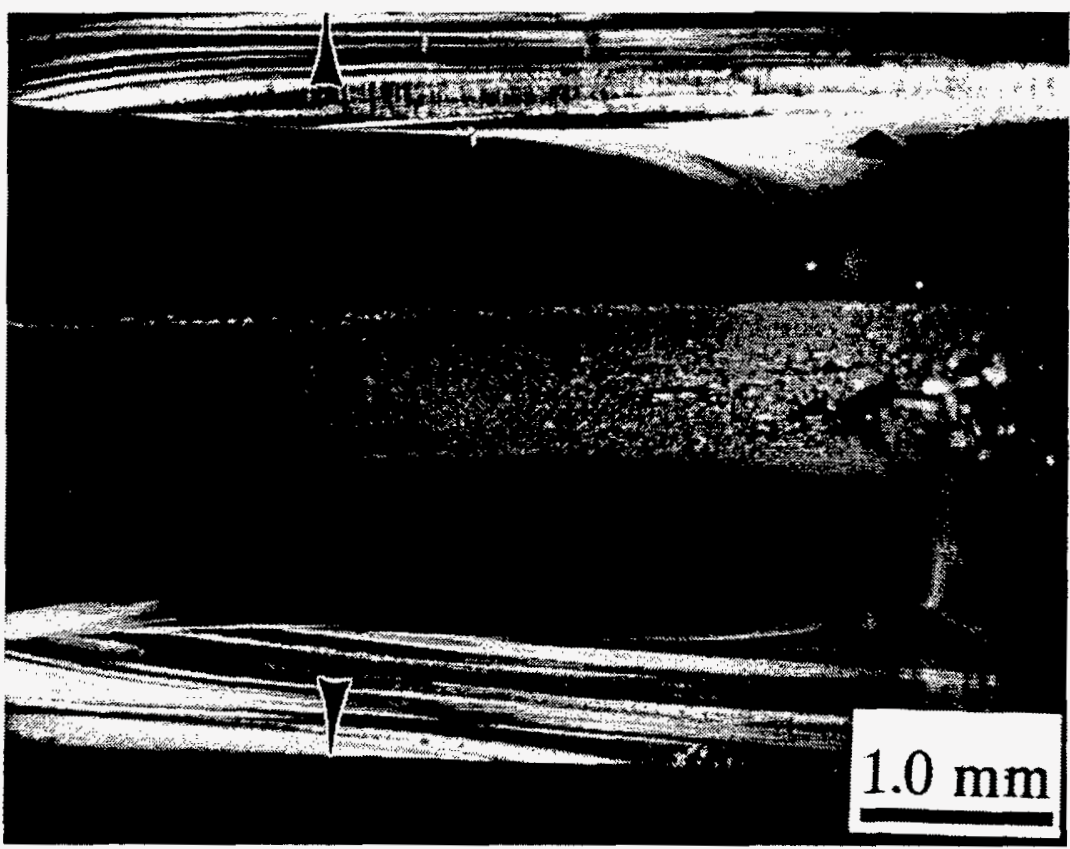

Figure A.2 Fracture Surface in Thermally Tempered Sheet with No Applied Stress (Small, blunt arrows indicate line of demarcation between tensile and compressive region. Note band of mist and hackle at center of sheet.)

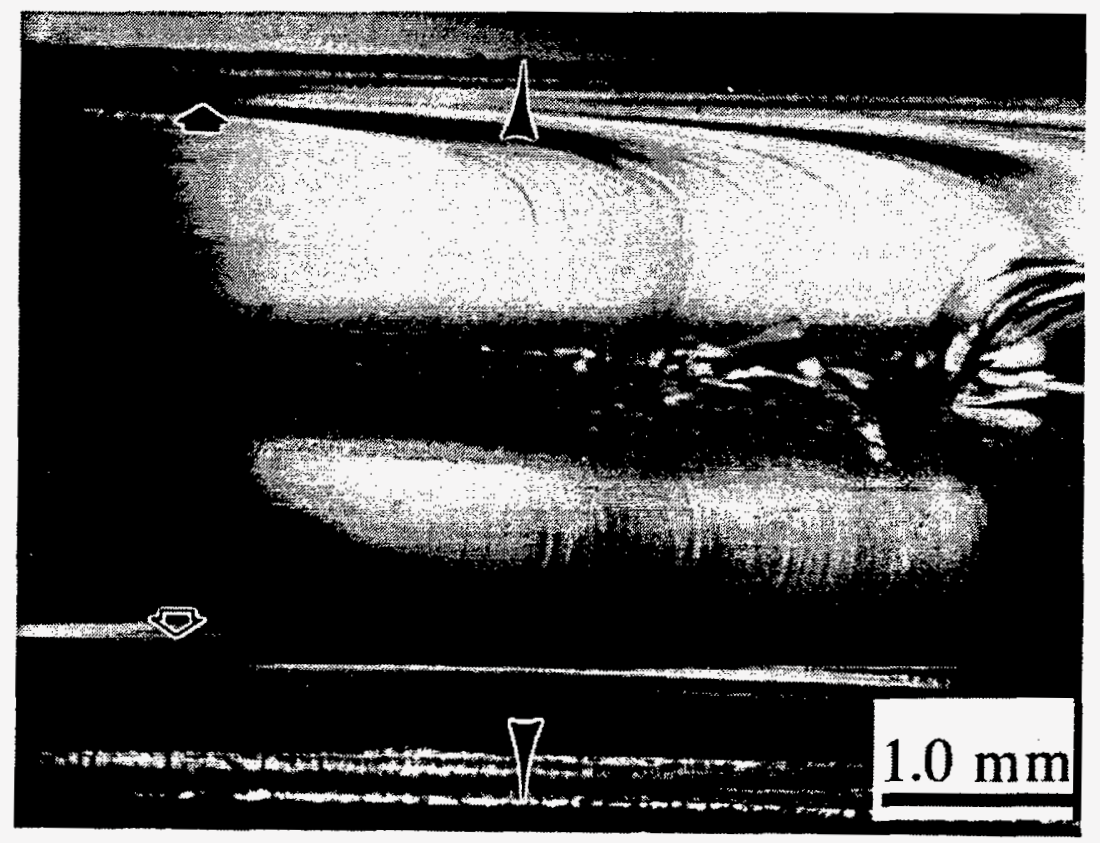

Figure A.3 Fracture Surface in Thermally Tempered Sheet with Applied Bending Load (Note shift of lines of demarcation and mist band toward upper (tensile) surface.) 


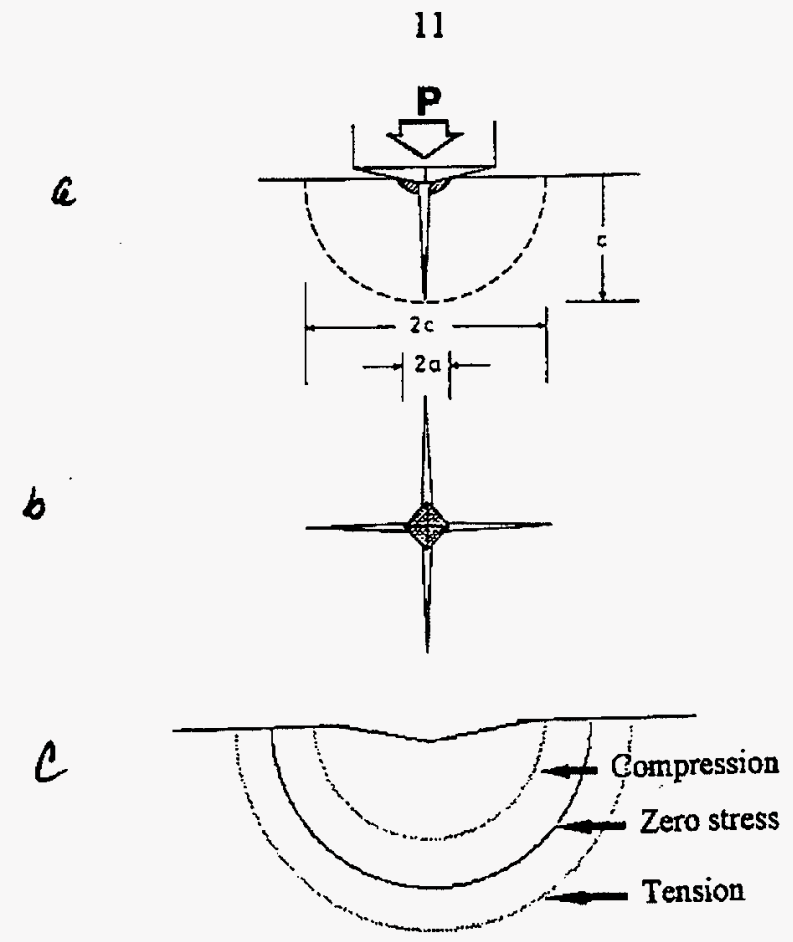

Figure A.4 Schematic of Indentation Crack Formation: a) Cross Section Through Indent Zone Showing Radial Crack Limits (dashed line), b) Intersection of Radial Cracks with Surface of Sheet, c) Dependence of Crack Size on Local Stresses

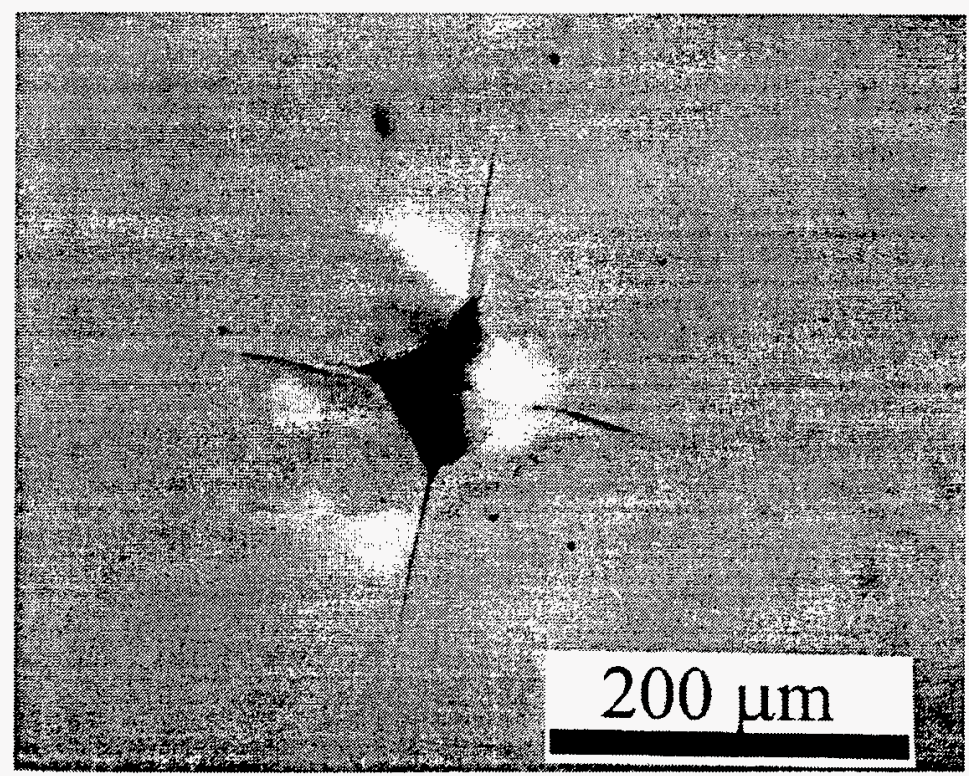

Figure A.5 Indentation Crack in Annealed Glass (3-kg load on indenter) 
Rearrangement of Equation A-8 yields an expression for the applied stress of:

$$
\sigma_{\mathrm{a}}=\left(\mathrm{K}_{\mathrm{lc}}-\chi_{\mathrm{r}} \mathbf{P} / \mathbf{c}^{3 / 2}\right) / \Phi \mathbf{c}^{1 / 2}
$$

where it is assumed that crack growth stopped when $\mathrm{K}_{\mathrm{I}}$ was no longer greater than $\mathrm{K}_{\mathrm{Ic}}$. The parameter $\chi_{\mathrm{r}}$ is a constant for a given material using the Vickers indenter. For most materials, a reasonable value for $\chi_{\mathrm{r}}$ is represented by:

$$
\chi_{\mathrm{r}}=0.015(\mathrm{E} / \mathrm{H})^{1 / 2}
$$

where $\mathrm{E}$ is Young's modulus and $\mathrm{H}$ is the Vickers hardness. A value of 0.034 for $\chi_{r}$, calculated in an earlier experimental study of indentation fracture in soda-lime glass, was used in the calculations in this report.

If subcritical crack growth had been possible, calculation of $\sigma_{a}$ directly from Equation A-9 would not be appropriate. Instead, it would be necessary to replace $\mathrm{K}_{\mathrm{Ic}}$ with the value of $\mathrm{K}_{\mathrm{I}}$ present at the crack tip at the moment that the crack length was measured.

In the indent measurements in this report, the indents were introduced in the annealed glass sheets while no stress was applied. Subsequently, the sheets were shock-loaded to create a local tensile stress for a short time. In this situation, a stress is applied after the indent is introduced into the surface; thus it is possible to obtain a value for the applied stress using the increase in length of the crack even if a value for $\chi_{\mathrm{r}}$ is not available. For the indent without applied stress:

$$
K_{1}(\text { initial })=\chi_{r} P / c_{i}^{3 / 2}
$$

so that:

$$
\chi_{\mathbf{r}} \mathbf{P}=\mathbf{K}_{1} \text { (initial) } \mathbf{c}_{\mathrm{i}}^{3 / 2}
$$

where $c_{i}$ is the initial crack length. Substituting this into Equation A-9 yields:

$\sigma_{\mathrm{a}}=\left(\mathbf{K}_{1 \mathrm{c}}-\mathrm{K}_{1}(\right.$ initial $\left.) \mathbf{c}_{\mathrm{i}}^{3 / 2} / \mathbf{c}_{\mathrm{f}}^{3 / 2}\right) / \Phi \mathbf{c}_{\mathrm{f}}^{1 / 2}$

where $c_{f}$ is the final crack length.

The identity of the initial $\mathrm{K}_{\mathrm{I}}$ value is retained because it is not necessarily the same as that existing at the crack tip when the stress, $\sigma_{a}$, is applied. In a controlled experiment, subcritical crack growth is prevented (by coating the surface with paraffin oil and measuring the crack lengths immediately, for example), and it can be assumed that the initial and final $K_{I}$ values both equal $\mathrm{K}_{\mathrm{Ic}}$. For the experiments described here, the delay between introducing the indent cracks and shock-loading the glass was three or more days. It was impractical to prevent subcritical crack growth during that time; rather it was assumed that crack growth had occurred. Using data for subcritical crack growth from Reference A-5, the $\mathrm{K}_{\mathrm{I}}$ value at the end of three days of crack growth would have been about $0.41 \mathrm{MPa} \cdot \mathrm{m}^{1 / 2}$. That value for $\mathrm{K}$ (initial) is used in Equation A-13.

On the other hand, in the explosive tests described in this report, the stress was applied for too short a time to permit subcritical crack growth: thus it could be assumed that the final $\mathrm{K}_{1}$ value as a result of that loading was equal to $\mathrm{K}_{\mathrm{Ic}}$. However, if the applied stress had been maintained long enough that subcritical crack growth occurred, $\mathrm{K}_{\mathrm{Ic}}$ in Equation A-13 would be replaced by $K_{I}$ (final), i.e., the $K_{I}$ value at the end of that subcritical crack growth.

\section{References}

A-1. V. D. Frechette, Failure Analysis of Brittle Materials, Adv. In Ceramics, Vol. 28, American Ceramic Soc., 1991.

A-2. E. K. Beauchamp, "Mechanisms for Hackle Formation and Crack Branching," Ceram. Trans. 64, pp. 409-445, 1996. 
A-3. J. J. Mecholsky, S. W. Freiman, R. W. Rice, "Fracture Surface Analysis of Ceramics," J. Mater. Sci., 11, pp. 13201329, 1976.

A-4. R. F. Cook and G. M. Pharr, "Direct Observation and Analysis of Indentation
Cracking in Glasses and Ceramics," J. Am. Ceram. Soc. 73 [4], pp. 787-817, 1990.

A-5. S. Wiederhorn, J. Amer. Ceram. Soc. 50, p. $407,1967$. 
Intentionally Left Blank 


\section{Distribution:}

Roger Adams

Counsel to Deputy Attorney General

Department of Justice

10th \& Constitution Ave. NW, Rm 4216

Washington, DC 20530
A. Emin Aktan
Drexel University
Drexel Intelligent Infrastructure Institute
Academic Building, Room 240
33rd \& Arch Street
Philadelphia, PA 19104

George K. Anderson, Major General, USAF, MC

Deputy Assistant Secretary of Defense

Health Services Operations \& Readiness

The Pentagon, Room 3E336

Washington, DC 20301-1200

Arlan Andrews

Survival Technologies International LLC

1009 Bradbury Drive SE

Albuquerque, NM 87106

Graham Armer

GA Consulting

Westwood House

Eaudyke, Friskney

Lincolnshire, United Kingdom PE22 8NL

George Y. Baladi

FCDSWA/FCTT

1680 Texas Street

Kirtland AFB, NM 87117-5669

Darrell Barker

Wilfred Baker Engineering

8700 Crownhill, Suite 310

San Antonio, TX 78209

\section{Robert Barnes}

Lester B. Knight \& Associates, Inc.

549 West Randolph St.

Chicago, IL 60661
Bill Barringer

1001 University Blvd. Suite 103

Albuquerque, NM 87106

Melvin L. Basye

Security Division

Office of Federal Protective Service

18th and F Streets N.W., Room 2341

Washington, DC 20405

Lynne Beason

Civil Engineering Department

Texas A\&M

College Station, TX 77843

Wade Belcher

Building Technology Division

General Services Administration

18th \& F St., NW - Rm 3329

Washington, DC 20405

Bobbie Borchardt

City of Oklahoma City

GIS Office

420 W. Main St., \#930

Oklahoma City, OK 73102-4435

David Boyd

Director, Science \& Technology

National Institute of Justice

633 Indiana Avenue NW

Washington, DC 20531

Jimmie Bratton

Applied Research Association, Inc.

4300 San Mateo Blvd. NE

Albuquerque, NM 87110

Ken Brill

The Uptime Institute

1347 Tano Ridge Road

Santa Fe, NM 87501 
Paul Bryant

Mitigation Directorate, FEMA

500 C Street SW

MT/HZ/RA

Washington, DC 20472

David Coltharp

Environmental Systems Division

Waterways Experimental Station

3909 Halls Ferry Rd.

Vicksburg, MS 39180-6199

Louise K. Comfort

Graduate School of Public and International Affairs

3E01 Forbes Quadrangle/GSPIA

University of Pittsburgh

Pittsburgh, PA 15260

Edward J. Conrath

Special Projects Branch

U.S. Army Corps of Engineers

Omaha Division

Omaha, NE 68102-4978

Kevin Cook

Planning, Policy \& Legislation

The Pentagon, Room 2E569

Washington, DC 20310-0103

Bob Cox

Cox \& Associates

6180 Pine St.

Pollock Pines, CA 95726

Paul Croce

Factory Mutual Research Corp.

1151 Boston-Providence Turnpike

Norwood, MA 02062

Robert Crossno

Crossno Engineering

3409 Calle Del Monte

Albuquerque, NM 87106

Michael Dennis

Dept. of Otorhinolaryngology

800 NE $13^{\text {th }}$, Room 6 NP522

Oklahoma City, OK 73104
Joel K. Dietrich

Director, Division of Architecture

The University of Oklahoma

830 Van Vleet Oval, Room 162

Norman, OK 73019-0265

John P. Dismukes

College of Engineering

University of Toledo

1016 Nitschke Hall

Toledo, $\mathrm{OH}$ 43606-3390

George Doremus

Parson Process Group, Inc.

$100 \mathrm{~W}$. Walnut Street

Pasadena, CA 91124

Clarence Edwards

General Services Administration

Office of Federal Protective Service

1800 F Street N.W., Suite 2341

Washington, DC 20405

Ata Elauf

The Sabre Group

4000 N. Mingo Rd.

MD 459

Tulsa, OK 74116-5020

Richard Fallgren

Myers, Nelson, Houghton, Inc.

15901 Hawthorne Blvd., Suite 400

Lawndale, CA 90260

Charles Farrar

Los Alamos National Laboratory

PO Box 1663 MS P946

Los Alamos, NM 87545

Tobias Flatow

FMSM

809 Copper Ave. NW

Albuquerque, NM 87102

Sean P. Foohey

Deputy Director of Operations

\& Planning Division - FEMA

500 C St. SW

Washington, DC 20472 
Jessica Glicken

Ecological Planning \& Toxicology, Inc.

851 University Blvd. SE, Suite 202

Albuquerque, NM 87106

Norman J. Glover

AEGIS Institute, Inc.

271 Central Park West

New York, NY 10024

Kent Goering

Hard Target Defeat Program

Defense Special Weapons Agency

6801 Telegraph Rd.

Alexandria, VA 22310

Hermann Gruenwald

Director Design Research Center

College of Architecture

University of Oklahoma

830 Van Vleet Oval, Room GH 214A

Norman; OK 73019-0265

Peter Gurvin

Building Design \& Engineering

Office of Foreign Buildings Operations

U.S. Department of State

P.O. Bop 12248, Rosslyn Station

Arlington, VA 22219

Bruce Hall

Building Technology Division

General Services Administration

18th \& F St., NW - Rm 3329

Washington, DC 20405

Lorraine Hall

The Write Equation

3219 El Toboso Drive NW

Albuquerque, NM 87104

Jerome Hall

Department of Civil Engineering

University of New Mexico

209 Tapy Hall

Albuquerque, NM 87131-1351
Rod Haraga

City of Los Angeles, Bureau of Engineering

650 South Spring Street, Suite 200

Los Angeles, CA 90014

Tim Hasselman

ACTA Inc.

2790 Skypark Drive \#310

Torrance, CA 90505

Eve Hinman

Hinman Consulting Engineers, Inc.

4163 24th Street

San Francisco, CA 94114

Jim Howard

Southwestern Bell Telephone Company

800 N Harvey, Room 102

Oklahoma City, OK 73102

Stephen C. Joseph

Assistant Secretary for Health Affairs

Department of Defense

The Pentagon, Room 3E346

Washington, DC 20301

John Kelmelis

U.S. Geological Survey

500 National Center

12201 Sunrise Valley Drive

Reston, VA 20192

Malcolm P. Keown

Environmental Systems Division

Waterways Experimental Station

3909 Halls Ferry Rd.

Vicksburg, MS 39180-6199

Do Kim

Institute for Business \& Home Safety

73 Tremont Street, Suite 510

Boston, MA 02108-3910

Anne Kiremidjian

Department of Engineering

Stanford University

Stanford, CA $94305-4020$ 
Stuart L. Knoop

Oudens \& Knoop, Architects, P.C.

2 Wisconsin Circle, Suite 820

Chevy Chase, MD 20815-7003

Steve Koffman

Merrick \& Company

195 East Road

Los Alamos, NM 87544

Dan Krivitzky

DOE/AL

P.O. Box 5400

ETDD

Albuquerque, NM 87185-5400

Dennis Kwiatkowski

Deputy Associate Director, Recovery

FEMA

500 C Street, SW

Washington, DC 20472

Freeman Leaming

Collins/Pina Consulting Engineers

1023 E. Helen St.

Tucson, AZ 85719

Dick Ling

Lawrence Livermore National Laboratories

P.O. Box 808, L-654

Livermore, CA 94550

Richard G. Little

National Research Council

National Academy of Science

2001 Wisconsin Ave., Harris Rm 274

Washington, DC 20418

Gabor Lorant

Gabor Lorant Architect, Inc.

2701 East Osborn, Suite 3

Phoenix, AZ 85016

Don MacCornack

MacCornack Engineering

2920 Carlisle NE

Albuquerque, NM 87110
Jim MacCornack

MacCornack Engineering

2920 Carlisle NE

Albuquerque, NM 87110

Arup Maji

Department of Civil Engineering

University of New Mexico

Albuquerque, NM 87131-1351

Sue Mallonee

Injury Prevention Service-0307

Oklahoma State Department of Health

1000 NE 10th Street

Oklahoma City, OK 73117

Ronald J. Massa

Lorron Corporation

44 Mall Road, Suite 2000

Burlington, MA 01803

Jon Matalucci

Arizona State University

School of Architecture

Tempe, AZ 85287-1605

Richard Meehan

Stanford

701 Welch Rd., Suite 1120

Palo Alto, CA 94304

Gerald Meyers

U.S. Department of Energy, EH-53

19901 Germantown Rd

Germantown, MD 20874

Doug Mitten

Project Management Services, Inc.

4 Courthouse Square

Rockville, MD 20850

Naser Mostaghel

Department of Civil Engineering

University of Toledo

Toledo, $\mathrm{OH}$ 43606-3390 
Peter Mote

The Nevada Testing Institute

Nevada Testing Institute

755 East Flamingo Road, P.O. 19360

Las Vegas, NV 89132

John Mulady

USAA Property \& Casualty Insurance

9800 Fredericksburg Road

San Antonio, TX 78288

William Murray

Failure Analysis Associates

P.O. Box 3015

Menlo Park, CA 94025

Priscilla P. Nelson

Construction/Geo Technology/Structure

Program Cluster

National Science Foundation

4201 Wilson Blvd., Room 505N

Arlington, VA 22230

Scott Norville

Department of Civil Engineering

Texas Tech University

Glass Research and Testing Laboratory

P. O. Box 41023

Lubbock, TX 79409-1023

Allen Patrick

NBBJ

55 Nationwide Blvd

Columbus, Ohio 43215

David Penasa

BPLW

2400 Louisiana NE, Bldg. 5, Suite 400

Albuquerque, NM 87110-7303

John Petkewich

Office of Property Development, General

Services Administration

18 th and F Streets

Washington, DC 20405

Ronald Polivka

EQE International, Inc.

44 Montgomery St. Suite 3200

San Francisco, CA 94104
Brian W. Randolph

Department of Civil Engineering

University of Toledo

Toledo, $\mathrm{OH}$ 43606-3390

Darren Rice

Hard Target Defeat Program

Defense Special Weapons Agency

6801 Telegraph Rd.

Alexandria, VA 22310

Robert Rocheleau

Merrick \& Company

4820 Basin NE

Albuquerque, NM 87111

Van Romero

Research and Economic Development Division

NM Tech

801 Leroy Place

Socorro, NM 87801

John Rupley

City of Albuquerque

P.O. Box 1293

Albuquerque, NM 87106

Lyman Sandy

Miller, Stratvert \& Torgerson

P.O. Box 25687

Albuquerque, NM 87125

Thornton Schwenk

SAIC

5125 Russell Drive, NW

Albuquerque, NM 87114

Douglas Seemann

FCDSWA/FCTT

1680 Texas St. SE

KAFB

Albuquerque, NM 87117-5669

Mike Shannon

The City of Oklahoma City, Fire Department 820 NW 5th Street

Oklahoma City, OK 73106 
Sheryll Shariat

Injury Prevention Service-0307

Oklahoma State Department of Health

1000 NE 10th Street

Oklahoma City, OK 73117

Jim Shaw

FBI

415 Silver

Albuquerque, NM 87122

Wendall Shingler

Chief of Administrative Services Division

U.S. Marshals Service

600 Army-Navy Drive

Arlington, Virginia 22202

Robert Smilowitz

Weidlinger Associates

375 Hudson Street

New York, NY 10014-3656

Milton L. Smith

Department of Industrial Engineering

Texas Tech University

Glass Research and Testing Laboratory

Box 41023

Lubbock, TX 79409-1023

James J. Smyth

Assistant Deputy for Planning Policy \& Legislation

The Pentagon, Room 2E569

Washington, DC 20310-0103

Melissa Spillenkothen

Assistant Secretary for Administration

U.S. Department of Transportation

4007 th Street, SW

Washington, DC 20590

Mukund Srinivasan

Hart Consultant Group

2425 Olympic Blvd., \#670

Santa Monica, CA 90404

Mike Stanley

Energetic Materials Research and Testing Center

NM Tech

801 Leroy Place

Socorro, NM 87801
J. D. Stevenson

Case Western Reserve University

Department of Civil Engineering

10900 Eulid Ave.

Cleveland, $\mathrm{OH} 44106$

John Strothman

Strothman/Associates, Inc.

1555 Sherman Ave. \#340

Evanston, IL 60201

Norris Stubbs

Department of Civil Engineering

Texas A\&M University

College Station, TX 77843-3136

Barry Sullivan

U.S. Marshals Service

600 Army-Navy Drive

Arlington, Virginia 22202

Doug Sunshine

Hard Target Defeat Program

Defense Special Weapons Agency

6801 Telegraph Rd.

Alexandria, VA 22310

Harvey Surgan

Depository Trust Company

55 Water St.

23rd Floor

New York, NY 10041

Glan Blake Thomas

Advanced Ergonomic Technologies, Ltd.

Danemore Place

Danemore Lane

South Godstone Surrey, England RH9 8jf

Beth Tubbs

ICBO

5360 Workman Mill Road

Whittier, CA 90601

Luann Van Campen

Dept. of Otorhinolaryngology

800 NE 13th

Room 6NP522

Oklahoma City, OK 73104 
Carlos Ventura

Civil Engineering Dept.

University of British Columbia

2324 Main Mall

Vancouver

British Columbia, Canada V6T 1Z4

Robert Vincent

Health Promotion and Policy Analysis

Oklahoma State Department of Health

1000 NE 10th Street

Oklahoma City, OK 73117

Robert Volland

Deputy Associate Director, Mitigation

FEMA

500 C Street, SW

Washington, DC 20472

Rick Waxweiler

CDC - NCIPC

4770 Buford Highway

Chamblee, GA 30342

Robert Weber

Clark County Building Dept.

P.O. Box 553530

Las Vegas, NV 89155-3530

Douglas Wehring

Director, Protective Design Center

U.S. Army Corps of Engineers

Omaha District

215 North 17 th Street

Omaha, NE 68102-4978

Dennis E. Wenger

Director, Hazard Reduction \& Recovery Center

Texas A\&M University

College Station, TX 77843-3136

Robert W. Whalin

Waterways Experiment Station

U.S. Army Corps of Engineers

3909 Halls Ferry Road

Vicksburg, MS 39180-6199
Bill White

Bechtel

50 Beale Street

San Francisco, CA 94105-1895

Paul D. Wilde

ACTA, Inc.

2790 Skypark Drive Suite 310

Torrance, CA 90505-5345

Peter Yanev

EQE Intl.

44 Montgomery St. Suite 3200

San Francisco, CA 94104

Rae Zimmerman

Robert F. Wagner Graduate School of Public Service

New York University

4 Washington Square North

New York, NY 10003-6671

1 MS 0127 John Cummings, 4512

1 MS 0127 Sandra-Begay Campbell, 4512

1 MS 0151 Russell Skocypec, 9002

1 MS 0165 John D. German III, 12640

1 MS 0188 Cynthia Harvey, 4523

1 MS 0342 Dick Salzbrenner, 1805

1 MS 0367 Brian Damkroger, 1833

1 MS 0367 S. Jill Glass, 1833

1 MS 0367 Clay Newton, 1833

1 MS 0367 Saundra Monroe, 1833

25 MS 0367 Ed Beauchamp, 1833

1 MS 0437 Steve Attaway, 9117

1 MS 0439 Howard Walther, 9234

1 MS 0455 Laura Gilliom, 6232

1 MS 0481 Keith Ortiz, 2167

1 MS 0486 W. Richard Burcham, 2123

1 MS 0511 Ray Bair, 1200

1 MS 0513 Bob Eagan, 1000

1 MS 0557 Randall Mayes, 9741

1 MS 0557 Todd Simmermacher, 9741

1 MS 0557 Tom Baca, 9741

1 MS 0644 Gwen Pirtle, 5512

1 MS 0724 Joan Woodard, 6000

1 MS 0736 Nestor Ortiz, 6400

1 MS 0744 Dennis Berry, 6403

1 MS 0744 Vince Luk, 6403

1 MS 0746 Robert Cranwell, 6411

1 MS 0751 Dale Preece, 6117 
1 MS 0759 Mary Jane Hicks, 5845

25 MS 0761 Rudy Matalucci, 5822

1 MS 0762 Mary Green, 5861

1 MS 0765 Sharon O'Connor, 5821

1 MS 0769 Dennis Miyoshi, 5800

1 MS 0781 Dick Wayne, 5831

1 MS 0781 James Chapek, 5831

1 MS 0781 Janet Ahrens, 5831

1 MS 0781 Ruth Duggan, 5831

1 MS 0782 Gordon Smith, 5848

1 MS 0790 John Moyer, 6313

1 MS 0827 John Brockmann, 9114

1 MS 0827 Richard Griffith, 9114

1 MS 0908 James Cox, 7832

1 MS 0933 Nenita Estes, 7823

1 MS 0933 Nick Winowich, 7823

1 MS 0937 Ricardo Ortiz, 7832
1 MS 0937 Tom Faturos, 7935

1 MS 0939 John Milloy, 7900

1 MS 0945 Karen Lowden, 7924

1 MS 0957 William Sullivan, 1401

1 MS 1003 John Hurtado, 9611

1 MS 1137 Ken Washington, 6534

1 MS 1231 Roger Hagengruber, 5000

1 MS 1351 Dominique Foley Wilson, 3613

1 MS 1353 Miguel Robles, 127001

1 MS 1433 Cesar Lombana, 4233

1 MS 1434 Gordon Pike, 1802

1 MS 1435 Dan Arvisu, 1800

2 MS 0899 Technical Library, 4916

2 MS 0619 Review/Approval Desk, 12690 for DOE/OSTI

1 MS 9018 Central Technical Files, 8940-2 


\section{M98005265}

||||||||||||||||||||||||||||||||||||||||||||||||||||||||

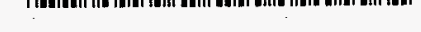

Report Number (14)

SAND- $98-0598$

$\begin{array}{ll}\text { Publ. Date (11) } & 199805 \\ \text { Sponsor Code (18) } & \text { DOE DP , XF } \\ \text { UC Category (19) } & U C-700, \text { DOE/ER }\end{array}$

\section{4}

